Distribution

Category:

All Transportation Systems

Reports (UC-330)

ANL- $-92 / 43$

DE93 009440

\title{
Dynamics and Controls in Maglev Systems
}

by

Y. Cai and S. S. Chen

Materials and Components Technology Division

D. M. Rote

Center for Transportation Research

September 1992

Work supported by

U.S. DEPARTMENT OF ENERGY

Office of Transportation Technologies 


\section{Contents}

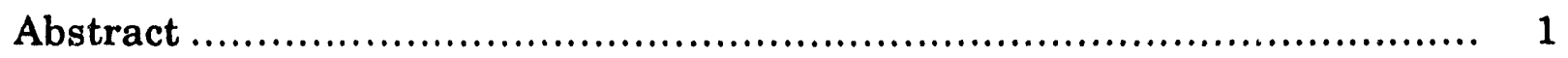

1 Introduction ..................................................................... 1

2 Dynamic Interactions of Maglev Vehicle/Guideway Systems................... 4

2.1 Background for Dynamic Interactions ........................................ . 4

2.2 The Vehicle Model.............................................................. 7

2.3 The Guideway Model ........................................................... 14

2.4 Numerical Simulations................................................. 16

2.5 Dynamic Analyses of Vehicle/Guideway Interactions...................... 18

3 Control Designs for Maglev Systems........................................ 28

3.1 Background of Control Law Designs ..................................... 28

3.2 Modeling of Maglev Vehicle Suspensions for Control Designs............. 32

3.3 Dynamic Response of Maglev Suspensions .................................. 34

3.4 Passive Control Design......................................................... 42

3.5 Active Control of Primary Suspension.......................................... 43

3.6 Semiactive Control of Secondary Suspension................................... 50

3.7 Parametric Analysis of Ciontrol Designs....................................... 55

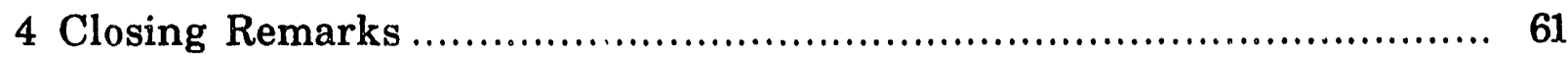

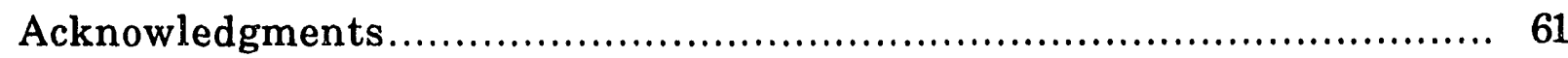

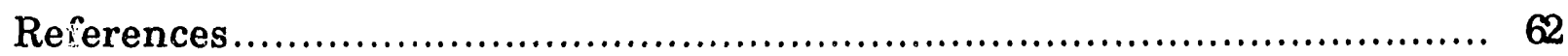

Figures

1 Model of multicar, multiload maglev vehicle traveling along

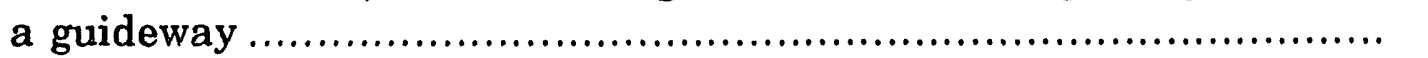

2 Model of single car supported with multiple magnets and traveling

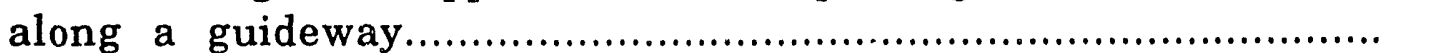

3 Time histories of steady-state guideway displacement ratio and vehicle acceleration with speed ratio $v / v_{c}=0.25$ for a two-degree-offreedom vehicle.... 
4 Time histories of steady-state guideway displacement ratio and vehicle acceleration with speed ratio $v / v_{c}=0.50$ for a two-degree-offreedom vehicle

5 Effects of single-span and double-span beams on maximum guideway displacement and vehicle acceleration ratios for a twodegree-of-freedom vehicle.

6 Midspan displacement of guideway when a single car with various magnets travels along the guideway at $100 \mathrm{~m} / \mathrm{s}$

7 Maximum midspan displacements of guideway when a single car with various magnets travels along the guideway at various speeds

8 Accelerations of car body when a single car with various magnets travels along the guideway at $100 \mathrm{~m} / \mathrm{s}$

9a Acceleration of car body when a single car with eight magnets travels along the guideway at $100 \mathrm{~m} / \mathrm{s}$

9b Accelerations of first and eighth magnets when a single car with eight magnets travels along the guideway at $100 \mathrm{~m} / \mathrm{s}$

10 Midspan displacements of guideway for multicar vehicles with eight magnets on each car traveling along the guideway at $100 \mathrm{~m} / \mathrm{s} . .$.

11 Maximum midspan displacements of guideway when multicar vehicles with eight magnets on each car travel along the guideway at various speeds

12 Accelerations of car body for multicar vehicles with eight magnets on eacl car traveling along the guideway at $100 \mathrm{~m} / \mathrm{s}$.

13 Peak-to-peak accelerations of car body when multicar vehicles with eight magnets on each car travel along the guideway at various speeds

14 Accelerations of car body when a two-car vehicle with eight magnets on each car travels along the guideway at $100 \mathrm{~m} / \mathrm{s}$ and when intercar stiffness varies 
15 PSD of car body acceierations when multicar vehicles with eight magnets on each car travel along the guideway at $100 \mathrm{~m} / \mathrm{s}$

16 PSD of car body accelerations when a single-car vehicle with eight magnets travels along the guideway at various speeds....

17 PSD of car body accelerations when a two-car vehicle with eight magnets on each car travels along the guideway at various speeds.....

18 One-dimensional two-degree-of-freedom vehicle model with primary and secondary suspensions for maglev systems ........................ 33

19 Block diagram for two-degree-of-freedom vehicle model ............... 36

20 Transient response $y_{p}$ of primary suspension of TR06 with unit-step input of guideway perturbation

21 Transient response $y_{s}$ of secondary suspension of TR06 with unit-step input of guideway perturbation................................ 40

22 Frequency response $G_{p}(j \omega)$ of primary suspension of TR06 ........... 42

23 Frequency response $G_{s}(j \omega)$ of secondary suspension of TR06........... 42

24 PSD of vehicle acceleration of TR06 with vehicle speed $v=100 \mathrm{~m} / \mathrm{s}$ and guideway roughness amplitude $A=10^{-6} \mathrm{~m}$.

25 Transient response $y_{p}$ of primary suspension with unit-step input of guideway perturbation using passive adjustments.

26 Transient response $y_{\mathrm{s}}$ of secondary suspension with unit-step input of guideway perturbation using passive adjustments.

27 Frequency response $G_{p}(j \omega)$ of primary suspension using passive adjustments.

28 Frequency response $G_{\mathbb{S}}(j \omega)$ of secondary suspension using passive adjustments.

29 PSD of vehicle acceleration using passive adjustments with vehicle speed $\mathrm{v}=100 \mathrm{~m} / \mathrm{s}$ and guideway roughness amplitude $A=10^{-6} \mathrm{~m} \ldots \ldots$

30 Active control configuration for primary suspension 46 


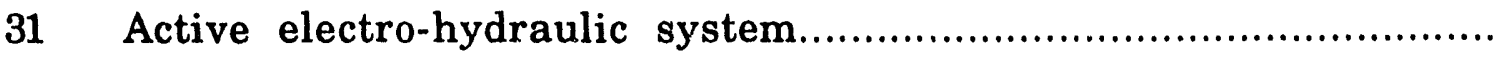

32 Block diagram for two-degree-of-freedom vehicle model of maglev system with primary and secondary suspension feedback controls.....

33 Root-locus diagram for primary suspension feedback control design..

34 PSD of vehicle acceleration using active feedback controls in primary suspension with vehicle speed $\mathrm{v}=100 \mathrm{~m} / \mathrm{s}$ and guideway roughness amplitude $A=10^{-6} \mathrm{~m}$.

35 Transient response $y_{p}$ of primary suspension with unit-step input of guideway perturbation using active feedback controls in primary suspension

36 Transient response $y_{s}$ of secondary suspension with unit-step input of guideway perturbation using active feedback controls in primary suspension

37 Frequency response $G_{p}(j \omega)$ of primary suspension using active feedback controls in primary suspension

38 Frequency response $G_{s}(j \omega)$ of secondary suspension using active feedback controls in primary suspension

39 Semiactive control for secondary suspensions.

40 Skyhook damper for secondary suspensions 52

41 ER fluids damper based on shear-mode principle 53

42 Root-locus diagram for secondary suspension feedback control design

43 PSD of vehicle acceleration using active and semiactive feedback controls in primary and secondary suspensions with vehicle speed $\mathrm{v}=100 \mathrm{~m} / \mathrm{s}$ and guideway roughness amplitude $\mathrm{A}=10^{-6} \mathrm{~m}$.

44 Transient response $y_{p}$ of primary suspension with unit-step input of guideway perturbation using active and semiactive feedback controls in primary and secondary suspensions. 
45 Transient response $y_{s}$ of secondary suspension with unit-step input of guideway perturbation using active and semiactive feedback controls in primary and secondary suspensions

46 Frequency response $G_{p}(j \omega)$ of primary suspension using active and semiactive feedback controls in primary and secondary suspensions.....

47 Frequency response $G_{\mathrm{s}}(j \omega)$ of secondary suspension using active and semiactive feedback controls in primary and secondary suspensions

48 Comparison of transient response $y_{p}$ of primary suspension with unit-step input of guideway perturbation using active and semiactive feedback controls in primary and secondary suspensions.

49 Comparison of frequency response $G_{p}(j \omega)$ of primary suspension using active and semiactive feedback controls in primary and secondary suspensions.

50 Comparison of PSD of vehicle acceleration using active and semiactive feedback controls in primary and secondary suspensions with vehicle speed $\mathrm{v}=100 \mathrm{~m} / \mathrm{s}$ and guideway roughness amplitude $A=10^{-6} \mathrm{~m}$

51 Comparison of transient response $y_{s}$ of secondary suspension with unit-step input of guideway perturbation using active and semiactive feedback controls in primary and secondary suspensions.

52 Frequency response $G_{\mathrm{s}}(j \omega)$ of secondary suspension using active and semiactive feedback controls in primary and secondary suspensions.

53 Comparison of PSD of vehicle acceleration using active and semiactive feedback controls in primary and secondary suspensions with vehicle speed $\mathrm{v}=100 \mathrm{~m} / \mathrm{s}$ and guideway roughness amplitude $\mathrm{A}=10^{-6} \mathrm{~m}$ 


\section{Tables}

1 Parameters for dynamic interaction analysis of maglev systems....... 18

2 Vehicle vertical dynamics model parameters of German Transrapid Maglev System TR06 ...................................................... 34

3 Eigenvalues, frequencies, and damping ratios in 1-D vehicle model with two degrees of freedom...................................................

4 Transient measurement of unit-step response of primary

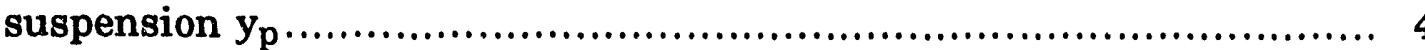

5 Transient measurement of unit-step response of secondary

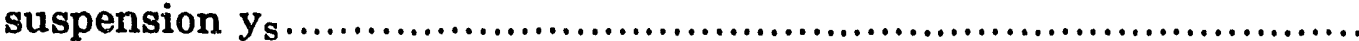




\title{
Dynamics and Controls in Maglev Systems
}

\author{
by
}

\author{
Y. Cai, S. S. Chen, and D. M. Rote
}

\begin{abstract}
The dynamic response of magnetically levitated (maglev) ground transportation systems has important consequences for safety and ride quality, guideway design, and system costs. Ride quality is determined by vehicle response and by environmental factors such as humidity and noise. The dynamic response of the vehicles is the key element in determining ride quality, and vehicle stability is an important safety-related element. To design a proper guideway that provides acceptable ride quality in the stable region, vehicle dynamics must be understood. Furthermore, the trade-off between guideway smoothness and the levitation and control systems must be considered if maglev systems are to be economically feasible. The link between the guideway and the other maglev components is vehicle dynamics. For a commercial maglev system, vehicle dynamics must be analyzed and tested in detail. In this study, the role of dynamics and controls in maglev vehicle/guideway interactions is discussed, and the literature on modeling the dynamic interactions of vehicle/guideway and suspension controls for ground vehicles is reviewed. Particular emphasis is placed on modeling vehicle/guideway interactions and response characteristics of maglev systems for a multicar, multiload vehicle traveling on a single- or doublespan flexible guideway, including coupling effects of vehicle/guideway, comparison of concentrated and distributed loads, and ride comfort. Different control-law designs are introduced into vehicle suspensions when a simple twodegree-of-freedom vehicle model is applied. Active and semiactive control designs for primary and secondary suspensions do improve the response of vehicle and provide acceptable ride comfort. Finally, future research associated with dynamics and controls of vehicle/guideway systems is identified.
\end{abstract}

\section{Introduction}

A high-speed ground transportation system, based on magnetically levitated (maglev) vehicles propelled by a linear electric motor, has been proposed to meet future intercity transportation requirements. One possible and attractive approach is in replacing air travel for selected intercity trips of 100 to 600 miles. The maglev system will offer the advantages of lower noise and emissions and 
better ride quality, as well as potential energy savings and economic benefits (Bohn and Steinmetz 1985; Chen et al. 1992; Coffey et al. 1991; Johnson et al. 1989; Katz et al. 1974; Zicha 1986).

While some design concepts have been developed nearly to commercial application, the attractiveness $c_{.}^{\delta}$ maglev systems is expected to be enhanced even further over the next several years by new or improved concepts, improved design and construction methods, and new material (including high-temperature superconductors, high-energy permanent magnets, and advanced material for guideways). It is therefore reasonable to expect that maglev systems may indeed be a key transportation mode in the 21st century (Chen et al. 1992).

For several decades, research and development have been performed in the areas of magnetic levitation, response of maglev vehicles to rough guideways, interaction of variously suspended vehicles with flexible guideways, and optimization of vehicle suspensions. The results of these efforts are useful in providing appropriate criteria for the design of maglev systems (Bohn and Steinmetz 1985; Chiu et al. 1971; Iguchi and Hara 1985; Katz et al. 1974; Sinha 1987).

The dynamic response of magnetically levitated vehicles is important because of safety, ride quality, guideway design, and system cost. More emphasis should be placed on guideway design, because the cost of the guideway structure is expected to be $60-80 \%$ of the overall initial capital investment cost (Uher 1989; Zicha 1986). Thus, guideway design is a critical area of potential capital savings. More-flexible guideways are less expensive, but cause complex vehicle/guideway interactions and affect ride quality. An optimized guideway design will be important for a high-speed maglev system that offers good ride quality. As maglev vehicle speeds increase to $200-300 \mathrm{mi} / \mathrm{hr}$, or as guideways become lighter and more flexible to reduce costs, the dynamic interactions between vehicle and guideway become an important problem and will play a dominant role in establishing vehicle suspension requirements and specifications for guideway stiffness, weight, and span length (Cai et al. 1992a, 1992c; Chiu et al. 1971; VuQuoc and Olsson 1989; Zicha 1986).

Light guideways, especially those made of steel, may be susceptible to dynamic instability and unacceptable vibration, and thus dynamic evaluation must be included in the structural analysis. Different dynamic responses of coupled vehicle/guideway systems may be observed, including periodic oscillation, random vibration, dynamic instability, chaotic motion, parametric resonance, combination resonance, and transient response (Chen et al. 1992). 
To design a proper guideway that provides acceptable ride quality, the dynamic interaction of vehicles and guideways must be understood. Furthermore, the trade-off between guideway smoothness and design of the levitation and control systems must be considered if the maglev system is to be economically feasible. The coupled vehicle/guideway dynamics are the link between the guideway and the other maglev components. Thus, reliable analytical and simulation techniques are needed in the design of vehicle/ guideway systems (Cai et al. 1992a, 1992c; Chen et al. 1992; Richardson and Wormley 1974). Furthermore, the coupled vehicle/guideway dynamic model with multiple cars and multiple loads must be developed to meet the design requirements of maglev systems. This analytical model should also be easily incorporated into the computer code for dynamic simulation of maglev systems (Cai et al. 1992a, 1992c).

Magnetically suspended systems are intrinsically underdamped. Achieving safe, stable operation and acceptable ride comfort requires some form of vehicle motion control. Moreover, vehicle tolerance to guideway flexibility and roughness, as well as to transient perturbing forces such as wind gusts and guideway misalignments, will be influenced by air-gap size and suspension control characteristics, ineliding response time and dynamic range. To the extent that tolerances can be increased through suitable suspension control systems, guideway cost can he reduced and the system made more robust (Cai et al. 1992; Faye et al. 1989; Kortum et al. 1988; Sinha 1987).

For safety, maglev systems should be stable. Thus, stability characteristics must be studied because instabilities in maglev system models have been observed at Argonne National Laboratory and other organizations (Cai et al. 1992b; Chu and Moon 1983; Moon 1974, 1975). With a better understanding of vehicle stability characteristics, a better control law can be adopted to ensure a high level of ride comfort and safety. Vehicle suspension control designs are therefore necessary to meet stability requirements of maglev systems.

Although the technical literature contains a substantial number of publications dealing with controls of conventional ground vehicles (Bernard et al. 1987; Chalasani 1987; Dukkipati et al. 1992; Elmadany 1990; Karnopp and Margolis 1984), very little work exists on suspension control designs of maglev systems (Faye et al. 1989; Gottzein et al. 1974; Katz et al. 1974; Kortum et al. 1988; Kortum and Utzt 1984; Sinha 1987).

Therefore, this study is focused on the dynamics and control of maglev vehicles/guideways. We first discuss the problems associated with modeling vehicle/guideway interactions and then explain the response characteristics of maglev systems for a multicar, multiload vehicle traveling on a single- or double- 
span flexible guideway, with an emphasis on coupling effects of vehicle/guideway, comparison of concentrated and distributed loads, and ride comfort. Second, different control-law designs are introduced into vehicle suspensions when a simple two degree-of-freedom vehicle model is applied. Active and semiactive control designs for primary and secondary suspensions indeed improve the response of vehicle and provide acceptable ride comfort. Finally, future research associated with dynamics and controls of vehicle/guideway systems are identified.

\section{Dynamic Interactions of Maglev Vehicle/Guideway Systems}

\subsection{Background for Dynamic Interactions}

To simplify the vehicle model, only vertical motions of the vehicle are considered, based on the assumption that vertical motion is dominant and that other motions can be ignored when vertical motion is evaluated. This is applicable in a system in which passenger-compartment vertical accelerations are limited to less than $0.05 \mathrm{~g}$ and in which vehicle unsprung mass (i.e., mass associated with the primary suspension) inertia forces are low compared to vehicle weight. Thus, the influence of vehicle heave acceleration, which is of particular interest because it is used as a measure of passenger comfort, can be determined in this simplified model (Cai et al. 1992a, 1992c; Richardson and Wormley 1974).

In general, at least a two-suspension vehicle model is necessary to model primary and secondary suspensions of maglev vehicles (Cai et al. 1992a, 1992c; Richardson and Wormley 1974; Vu-Quoc and O!sson 1989). Lumped masses and passive parameters, such as linear springs and dashpots, are used to represent these suspensions. For example, in most cases, the secondary suspension was described as consisting of mass, spring, and dashpot, while the primary suspension consists only of spring or mass and spring without dashpot (Richardson and Wormley 1974). The model developed in our previous work included masses, springs, and dampings in both primary and secondary suspensions (Cai et al. 1992a, 1992c). The spring in the primary suspension represents the magnetic gap stiffness, while the damping represents a passive damping control for magnets.

When vehicle acceleration forces are much lower than the constant force due to vehicle weight, a constant moving force can be used to represent the simplest vehicle model. Both concentrated and distributed moving forces were used as suspension forces in previous studies (Richardson and Wormley 1974). Cai et al. 
(1992a, 1992c) studied different cases for various combinations of constant and pulsating forces moving along the guideway and compared the moving-force and quarter-car models.

Only the single-car model can be found in published literature in analyzing vehicle/guideway interactions. In practice, a maglev vehicle may include two or more cars. Moreover, couplings between car bodies will certainly affect vehicle/ guideway dynamics because of constraint forces. Therefore, a model that represents a multiple-car vehicle should be developed to study dynamic analysis of vehicle/guideway systems.

For a flexible guideway, elastic deformation must be considered. The guideway vertical motion is excited by the full vehicle weight, while lateral and longitudinal motions are excited by only a fraction of vehicle weight; therefore, attention is focused on vertical guideway deflection when analyzing vehicle/ guideway interactions. Beam theory has been verified as a good approximation for guideway dynamics when span width to length ratio is less than 0.7 (Richardson and Wormley 1974). Theref, ${ }^{*}$, , ti.e classical Bernoulli-Euler beam equation is used to model guideway characues s ics in virtually all recent analyses of vehicle/guideway interactions.

Guideway surface irregularities are very important to the ride quality of maglev systems. These irregularities may be caused by imperfections in manufacturing and assembling of the structural components, as well as by thermal effects or surface wear. In practice, guideway surface irregularities are an important input to maglev vehicles and affect dynamic interactions (Cai et al. 1992a, 1992c). Guideway irregularities can be measured and statistically studied to determine quantitative relationships between tolerances and resulting guideway smoothness. The guideway profile is the sum of a static profile and a dynamic profile. Static irregularities depend on construction practice, settling, dead-weight loads, and environmental conditions (Snyder and Wormley 1977). The dynamic profile of a guideway is composed of periodic and random motions or disturbances due to guideway deflections from the moving vehicle (Chen et al. 1992).

Analytical methods to predict dynamic vehicle/guideway interaction can be divided into three groups: lumped mass, direct numerical, and modal. The lumped mass method is simple and can be used easily to account for nonuniform properties, while the direct numerical method is accurate ut requires more computer time. The modal analysis method is an efficient compromise between the other two methods (Chen et al. 1992; Fryba 1972; Olsson 1985; Richardson and Wormley 1974). 
In the modal analysis technique, the Bernoulli-Euler equation is used as the basis for the modal solution technique of distributed guideway dynamics. And the space- and time-varying guideway motion is represented as an infinite summation of the natural mode solutions, which is formulated as the infinite sum of the products of mode shapes and time-varying modal amplitudes. Timevarying modal amplitudes depend on the forcing functions (i.e., interaction forces between vehicle and guideway) and initial conditions.

In practice, a finite number of modes are used to represent guideway motion. The number of modes required for a given level of accuracy depends on the frequency content of the guideway forcing function, the traverse speed of this function, and the beam properties.

Mode shapes are determined from the natural unforced vibration of the span and are affected by support boundary conditions at the ends of the beams, and at termediate supports in the case of multiple-span beams. Boundary conditions

e defined by the characteristics of the supports and the coupling between successive beam spans. The simplest case occurs for beams of only one span length, which are simply supported on rigid supports. If the beam extends over more than one span, then at interior simple supports the slope and bending moment must be continuous across the support. Single-, multiple-, and continuous-span guideway models for vehicle/guideway interaction in high-speed maglev systems can be found in recent literature (Chiu et al. 1974; Smith et al. $1975 \mathrm{a}, 1975 \mathrm{~b}$ ). In most of these studies, however, vehicles were described as constant concentrated or distributed force traveling along the beams. Cai et al. (1992a, 1992r) presented a detailed analysis for a two-degree-of-freedom vehicle traveling along both single- and double-span guideways.

For maglev vehicles restricted to vertical accelerations of less than $0.05 \mathrm{~g}$, the inertia force is much smaller than the static load, normally about $5 \%$ or less. Also, coupling between vehicles and guideways will be small, i.e., if the dynamic suspension forces acting on the guideway are low compared with the static force due to vehicle weight, dynamic coupling will be low (Richardson and Wormley 1974). In this case, the guideway deflection profile is computed by assuming that the suspension forces are constant at their static values and more along the guideway at vehicle speed. The deflection is then used as known displacement input into the suspension, and the vehicle dynamic motions are determined by standard transfer function analysis.

When the unsprung mass is greater than $25 \%$ of the vehicle mass, such as in an electromagnetic system (EMS), or when vertical vehicle accelerations can be greater than $0.1 \mathrm{~g}$, guideway deflection may be significantly affected by dynamic suspension forces, and fully coupled analysis of vehicle/guideway interaction is 
needed. In the EMS system, the large accelerations of the primary suspension system mass due to guideway roughness cause significant excursions in magnet reaction force, and it appears that the vehicle/guideway equations should not be decoupled (Katz et al. 1974). Cai et al. (1992a, 1992c) extensively investigated coupled effects of vehicle/guideway interactions in a wide range of vehicle speeds with various vehicle and guideway parameters for maglev systems and provided appropriate criteria for decoupling at critical vehicle speeds or crossing frequencies.

To evaluate a wide range of vehicle and guideway designs for an equally wide range of operating conditions, it is necessary to develop dynamic models 1 : describe dynamic response of vehicle/guideway interactions. Various compute: codes have been developed to provide the necessary dynamic simulations (Wang et al. 1991). However, most existing computer codes for maglev systems cannot simulate dynamic interaction of vehicle/guideway because these codes can only model the guideway as a rigid body. We recently incorporated dynamic interaction of vehicle/guideway for multicar, multiload maglev systems into a new computer program based on the ANLMAGLEV program, which we developed in 1991 at Argonne National Laboratory. ANLMAGLEV can simulate the dynamic behavior of a wide range of vehicle and guideway dosigns over a broad range of operating conditions and provides broad applicability to maglev system analysis (Coffey et al. 1991; Wang et al. 1991).

\subsection{The Vehicle Model}

A multicar, multiload vehicle traveling along a flexible guideway at a velocity $\mathrm{v}$, as shown in Fig. 1, is considered in our mathematical model for dynamic analysis of vehicle/guideway interactions. The car body is rigid and has a uniform mass. The center of mass is consistent with that of moment of inertia. Each car is supported by certain numbers of magnets (or bogies) with linear springs and dampings (see Fig. 2), which form the primary and secondary suspensions of the vehicle. If there is only one magnet (i.e., the unsprung mass)

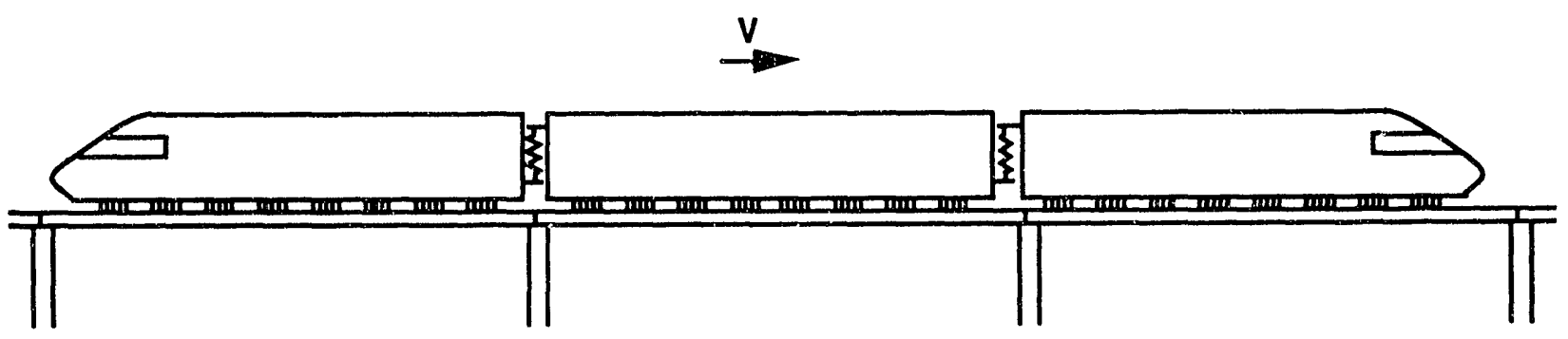

Fig. 1. Model of multicar, multiload maglev vehicle traveling along a guideway 


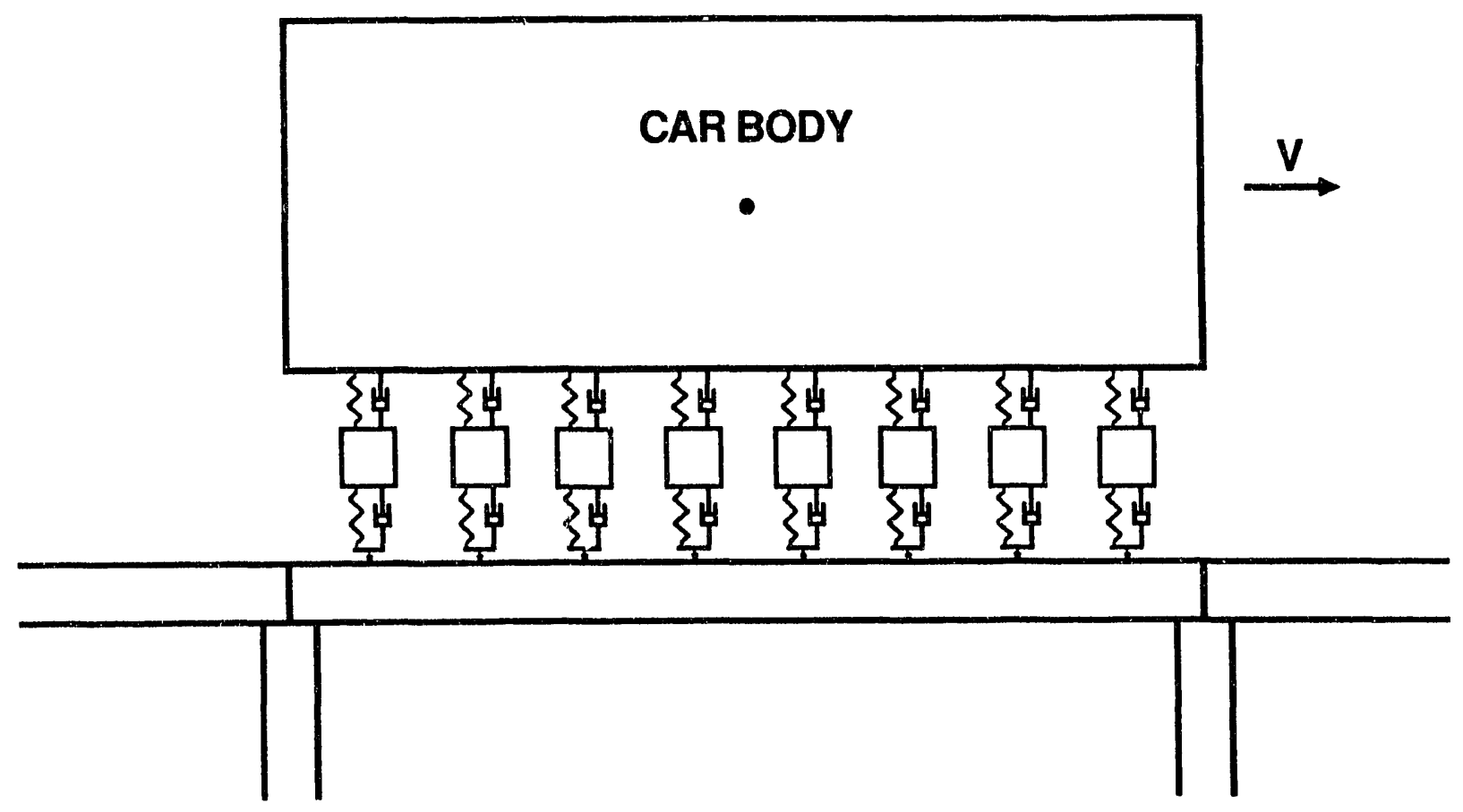

Fig. 2. Model of single car supported with multiple magnets and traveling along a guideway

attached to the vehicle, there is a single concentrated load and only onedimensional motion (i.e., heave motion) of the vehicle. If there are multiple magnets on the vehicle, the loads are considered multiple or distributed and the vehicle is capable of both heave and pitch motions. But in this study, only vertical vehicle motion is considered because it is dominant in the dynamic analysis of vehicle/guideway interactions.

The equations of motion for the vehicle are then

$$
\begin{aligned}
m_{s} \ddot{y}_{s i}+c_{s} \sum_{j=1}^{N}\left(\dot{y}_{s i}-\dot{y}_{p i j}\right)+k_{s} \sum_{j=1}^{N}\left(y_{s i}-y_{p i j}\right) \\
+c_{v}\left\{\left[\dot{y}_{s i}-\dot{y}_{s(i-1)}\right]+\left[\dot{y}_{s i}-\dot{y}_{s(i+1)}\right]\right\} \\
+k_{v}\left\{\left[y_{s i}-y_{s(i-1)}\right]+\left[y_{s i}-y_{s(i+1)}\right]\right\}=-m_{s} g \\
(i=2, \ldots, M-1 ; \quad j=1, \ldots, N)
\end{aligned}
$$




$$
\begin{aligned}
& \mathrm{m}_{\mathrm{s}} \ddot{\mathrm{y}}_{\mathrm{s} 1}+\mathrm{c}_{\mathrm{s}} \sum_{\mathrm{j}=1}^{\mathrm{N}}\left(\dot{\mathrm{y}}_{\mathrm{s} 1}-\dot{\mathrm{y}}_{\mathrm{p} 1 \mathrm{j}}\right)+\mathrm{k}_{\mathrm{s}} \sum_{\mathrm{j}=1}^{\mathrm{N}}\left(\mathrm{y}_{\mathrm{s} 1}-\mathrm{y}_{\mathrm{p} 1 \mathrm{j}}\right) \\
& +c_{v}\left(\dot{y}_{s 1}-\dot{y}_{s 2}\right)+k_{v}\left(y_{s 1}-y_{s 2}\right)=-m_{s} g \\
& (i=1 ; j=1, \ldots, N) \\
& m_{s} \ddot{y}_{s M}+c_{s} \sum_{j=1}^{N}\left(\dot{y}_{s M}-\dot{y}_{p M j}\right)+k_{s} \sum_{j=1}^{N}\left(y_{s M}-y_{p M j}\right) \\
& +c_{v}\left[\dot{y}_{s M}-\dot{y}_{s}(M-1)\right]+k_{v}\left[y_{s M}-y_{s}(M-1)\right]=-m_{s} g \\
& (i=M ; j=1, \ldots, N)
\end{aligned}
$$

and

$$
\begin{array}{r}
m_{p} \ddot{y}_{p i j}+c_{p}\left(\dot{y}_{p i j}+\dot{y}_{g i j}\right)+k_{p}\left(y_{p i j}+y_{g i j}\right) \\
-c_{s}\left(\dot{y}_{s i}-\dot{y}_{p i j}\right)-k_{s}\left(y_{s i}-y_{p i j}\right)=-m_{p} g \\
(i=1, \ldots, M ; \quad j=1, \ldots, N)
\end{array}
$$

where lumped masses $m_{p}$ and $m_{s}$, linear springs $k_{p}$ and $k_{s}$, and dampings $c_{p}$ and $c_{s}$ represent primary and secondary suspensions; the displacement of two suspensions are $y_{p}$ and $y_{s}$; subscripts $i$ represent $i$-th car body and $j$ represents $j$-th magnet on the $i$-th car; $M$ is number of cars; $N$ is number of magnets on each car; and $k_{v}$ and $c_{v}$ are intercar stiffness and damping, representing constraints between adjacent cars. For a magnetic primary suspension, $k_{p}$ and $c_{p}$ represent magnetic gap stiffness and passive damping. ygij is guideway displacement input at the $\mathrm{i}$-th car and the $\mathrm{j}$-th magnet.

Uncoupled natural frequencies and modal damping ratios are defined as follows: 


$$
\begin{array}{ll}
\omega_{p}=\sqrt{\frac{k_{p}}{m_{p}}}, \quad \zeta_{p}=\frac{c_{p}}{2 m_{p} \omega_{p}}, \\
\omega_{s}=\sqrt{\frac{N k_{s}}{m_{s}}}, & \zeta_{s}=\frac{N c_{s}}{2 m_{s} \omega_{s}} .
\end{array}
$$

And several nondimensional parameters are introduced:

$$
\begin{array}{ll}
\alpha_{c}=\frac{c_{v}}{c_{s}}, & \alpha_{k}=\frac{k_{v}}{c_{s}}, \\
\beta_{c}=\frac{c_{s}}{c_{p}}, & \beta_{k}=\frac{k_{s}}{k_{p}} .
\end{array}
$$

Using Eqs. 5 and 6, we can rewrite Eqs. 1, 2, 3, and 4 as

$$
\begin{aligned}
& \ddot{y}_{s i}+2 \zeta_{s} \omega_{s} \dot{y}_{s i}-2 \zeta_{s} \omega_{s} / N \sum_{j=1}^{N} \dot{y}_{p i j}+\omega_{s}^{2} y_{s i}-\omega_{s}^{2} / N \sum_{j=1}^{N} y_{p i j} \\
& +2 \zeta_{s} \omega_{s} \alpha_{c}\left[2 \dot{y}_{s i}-\dot{y}_{s(i-1)}-\dot{y}_{(i+1)}\right] \\
& +\omega_{s}^{2} \alpha_{k}\left[2 y_{s i}-y_{s(i-1)}-y_{s(i+1)}\right]=-g \\
& \quad(i=2, \ldots, M-1 ; j=1, \ldots, N) \\
& \ddot{y}_{s 1}+2 \zeta_{s} \omega_{s} \dot{y}_{s 1}-2 \zeta_{s} \omega_{s} / N \sum_{j=1}^{N} \dot{y}_{p 1 j}+\omega_{s}^{2} y_{s 1}-\omega_{s}^{2} / N \sum_{j=1}^{N} y_{p 1 j} \\
& +2 \zeta_{s} \omega_{s} \alpha_{c}\left(\dot{y}_{s 1}-\dot{y}_{s 2}\right)+\omega_{s}^{2} \alpha_{k}\left(y_{s 1}-y_{s 2}\right)=-g \\
& (i=1 ; j=1, \ldots, N)
\end{aligned}
$$




$$
\begin{gathered}
\ddot{y}_{s M}+2 \zeta_{s} \omega_{s} \dot{y}_{s M}-2 \zeta_{s} \omega_{s} / N \sum_{j=1}^{N} \dot{y}_{p M j}+\omega_{s}^{2} y_{s M}-\omega_{s}^{2} / N \sum_{j=1}^{N} y_{p M j} \\
+2 \zeta_{s} \omega_{s} \alpha_{c}\left[\dot{y}_{s M}-\dot{y}_{s}(M-1)\right]+\omega_{s}^{2} \alpha_{k}\left[y_{s M}-y_{s(M-1)}\right]=-g \\
(i=M ; j=1, \ldots, N)
\end{gathered}
$$

and

$$
\begin{gathered}
\ddot{y}_{p i j}+2 \zeta_{p} \omega_{p}\left(1+\beta_{c}\right) \dot{y}_{p i j}+\omega_{p}^{2}\left(1+\beta_{k}\right) y_{p i j} \\
-2 \zeta_{p} \omega_{p} \beta_{c} \dot{y}_{s i}-\omega_{p}^{2} \beta_{k} y_{s i}=-g-2 \zeta_{p} \omega_{p} \dot{y}_{g i j}-\omega_{p}^{2} y_{g i j} \\
(i=1, \ldots, M ; j=1, \ldots, N) .
\end{gathered}
$$

The system of Eqs. 7-10 can be represented in matrix form by an $M+M \times N$ size set:

$$
M \ddot{\mathbf{y}}+\mathbf{C} \dot{\mathbf{y}}+\mathbf{K y}=\mathbf{Q}
$$

where

$$
\mathbf{y}=\left[\frac{\mathbf{y}_{1}}{\mathbf{y}_{2}}\right]
$$

$$
\mathbf{y}_{1}=\left[\begin{array}{c}
y_{\mathrm{s} 1} \\
y_{\mathrm{s} 2} \\
\vdots \\
y_{\mathrm{sM}}
\end{array}\right]_{\mathrm{M} \times 1}, \quad \mathbf{y}_{2}=\left[\begin{array}{c}
\mathrm{y}_{\mathrm{p} 11} \\
\mathrm{y}_{\mathrm{p} 12} \\
\mathrm{y}_{\mathrm{p} 1 \mathrm{~N}} \\
\vdots \\
\mathrm{y}_{\mathrm{pM} 1} \\
\mathrm{y}_{\mathrm{pM} 2} \\
\vdots \\
\mathrm{y}_{\mathrm{pMN}}
\end{array}\right]_{(\mathrm{M} \cdot \mathrm{N}) \times 1}
$$


$\mathbf{Q}=\left[\frac{\mathbf{Q}_{1}}{\mathbf{Q}_{2}}\right]$

$\mathbf{Q}_{1}=\left[\begin{array}{c}-\mathrm{g} \\ -\mathrm{g} \\ \vdots \\ -\mathrm{g}\end{array}\right]_{\mathrm{M} \times 1}$

$$
\mathbf{Q}_{2}=\left[\begin{array}{c}
-g-2 \zeta_{p} \omega_{p} \dot{y}_{g 11}-\omega_{p}^{2} y_{g 11} \\
-g-2 \zeta_{p} \omega_{p} \dot{y}_{g 12}-\omega_{p}^{2} y_{g 12} \\
\vdots \\
-g-2 \zeta_{p} \omega_{p} \dot{y}_{g 1 N}-\omega_{p}^{2} y_{g 1 N} \\
\vdots \\
-g-2 \zeta_{p} \omega_{p} \dot{y}_{g M 1}-\omega_{p}^{2} y_{g M 1} \\
-g-2 \zeta_{p} \omega_{p} \dot{y}_{g M 2}-\omega_{p}^{2} y_{g M 2} \\
\vdots \\
-g-2 \zeta_{p} \omega_{p} \dot{y}_{g M N}-\omega_{p}^{2} y_{g M N}
\end{array}\right]_{(M \cdot N) \times 1}
$$

$\mathbf{M}=\left[\begin{array}{lllll}1 & & & & \\ & 1 & & 0 & \\ & & \ddots & & \\ & 0 & & & \\ & & & & 1\end{array}\right]_{(M+M \cdot N) \times(M+M \cdot N)}$

$\mathbf{C}=\left[\begin{array}{l|l}\mathrm{C}_{11} & \mathbf{C}_{12} \\ \hline \mathbf{C}_{21} & \mathbf{C}_{22}\end{array}\right]_{(\mathrm{M}+\mathrm{M} \cdot \mathrm{N}) \times(\mathrm{M}+\mathrm{M} \cdot \mathrm{N})}$,

(Contd.)

$\mathbf{C}_{11}=\left[\begin{array}{ccccc}2 \zeta_{s} \omega_{s}\left(1+\alpha_{c}\right) & -2 \zeta_{s} \omega_{s} \alpha_{c} & 0 & 0 & \cdots \\ -2 \zeta_{s} \omega_{s} \alpha_{c} & 2 \zeta_{s} \omega_{s}\left(1+2 \alpha_{c}\right) & -2 \zeta_{s} \omega_{s} \alpha_{c} & 0 & \cdots \\ 0 & -2 \zeta_{s} \omega_{s} \alpha_{c} & 2 \zeta_{s} \omega_{s}\left(1+2 \alpha_{c}\right) & -2 \zeta_{s} \omega_{s} \alpha_{c} & \cdots \\ \vdots & \vdots & \vdots & \vdots & \vdots\end{array}\right]_{M \times M}$

$\mathbf{C}_{12}=\left[\begin{array}{ccccccc}-2 \zeta_{\mathrm{s}} \omega_{\mathrm{s}} / \mathrm{N} & \cdots & -2 \zeta_{\mathrm{s}} \omega_{\mathrm{s}} / \mathrm{N} & 0 & \cdots & 0 & \cdots \\ 0 & \cdots \cdots & 0 & -2 \zeta_{\mathrm{s}} \omega_{\mathrm{s}} / \mathrm{N} & \cdots & -2 \zeta_{\mathrm{s}} \omega_{\mathrm{s}} / \mathrm{N} & \cdots \\ \vdots & \vdots & \vdots & \vdots & \vdots & \vdots & \vdots\end{array}\right]_{\mathrm{M} \times(\mathrm{M} \cdot \mathrm{N})}$ 
$\mathbf{C}_{21}=\left[\begin{array}{ccc}-2 \zeta_{p} \omega_{p} \beta_{c} & 0 & \cdots \\ \vdots & \vdots & \cdots \\ -2 \zeta_{p} \omega_{p} \beta_{c} & 0 & \cdots \\ 0 & -2 \zeta_{p} \omega_{p} \beta_{c} & \cdots \\ \vdots & \vdots & \cdots \\ 0 & -2 \zeta_{p} \omega_{p} \beta_{c} & \cdots \\ \vdots & \vdots & \vdots\end{array}\right]_{(M \cdot N) \times M}$

$\mathbf{C}_{22}=\left[\begin{array}{cccc}2 \zeta_{p} \omega_{p}\left(1+\beta_{c}\right) & 0 & 0 & \cdots \\ 0 & 2 \zeta_{p} \omega_{p}\left(1+\beta_{c}\right) & 0 & \cdots \\ 0 & 0 & 2 \zeta_{p} \omega_{p}\left(1+\beta_{c}\right) & \cdots \\ \vdots & \vdots & \vdots & \vdots\end{array}\right]_{(M \cdot N) \times(M \cdot N)}$

$\mathbf{K}=\left[\begin{array}{l|l}\mathbf{K}_{11} & \mathbf{K}_{12} \\ \hline \mathbf{K}_{21} & \mathbf{K}_{22}\end{array}\right]$,

$\mathbf{K}_{11}=\left[\begin{array}{ccccc}\omega_{s}^{2}\left(1+\alpha_{k}\right) & -\omega_{s}^{2} \alpha_{k} & 0 & 0 & \cdots \\ -\omega_{s}^{2} \alpha_{k} & \omega_{s}^{2}\left(1+2 \alpha_{k}\right) & -\omega_{s}^{2} \alpha_{k} & 0 & \cdots \\ 0 & -\omega_{s}^{2} \alpha_{k} & \omega_{s}^{2}\left(1+2 \alpha_{k}\right) & -\omega_{s}^{2} \alpha_{k} & \cdots \\ \vdots & \vdots & \vdots & \vdots & \vdots\end{array}\right]_{M \times M}$,

$\mathbf{K}_{12}=\left[\begin{array}{ccccccc}-\omega_{\mathrm{s}}^{2} / \mathrm{N} & \cdots & -\omega_{\mathrm{s}}^{2} / \mathrm{N} & 0 & \cdots & 0 & \cdots \\ 0 & \cdots \cdots & 0 & -\omega_{\mathrm{s}}^{2} / \mathrm{N} & \cdots & -\omega_{\mathrm{s}}^{2} / \mathrm{N} & \cdots \\ \vdots & \vdots & \vdots & \vdots & \vdots & \vdots & \vdots\end{array}\right]_{\mathrm{M} \times(\mathrm{M} \cdot \mathrm{N})}$

$\mathbf{K}_{21}=\left[\begin{array}{ccc}-2 \omega_{p}^{2} \beta_{k} & 0 & \cdots \\ \vdots & \vdots & \cdots \\ -2 \omega_{p}^{2} \beta_{k} & 0 & \cdots \\ 0 & -2 \omega_{p}^{2} \beta_{k} & \cdots \\ \vdots & \vdots & \cdots \\ 0 & -2 \omega_{p}^{2} \beta_{k} & \cdots \\ \vdots & \vdots & \vdots\end{array}\right]_{(M \cdot N) \times M}$

(Contd.) 


$$
\mathbf{K}_{22}=\left[\begin{array}{cccc}
\omega_{\mathrm{p}}^{2}\left(1+\beta_{\mathrm{k}}\right) & 0 & 0 & \cdots \\
0 & \omega_{\mathrm{p}}^{2}\left(1+\beta_{\mathrm{k}}\right) & 0 & \cdots \\
0 & 0 & \omega_{\mathrm{p}}^{2}\left(1+\beta_{\mathrm{k}}\right) & \cdots \\
\vdots & \vdots & \vdots & \vdots
\end{array}\right]_{(\mathrm{M} \cdot \mathrm{N}) \times(\mathrm{M} \cdot \mathrm{N})}
$$

If $M=1$ and $N=1$, the system of Eqs. 11 and 12 will represent the vehicle to be a one-dimensional model with two degrees of freedom (Cai et al. 1992a).

\subsection{The Guideway Model}

For typical guideway systems, span-length-to-width ratios are large enough so that individual spans may be considered as beams rather than as plates. Thus, a Bernoulli-Euler beam model can be applied to a freely supported, homogeneous, isotropic, and uniform-cross-section guideway.

The equations of motion for guideway spans where a multicar, multiload vehicle traveling along may be derived as

$$
E I \frac{\partial^{4} y_{k}}{\partial x^{4}}+C \frac{\partial y_{k}}{\partial t}+m \frac{\partial^{2} y_{k}}{\partial t^{2}}=F_{k}(x, t),
$$

where $\mathrm{x}$ is the axial coordinate of the beams, $t$ is time, EI is the bending rigidity of the beams, $\mathrm{C}$ is the viscous damping coefficient (where we assume damping in a span is linear, viscous damping), and $m$ is the beam mass per unit length. $y_{k}$ is displacement of the $k$-th beam where the vehicle is traveling. $F_{k}(x, t)$ is the exciting force of the $\mathrm{k}$-th beam due to the multicar, multiload vehicle acting on the beam,

$$
\begin{aligned}
& \mathrm{F}_{\mathrm{k}}(\mathrm{x}, \mathrm{t})=\sum_{\mathrm{k}_{1}=1}^{\mathrm{k}_{\mathrm{n}}} \mathrm{f}_{\mathrm{k}_{\mathrm{i}}}(\mathrm{t}) \delta\left(\mathrm{x}_{\mathrm{k}_{\mathrm{i}}}-\mathrm{vt}\right), \\
& \mathrm{f}_{\mathrm{k}_{\mathrm{i}}}(\mathrm{t})=-\left[\mathrm{c}_{\mathrm{p}}\left(\dot{y}_{\mathrm{pij}}-\dot{y}_{\mathrm{k}_{\mathrm{i}}}\right)+\mathrm{k}_{\mathrm{p}}\left(\mathrm{y}_{\mathrm{pij}}-\mathrm{y}_{\mathrm{k}_{\mathrm{i}}}\right)\right],
\end{aligned}
$$

where $y_{p i j}$ is the displacement of primary suspension of $i$-th car and $j$-th magnet on the $k$-th beam, $y_{k_{i}}$ is the displacement of $k$-th beam on the point $k_{i}$ corresponding to the displacement $\mathrm{y}_{\mathrm{pij}}$, and $\mathrm{k}_{\mathrm{n}}$ is the total number of forces applied to the $\mathrm{k}$-th beam by the vehicle. 
For simply supported beams, the boundary conditions of the k-th beam are

$$
\begin{aligned}
& y_{k}(t, 0)=\frac{\partial^{2} y_{k}(t, 0)}{\partial x^{2}}=0, \\
& y_{k}(t, L)=\frac{\partial^{2} y(t, L)}{\partial x^{2}}=0 .
\end{aligned}
$$

If there is a double-span beam (total length is $2 \mathrm{~L}$ ), the slope and bending moment at an interior simple support must be continuous (Cai et al. 1992a); thus

$$
\begin{aligned}
& \left.y_{k}(t, x)\right|_{x \rightarrow L-}=\left.y_{k}(t, x)\right|_{x \rightarrow L+}=0, \\
& \left.\frac{\partial y_{k}(t, x)}{\partial x}\right|_{x \rightarrow L-}=\left.\frac{\partial y_{k}(t, x)}{\partial x}\right|_{x \rightarrow L+}, \\
& \left.\frac{\partial^{2} y_{k}(t, x)}{\partial x}\right|_{x \rightarrow L-}=-\left.\frac{\partial^{2} y_{k}(t, x)}{\partial x}\right|_{x \rightarrow L+},
\end{aligned}
$$

and there are

$$
y_{k}(t, 2 L)=\frac{\partial^{2} y(t, 2 L)}{\partial x^{2}}=0
$$

The initial conditions are

$$
y_{k}(x, 0)=\frac{\partial y_{k}(x, j)}{\partial t}=0
$$

In the modal analysis method, displacement of the beam is expressed as

$$
y_{k}(x, t)=\sum_{n=1}^{\infty} q_{k n}(t) \varphi_{n}(x)
$$

where $q_{k n}(t)$ are time-varying modal amplitudes and $\varphi_{n}(x)$ are modal shape functions that are orthogonal over the beam length $0<x<L$. For a single-span beam,

$$
\varphi_{\mathrm{n}}(\mathrm{x})=\sqrt{2} \sin \left(\frac{\mathrm{n} \pi \mathrm{x}}{\mathrm{L}}\right)=\sqrt{2} \sin \left(\lambda_{\mathrm{n}} \frac{\mathrm{x}}{\mathrm{L}}\right), \quad \mathrm{n}=1,2,3, \ldots
$$


for a double-span beam

$$
\left.\begin{array}{c}
\varphi_{n}(x)=\sin \left[\frac{(n+1) \pi}{2} \frac{x}{L}\right]=\sin \left(\lambda_{n} \frac{x}{L}\right), \quad n=1,3,5,7,9, \ldots, \\
\varphi_{n}(x)=\sin \lambda_{n} \frac{x}{L}-\frac{\sin \lambda_{n}}{\sinh \lambda_{n}} \sinh \lambda_{n} \frac{x}{L} \\
0 \leq x \leq L \\
\varphi_{n}(x)=\sin \lambda_{n}\left(\frac{2 L-x}{L}\right)-\frac{\sin \lambda_{n}}{\sinh \lambda_{n}} \sinh \lambda_{n}\left(\frac{2 L-x}{L}\right) \\
L \leq x \leq L
\end{array}\right\} n=2,4,6,8,10, \ldots,
$$

where $\lambda_{n}$ in Eq. 23 (eigenvalue of the $n$-th mode for double-span beam vibration) is the solution of the characteristic equation

$$
\tan \lambda_{n}=\tanh \lambda_{n} .
$$

The values of $\lambda_{n}$ obtained from Eq. 24 are $3.39,7.07,10.21,13.35, \ldots$.

$\mathrm{q}_{\mathrm{kn}}(\mathrm{t})$ are the solution of the equations

$$
\frac{d^{2} q_{k n}}{d t^{2}}+2 \zeta_{n} \omega_{n} \frac{d q_{k n}}{d t}+\omega_{n}^{2} q_{k n}=\frac{1}{L m} \int_{0}^{L} F_{k}(x, t) \varphi_{n}(x) d x
$$

where $\omega_{\mathrm{n}}$ and $\zeta_{\mathrm{n}}$ (the circular frequency and modal damping ratio of the beams) are given by

$$
\omega_{\mathrm{n}}=\frac{\lambda_{\mathrm{n}}^{2}}{\mathrm{~L}^{2}} \sqrt{\frac{\mathrm{EI}}{\mathrm{m}}}, \quad \zeta_{\mathrm{n}}=\frac{\mathrm{C}}{2 \mathrm{~m} \omega_{\mathrm{n}}} .
$$

\subsection{Numerical Simulations}

Numerical simulations of dynamic interactions of vehicle/guideway systems, schematically shown in Figs. 1 and 2, were carried out on the basis of the governing equations described in Sections 2.2 and 2.3 for the vehicle and guideway. Because of the coupled dynamic interaction between the vehicle and guideway (as indicated in Eq. 10 where guideway deflections are input to the vehicle, and in Eq. 15 where vehicle static weight and acceleration forces are 
excitations to the guideway), an iterated method is required in numerical simulations to calculate dynamic response of both vehicle and guideway, when the fourth-order Runge-Kutta method is applied in the simulations. For maglev vehicles restricted to vertical accelerations of less than $0.05 \mathrm{~g}$, the inertia force is much lower than the static load, and dynamic coupling will be weak (Richardson and Wormley 1974). In this case, the iteration is not needed. Because the integrating time-step is small enough, deflections of guideway spans in the previous time-step can be used as input to the vehicle, and dynamic responses of a vehicle can then be calculated and the results used to calculate guideway response at the current time-step. This calculating sequence proved efficient when coupling between the vehicle and guideway is weak or when vehicle speed is below certain values (Cai et al. 1992a, 1992c).

In the modal analysis method, the infinite sum in Eq. 20 is truncated and a finite number of modes is used to represent guideway motion. The number of modes, $\mathrm{n}$, required for a given level of accuracy depends on the frequency content of the guideway forcing function (Eqs. 14 and 15), the traverse speed of this forcing function, and the beam properties. For maglev systems, the number of modes is related to vehicle speed or crossing frequency (Cai et al. 1992a; Chiu et al. 1971; Richardson and Wormley 1974). Five modes are sufficient for maglev guideways with vehicle speeds under $500 \mathrm{~km} / \mathrm{hr}$, in accordance with calculated results (Cai et al. 1992a).

The focus of our study is the steady-state or repetitive condition of guideway deflections and vehicle heave accelerations for the vehicles with a vertical motion. The steady state exists after a vehicle with a given arbitrary set of initial conditions has traversed a sufficient number of spans in which the state of the vehicle entering a span is identical to its state when leaving the span or, in fact, entering the next span. For a vehicle starting under zero initial conditions, the number of spans a vehicle must cross to reach a steady-state condition depends on the number of modes and traveling-speed ratio of the vehicle. The maximum number of spans a vehicle must cross to reach a steady state is less than 100 , in accordance with calculated results (Cai et al. 1992a).

In addition, to avoid numerical overflow in simulation from the effect of equally spaced multiple cars that may excite a very large resonance of guideway deflections (Richardson and Wormley 1974), the length of each car should not be the same as the length of the beam span. 


\subsection{Dynamic Analyses of Vehicle/Guideway Intractions}

Table 1 shows the parameters of vehicle and guideway we used in our simulation for the maglev systems shown in Figs. 1 and 2.

Two-Degree-of-Freedom Vehicle. If we set $M=1$ and $N=1$ in Eqs. 11 and 12 , the vehicle appears to be a two-degree-of-freedom model that provides a relatively simple explanation of the dynamic behavior of vehicle/guideway systems (Cai et al. 1992a, 1992c).

Figures 3 and 4 show the time histories of steady-state guideway displacement ratio $Y_{g}\left(=y_{g} / y_{m}\right)$ and vehicle acceleration ratios $\ddot{Y}_{p}\left(=\ddot{y}_{p} / y_{m}\right)$ and $\ddot{Y}_{s}\left(=\ddot{y}_{s} / y_{m}\right)$ for both primary and secondary suspensions on the single-span beam vs. the location of the vehicle on span $\xi_{\mathrm{v}}(=\mathrm{vt} / \mathrm{L})$, for two vehicle-traveling-speed ratios, i.e., $v / v_{c}=0.25$ in Fig. 3 and $v / v_{c}=0.5$ in Fig. 4, where $v_{c}$ is critical speed and is equal to $2 f_{1} L\left(f_{1}=\omega_{1} / 2 \pi\right)$. $y_{m}$ is the midspan displacement associated with the fundamental mode when a concentrated static load $\left(m_{p}+m_{s}\right) g$ is placed at the midspan, i.e., $y_{m}=2\left(m_{p}+m_{s}\right) g / m L \omega_{1}^{2}$. The nondimensional parameters in this model are chosen as $\left(\mathrm{m}_{\mathrm{p}}+\mathrm{m}_{\mathrm{s}}\right) /(\mathrm{mL})-0.5 ; \mathrm{m}_{\mathrm{p}} / \mathrm{m}_{\mathrm{s}}=0.1 ; \omega_{1} / \omega_{\mathrm{p}}=0.3 ; \omega_{\mathrm{s}} / \omega_{\mathrm{p}}=0.25$; $\zeta_{n}=2 \% ; \zeta_{p}=10 \% ; \zeta_{s}=25 \%$. The results show that dynamic interaction between

Table 1. Parameters for dynamic interaction analysis of maglev systems

\section{Vehicle}

Vehicle length $\ell$

Magnet mass $\mathrm{m}_{\mathrm{p}}$

Car body mass $\mathrm{m}_{\mathrm{s}}$

Primary damping $c_{p}$

Secondary damping $c_{s}$

Primary stiffness $k_{p}$

Secondary stiffness $\mathbf{k}_{\mathbf{s}}$

Intercar vertical stiffness $\mathbf{k}_{\mathbf{v}}$

Intercar vertical dampings $c_{v}$

Guideway

Length of span L

Bending rigidity EI

Mass per unit length $\mathrm{m}$

Damping $\zeta_{\mathrm{n}}$
$25.0 \mathrm{~m}$

$1016 \mathrm{~kg}$

$45700 \mathrm{~kg}$

$3.45 \times 10^{4} \mathrm{~N}-\mathrm{s} / \mathrm{m}$

$2.15 \times 10^{4} \mathrm{~N}-\mathrm{s} / \mathrm{m}$

$1.45 \times 10^{4} \mathrm{~N} / \mathrm{m}$

$2.26 \times 10^{4} \mathrm{~N} / \mathrm{m}$

$2.26 \times 10^{4} \mathrm{~N} / \mathrm{m}$

0.0

$25.0 \mathrm{~m}$

$7.16 \times 10^{9} \mathrm{~N}-\mathrm{m}^{2}$

$1.82 \times 10^{3} \mathrm{~kg} / \mathrm{m}$

$3 \%$ 

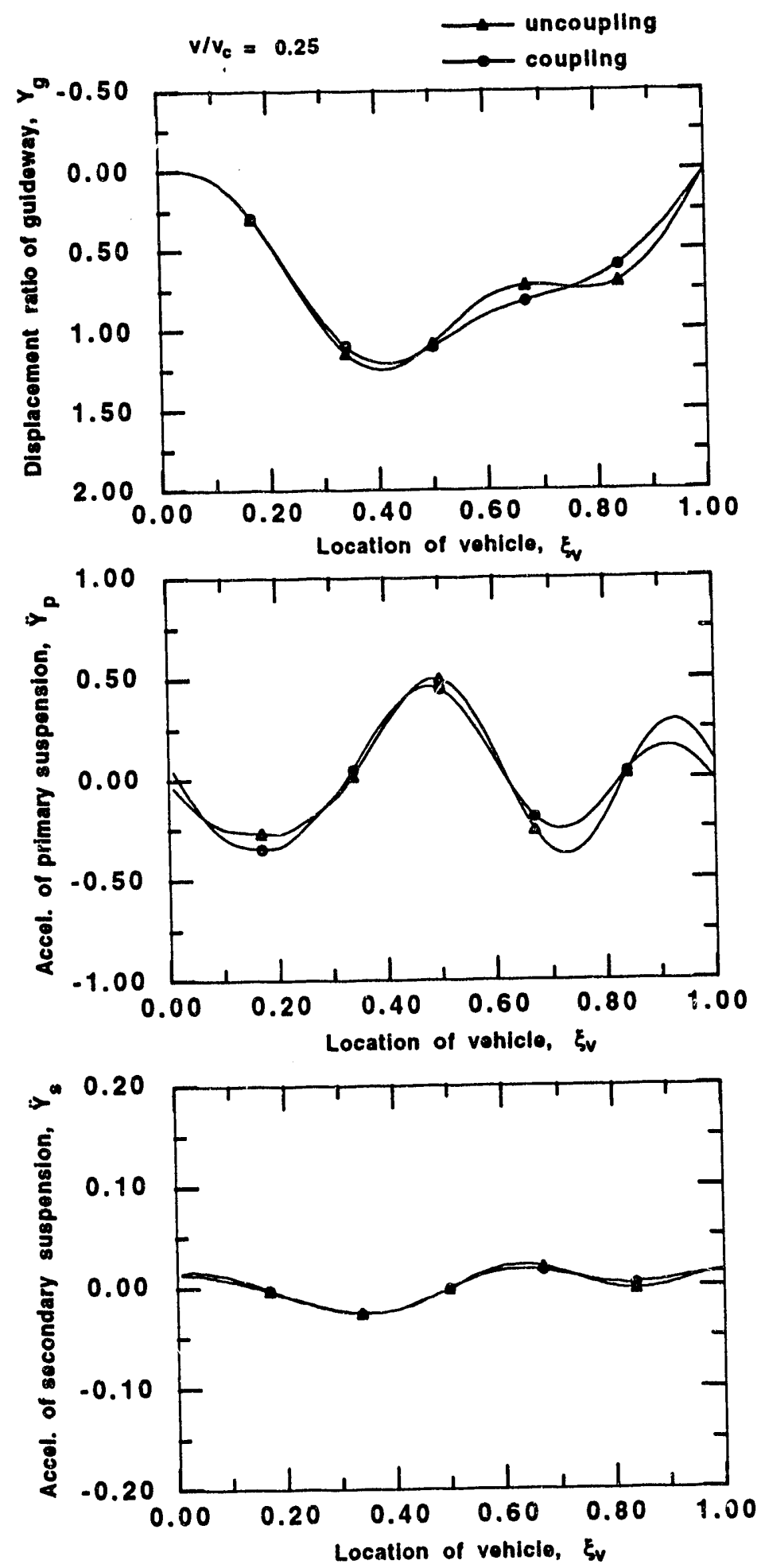

Fig. 3. Time histories of steady-state guideway displacement ratio and vehicle acceleration with speed ratio $v / v_{c}=0.25$ for a two-degree-of-freedom vehicle 

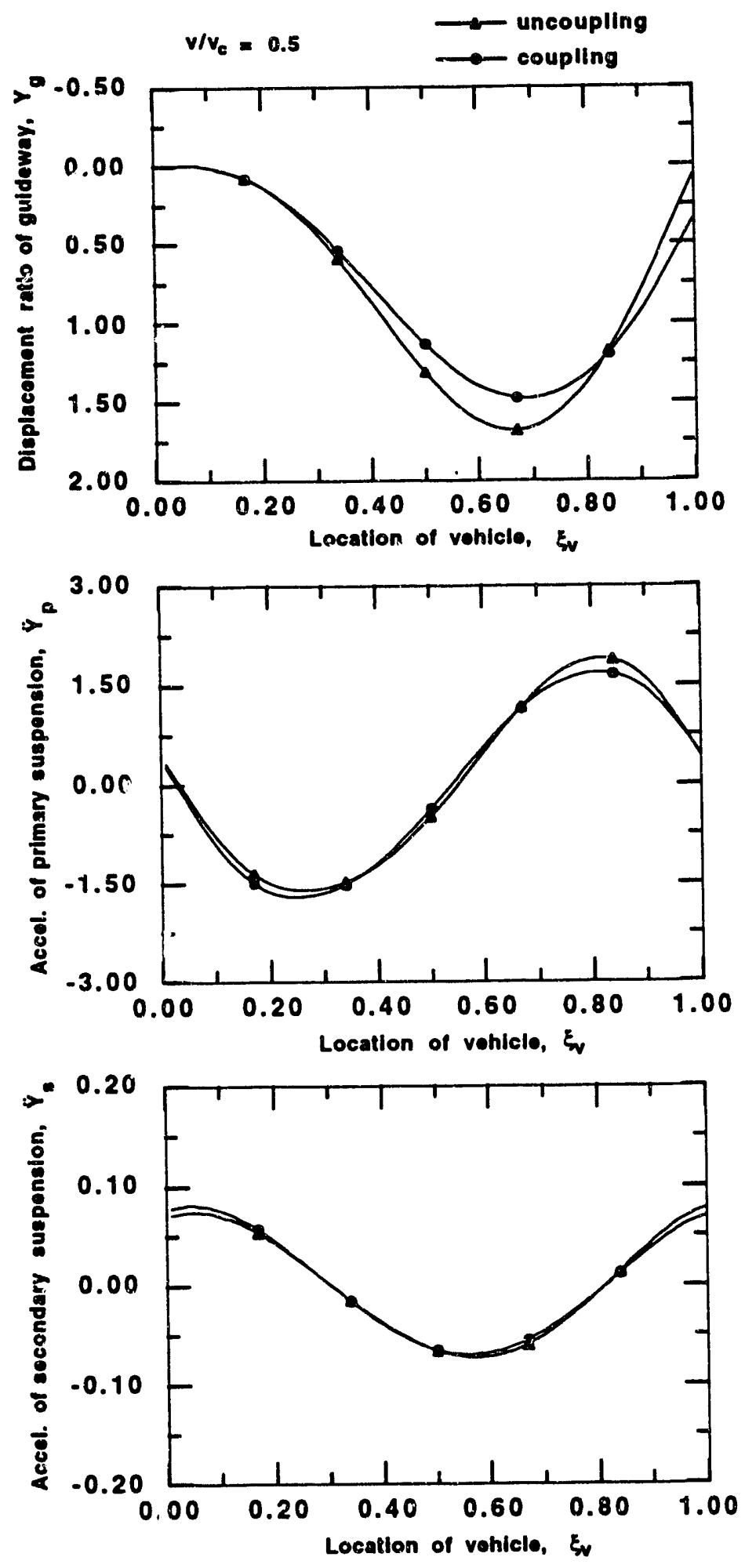

Fig. 4. Time histories of steady-state guideway displacement ratio and vehicle acceleration with speed ratio $v / v_{c}=0.50$ for a two-degree-of-freedom vehicle 
vehicle and guideway (comparing uncoupled and coupled curves) has relatively little influence on the secondary suspension at the given parameter values; the effect on guideway displacement is smaller for $\mathrm{v} / \mathrm{v}_{\mathrm{c}}=0.25$ than for $\mathrm{v} / \mathrm{v}_{\mathrm{c}}=0.5$, but the effect on the acceleration of the primary suspension is greater for $\mathrm{v} / \mathrm{v}_{\mathrm{c}}=0.25$ than for $v / v_{c}=0.5$. Also, we found that the location of vehicle $\xi_{v}$ at maximum displacement varies with the vehicle-traveling-speed ratio $\mathrm{v} / \mathrm{v}_{\mathbf{c}}$. In Fig. 3, v/ $\mathbf{v}_{\mathbf{c}}$ is 0.25 and $\xi_{\mathrm{v}}$ is about 0.4 , while in Fig. $4, \mathrm{v} / \mathrm{v}_{\mathrm{c}}$ is 0.5 and $\xi_{\mathrm{v}}$ is about 0.65 .

Figure 5 shows the maximum guideway displacement ratio $Y_{g}\left(=y_{g} / y_{m}\right)$ and maximum vehicle acceleration ratios $\ddot{Y}_{p}\left(=\ddot{y}_{p} / y_{m}\right)$ and $\ddot{Y}_{S}\left(=\ddot{y}_{s} / y_{m}\right)$ for both primary and secondary suspensions as a function of vehicle-traveling-sioeed ratio $\mathrm{v} / \mathrm{v}_{\mathrm{c}}$ on both single- and double-span guideways. For a single-span beani the peak of maximum displacement ratio is about 1.7 when $v / v_{c}$ is about 5 for an uncoupling model, while for a coupling model the peak of maximum displacement declines to 1.5 when $\mathrm{v} / \mathrm{v}_{\mathrm{c}}$ is about 0.4 . When $\mathrm{v} / \mathrm{v}_{\mathrm{c}}$ is below 0.4 , the coupled and uncoupled modes remain in good agreement. Therefore, for small values of $v / v_{c}$, an uncoupling model may be sufficient to simulate dynamics of vehicle/guideway systems, i.e., dynamic motions of the vehicle and guideway can be decoupled, the vehicle may be considered a moving force on the guideway, and guideway deflection is then used as a known displacement input into the suspensions. For the double-span guideway, when the vehicle-traveling-speed ratio $\mathrm{v} / \mathrm{v}_{\mathrm{c}}<0.5$, the maximum displacement ratios at both $\xi=0.5$ and $\xi=1.5(\xi=$ $\mathrm{x} / \mathrm{L}$ ) are much smaller than those of the single-span guideway. The differences between uncoupling and coupling models for the double-span guideway are smaller than those of the single-span guideway. From comparisons of vehicle accelerations, the amplitudes of maximum accelerations of both primary and secondary suspensions for the double-span guideway are lower than those of the single-span guideway. Because $\mathrm{v} / \mathrm{v}_{\mathrm{c}}$ in maglev systems is expected to be no larger than 0.5 (Sinha 1987), and without considering other factors, a two-span beam appears to be more efficient in achieving better ride quality.

More detailed parameter analyses for the two-degree-of-freedom vehicle model can be found in Cai et al. 1992a.

Effects of Distributed Loads. In a dynamic analysis of vehicle/guideway interactions, an understanding of the effects of distributed loads is essential. In a single-car vehicle (system parameters are given in Table 1) as shown in Fig. 2, for any given span configuration, span deflections decrease as the number of magnets is increased and total force is held constant. These effects exist when the vehicle travels at certain speeds. Figure 6 shows the midspan deflections of a single-span beam when a single-car vehicle, which has one, two, four, and eight magnets attached, travels at $100 \mathrm{~m} / \mathrm{s}$. Figure 7 shows the maximum midspan 

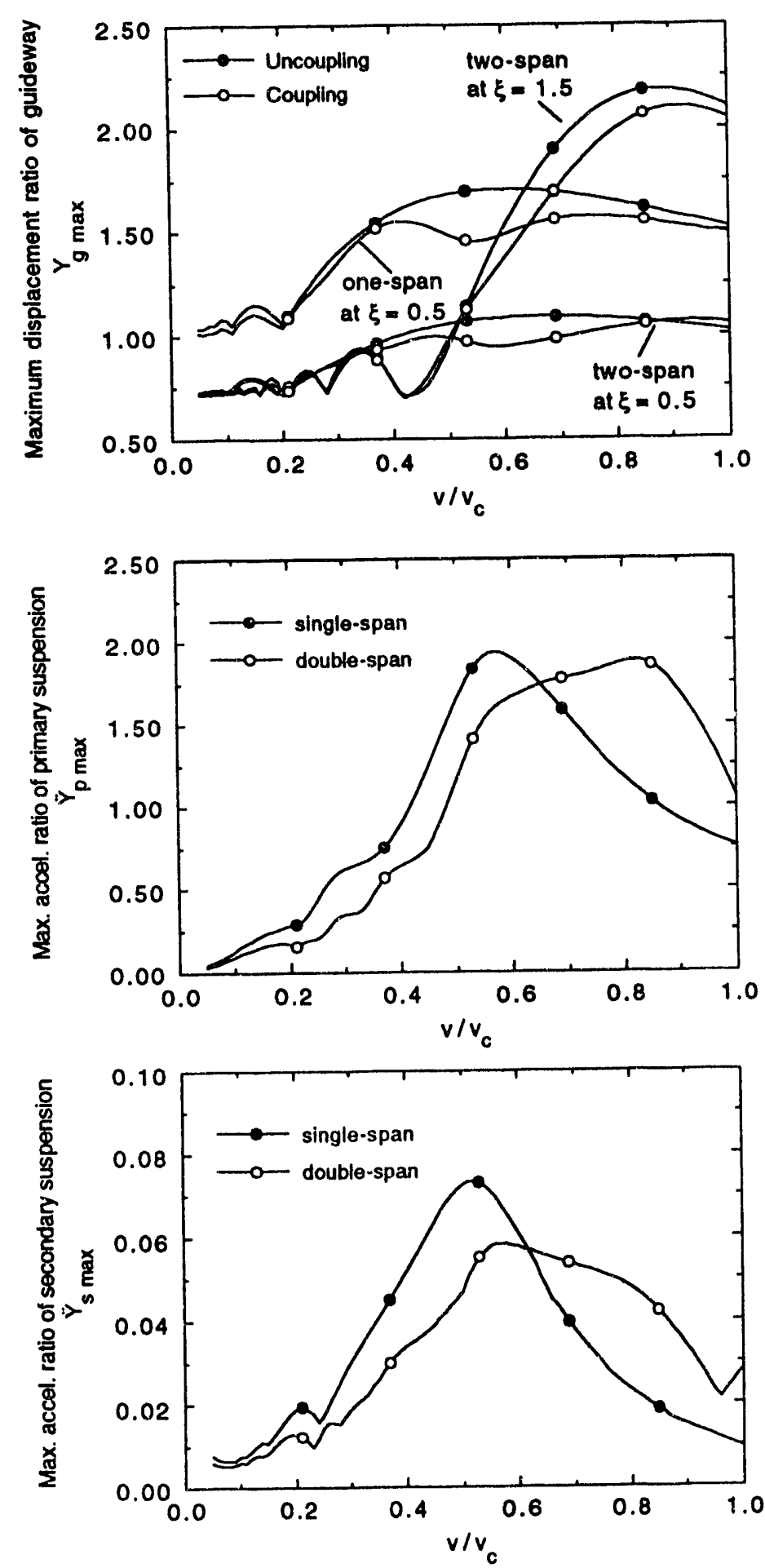

Fig. 5. Effects of single-span and double-span beams on maximum guideway dispiacement and vehicle acceleration ratios for a two-degree-of-freedom vehicle 


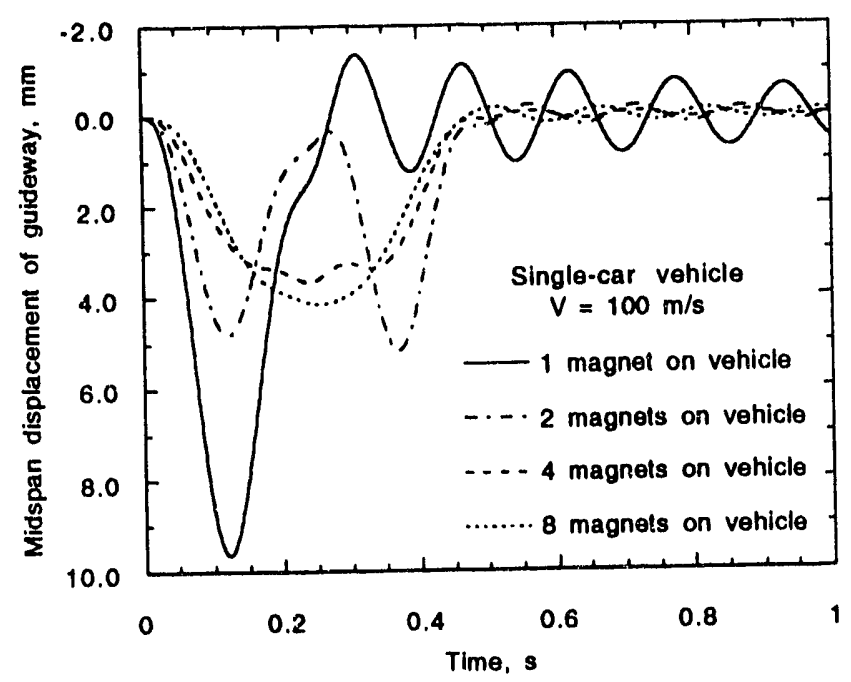

Fig. 6. Midspan displacement of guideway when a single car with various magnets travels along the guideway at $100 \mathrm{~m} / \mathrm{s}$

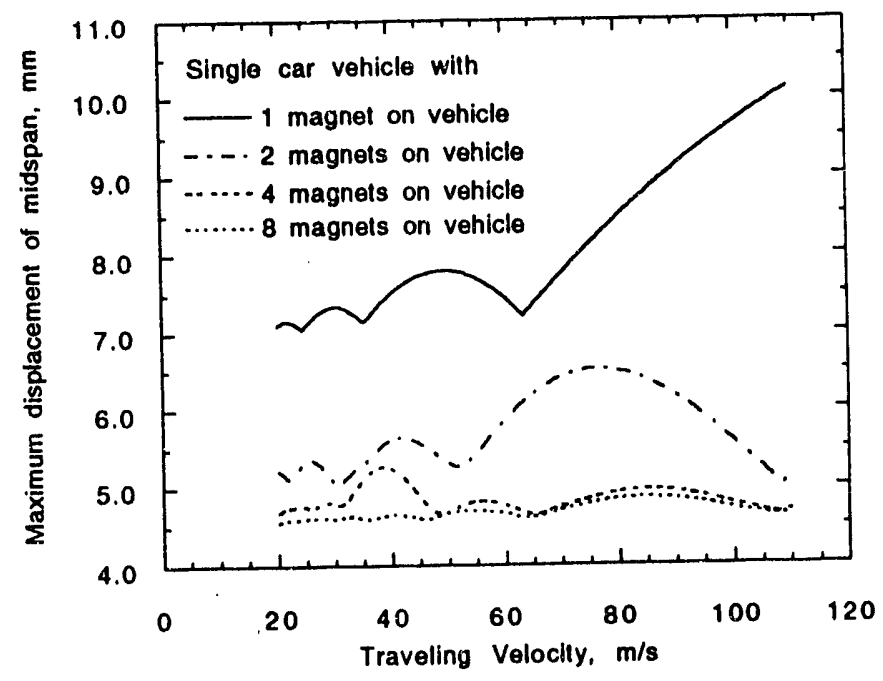

Fig. 7. Maximum midspan displacements of guideway when a single car with various magnets travels along the guideway at various speeds

deflections as a function of vehicle traveling velocity. Apparently, the one-magnet case, which represents a two-degree-of-freedom vehicle with a concentrated load, causes the largest beam deflection. The responses of four magnets and eight magnets have almost the same order deflections when the traveling velocity is greater than $50 \mathrm{~m} / \mathrm{s}$. 
Figure 8 shows car-body vertical accelerations with one, two, four, and eight magnets attached to the vehicle. Note that distributed loads affect absolute acceleration levels. We have conducted many calculations to increase the number of magnets above eight, but the results are the same as those with eight magnets. Therefore, we believe that eight magnets are sufficient for accurate modeling of distributed loads in the simulation. Thus, we always use eight magnets for each car when simulating dynamics of a multiple-car vehicle (described later).

Figures 9(a) and (b) show the steady-state accelerations of car body and magnets, respectively, when a single car with eight magnets travels along the guideway at $100 \mathrm{~m} / \mathrm{s}$.

Dynamics of Multicar Vehicle. Simulations on dynamics of a multicar vehicle are completed by using the model given in Fig. 1.

Figure 10 shows midspan beam deflections when multicar vehicles $(1,2,3$, and 4 cars) travel at $100 \mathrm{~m} / \mathrm{s}$. No matter how many cars are included in the vehicle, the maximum beam deflection remains the same. But the duration of deflections increases as car number increases. Figure 11 shows the maximum displacements of the guideway midspan when the multicar vehicle travels at various speeds. Again, results for 1,2,3, and 4 cars are the same. As in previous studies on the concentrated-load single-car vehicle, maximum guideway displacements tend to increase as vehicle speed increases.

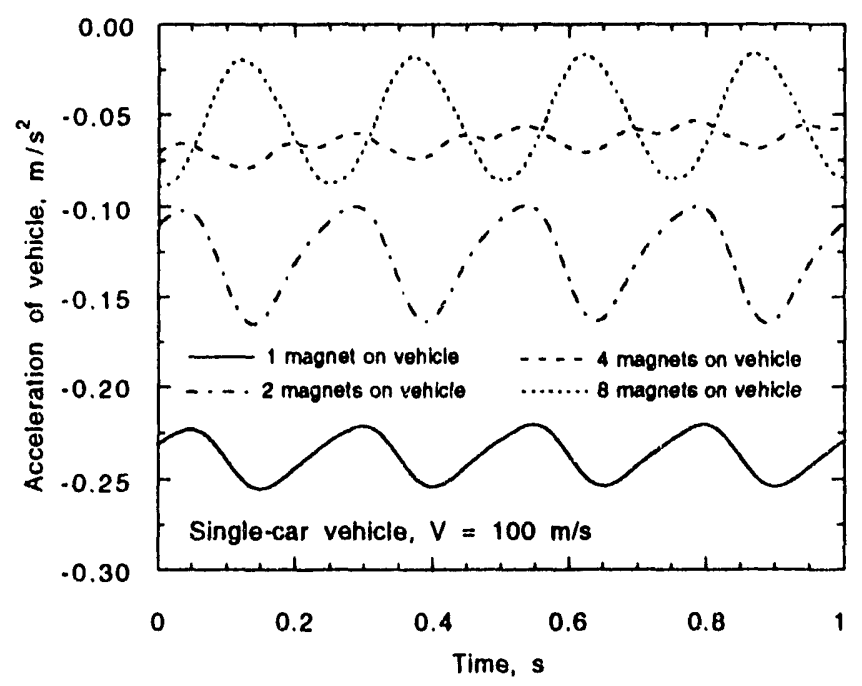

Fig. 8. Accelerations of car body when a single car with various magnets travels along the guideway at $100 \mathrm{~m} / \mathrm{s}$ 


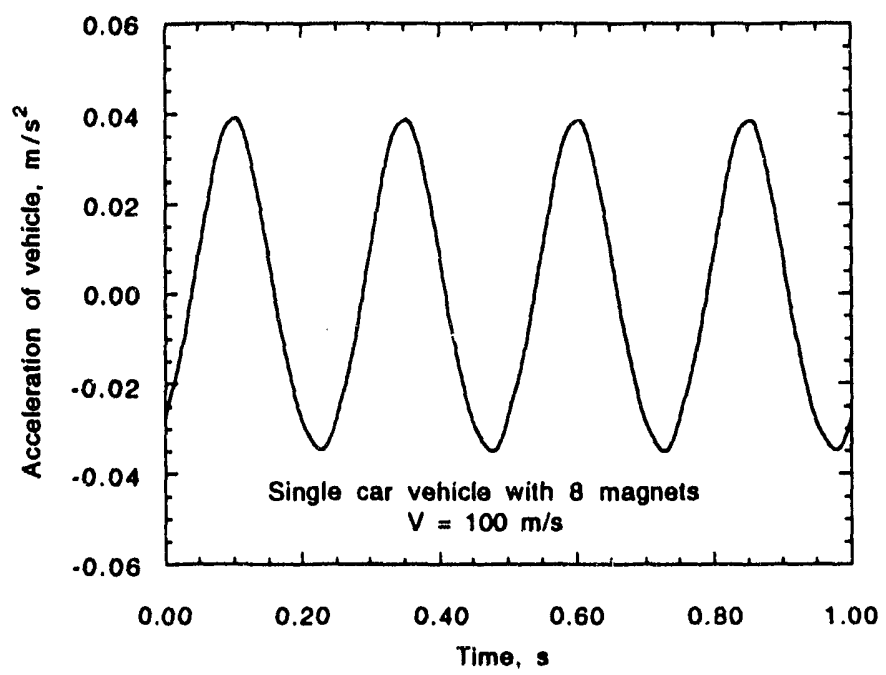

Fig. 9(a). Acceleration of car body when a single car with eight magnets travels along the guideway at $100 \mathrm{~m} / \mathrm{s}$

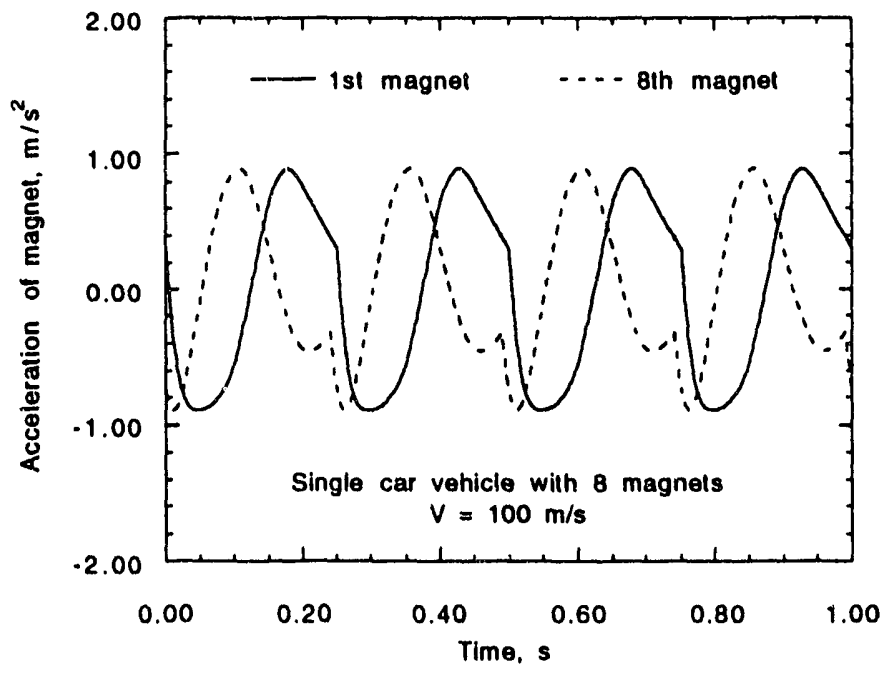

Fig. 9(b). Accelerations of first and eighth magnets when a single car with eight magnets travels along the guideway at $100 \mathrm{~m} / \mathrm{s}$

Figure 12 shows car body accelerations for vehicles with various cars when traveling speed is $100 \mathrm{~m} / \mathrm{s}$. We note that the single-car vehicle has the largest peak-to-peak acceleration and that the multicar-vehicle peak-to-peak acceleration decreases, which indicates that intercar restraints affect vehicle motions and that 


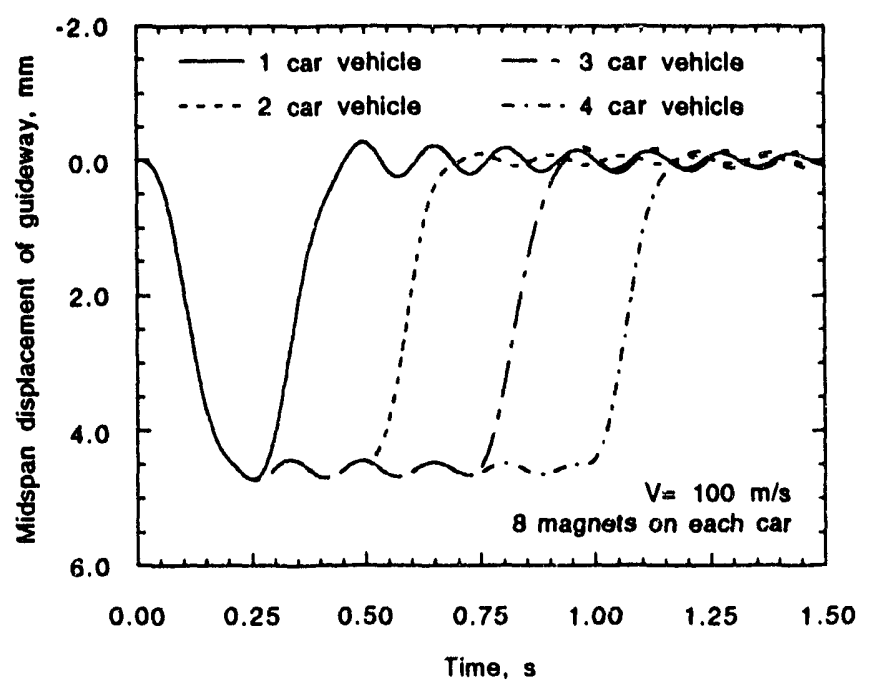

Fig. 10. Midspan displacements of guideway for multicar vehicles with eight magnets on each car traveling along the guideway at $100 \mathrm{~m} / \mathrm{s}$

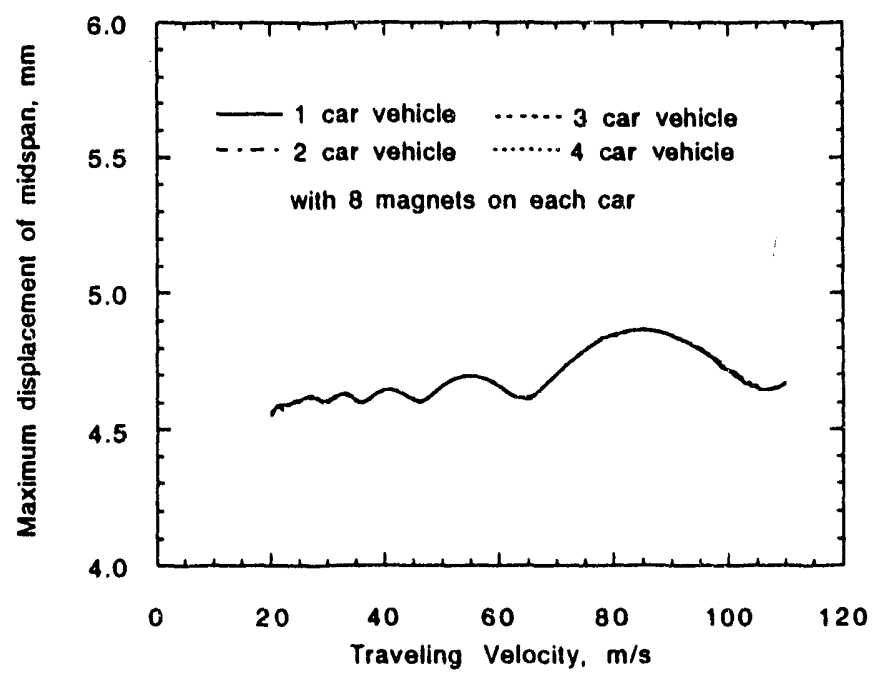

Fig. 11. Maximum midspan displacements of guideway when multicar vehicles with eight magnets on each car travel along the guideway at various speeds

the multicar vehicles may have better ride comfort. Figure 13 gives the peak-topeak car body accelerations for vehicles at various speeds; the results are the same as in Fig. 12. The peak-to-peak accelerations for a single car are much larger than those of a multicar vehicle. 


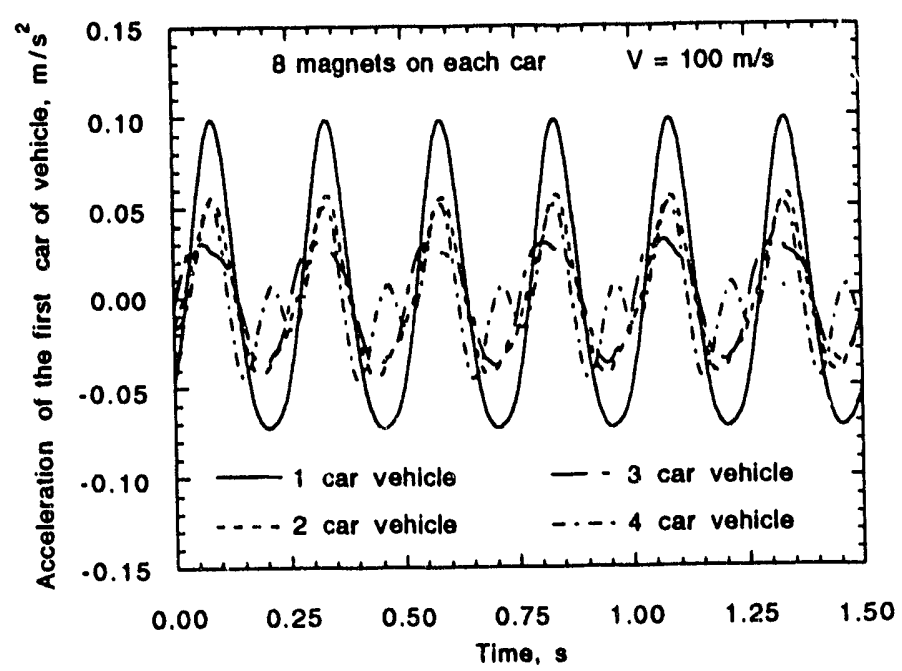

Fig. 12. Accelerations of car body for multicar vehicles with eight magnets on each car traveling along the guideway at $100 \mathrm{~m} / \mathrm{s}$

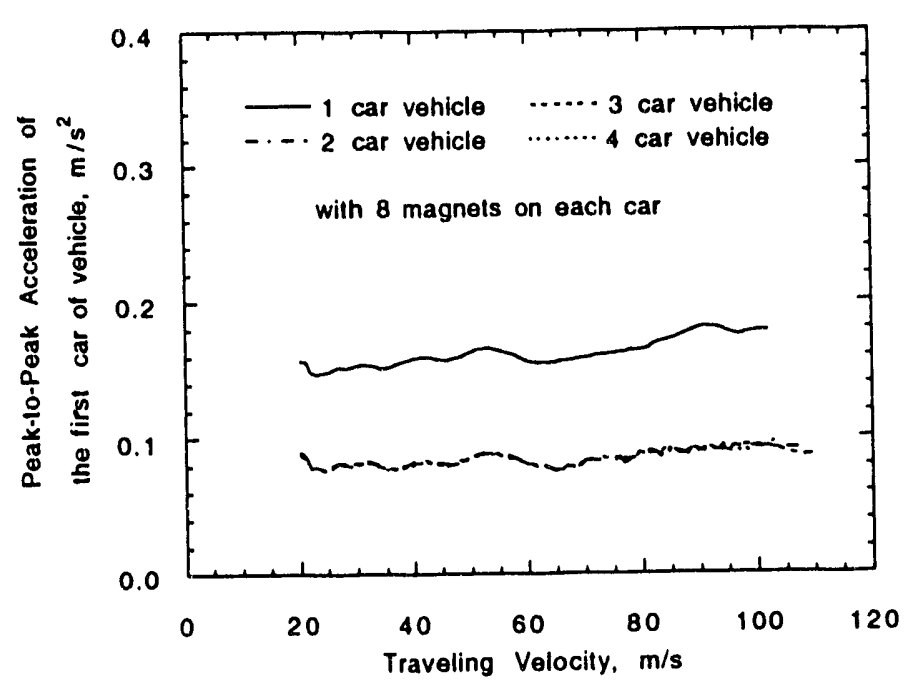

Fig. 13. Peak-to-peak accelerations of car body when multicar vehicles with eight magnets on each car travel along the guideway at various speeds

To determine effects of intercar constraints on vehicle dynamics, further calculations are completed for different intercar stiffness, and the results for a two-car vehicle are shown in Fig. 14. As stiffness decreases, peak-to-peak acceleration increases. 


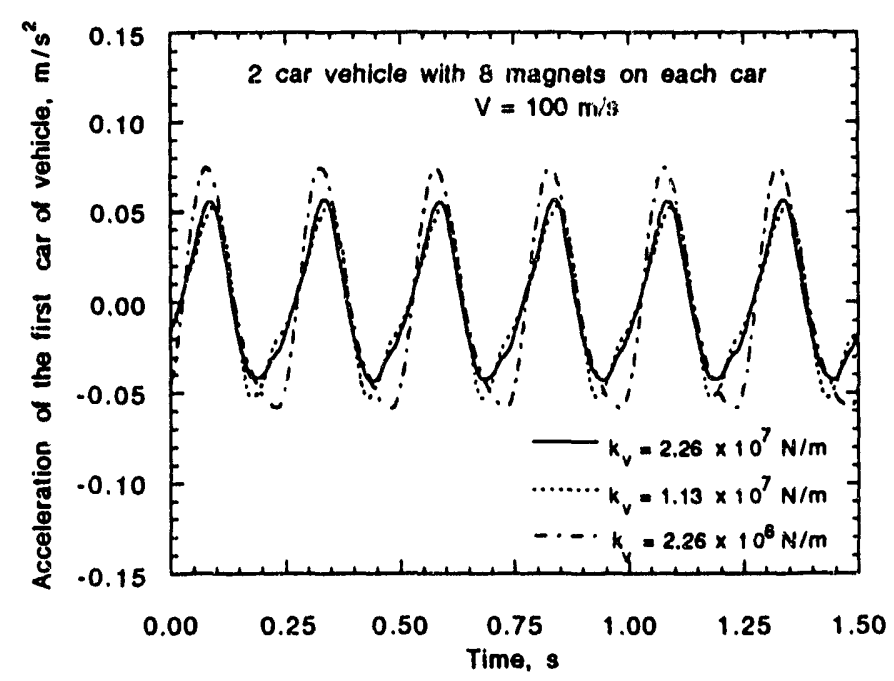

Fig. 14. Accelerations of car body when a twocar vehicle with eight magnets on each car travels along the guideway at $100 \mathrm{~m} / \mathrm{s}$ and when intercar stiffness varies

Ride Comfort of Multicar Vehicle. Figure 15 shows a comparison of the Urban Tracked Air Cushion Vehicle (UTACV) ride comfort specification (ranging from $0-10 \mathrm{~Hz}$ ) for multicar vehicles traveling at $100 \mathrm{~m} / \mathrm{s}$. With the parameters from Table 1, power spectral densities (PSDs) of multicar vehicle accelerations satisfy the ride comfort criterion. It appears that the vehicle with those parameters can provide an acceptable ride. From Fig. 15, we also note that at the fundamental frequency, the PSDs of acceleration decrease as car number increases; however, at higher harmonic frequencies, this tendency is not so clear.

Figures 16 and 17 show PSDs of acceleration of a single-car and a two-car vehicle, respectively, traveling at various speeds; the harmonic frequencies vary with traveling speed.

\section{Control Designs for Maglev Systems}

\subsection{Background of Control Law Designs}

Suspension systems are dominant in determining the basic dynamic and vibrational behavior of the maglev vehicle. Primary suspensions, which consist of magnets, provide basic support and guidance along the guideway and should respond quickly to guideway disturbances and perturbations. Secondary 


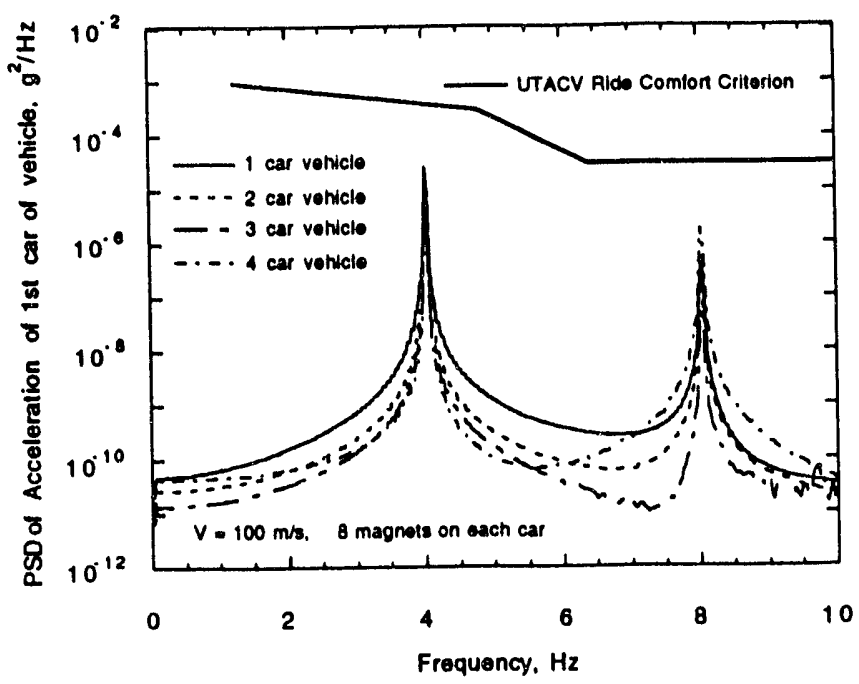

Fig. 15. PSD of car body accelerations when multicar vehicles with eight magnets on each car travel along the guideway at $100 \mathrm{~m} / \mathrm{s}$

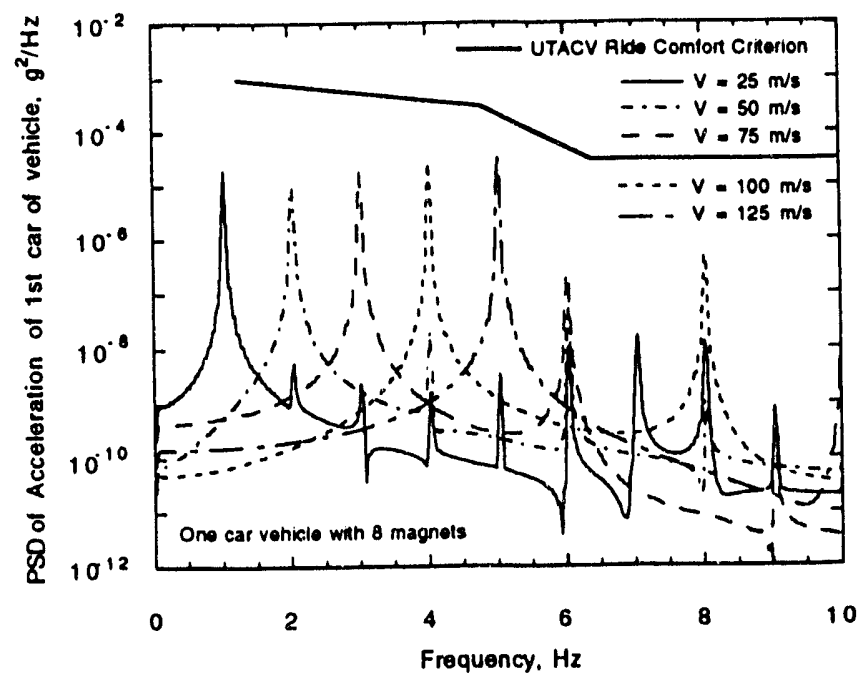

Fig. 16. PSD of car body accelerations when a singie-car vehicle with eight magnets travels along the guideway at various speeds

suspensions support the vehicle bodies and provide acceptable ride comfort to the passengers.

To achieve a quick response and a high-quality ride over a less-expensive guideway, control designs must be exploited in suspension systems. Moreover, with the assistance of suspension controls, a rougher guideway surface could be used and overall investment cost of the guideway could be reduced. 


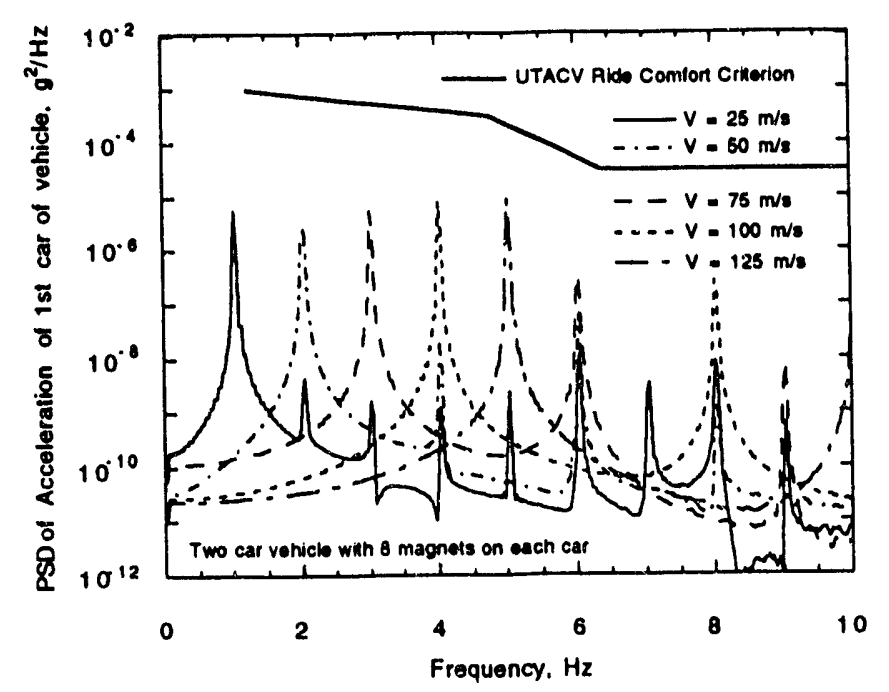

Fig. 17. PSD of car body accelerations when a two-car vehicle with eight magnets on each car travels along the guideway at various speeds

Primary suspension control strategies include two basic principles: position control and air-gap control. The position control maintains the vehicle in a stable levitation and guidance attitude against the various guideway irregularities that are the dominant excitation force to the suspension systems and may be represented by a stationary stochastic signal. This control guides the vehicle on the guideway curve purely on the basis of alignment and compensates for all deviations of the guideway from this ideal line. Primary suspension controls must also respond quickly to small air-gap changes and overcome the effects of high-frequency perturbations. The air-gap control aims at following the actual path of the track, including its deviations from the line of alignment caused by constructional features, to maintain a constant air-gap.

Secondary suspension control systems should provide ride comfort to the passengers over guideway sections that are irregular or when the vehicle is operating in gusty winds.

Even though suspension control designs are important to maglev systems, only a few studies on the control design of maglev suspensions can be found in the literature. Katz et al. (1974) studied a linearized control system for magnets with a proportional feedback in primary suspension. Kortum and Utzt (1984) used quadratic synthesis in the control design of a vertical maglev vehicle model. Kortum et al. (1988) and Faye et al. (1989) studied dynamic modeling of maglev vehicles for control design and performance evaluations. They applied two control strategies, i.e., feedback controls with pole assignment and with the Riccati (quadratic) design. 
Existing maglev suspension systems contain passive control elements such as dampers and springs (Bohn and Alscher 1986; Bohn and Steinmetz 1985), which are passive in the sense that no power source is required, i.e., the vibration-control elements only store or dissipate the energy associated with vibration. Such passive suspension systems may be insufficient to improve suspension performance unless radical changes are made to the basic principle of suspension operation (Faye et al. 1989; Kortum et al. 1988).

The alternative proposed here is that of an active suspension system, which has been investigated by many researchers over the last 30 or more years on conventional ground vehicles due to its potential to improve vehicle performance (Bernard et al. 1987; Chalasani 1987; Elmadany 1990; Dukkipati et al. 1992; Goodal and Kortum 1983; Karnopp et al. 1974; Karnopp and Margolis 1984; McCormac et al. 1992).

An active suspension system offers a solution to the conflicting requirements of a constant-parameter suspension design and allows continuous or discrete variation in effective spring constants and damping coefficients. An active suspension may be adapted to specific vehicle/guideway conditions by control devices that can adjust the dynamics of hydraulic or pneumatic actuators. In such a system, the passive spring and damper of a conventional suspension are replaced by force actuators that continuously supply and modulate the flow of energy by generating forces on the basis of some control law to achieve the required performance (Bernard et al. 1987). It is apparent that an active system exhibits significantly low PSD values. In other words, the active system does not amplify accelerations as one would expect with a passive system. Also, in the active-system concept, algorithms can be designed (in software rather than hardware) to provide the same function to achieve suspension performance (McCormac et al. 1992). In general, however, active systems are more costly, more complex, and often less reliable than passive systems (Bernard et al. 1987; Karnopp et al. 1974).

Semiactive suspensions, which have been under development in recent years (Alonoly and Sankar 1987, 1988; Hrovat et al. 1988; Karnopp et al. 1974), present a compromise between active and passive suspensions. Semiactive suspensions can achieve performance close to that of active suspensions with much lower cost and complexity. These systems, which require relatively little external power, use an active damper in parallel with a passive spring. Desired forces in the damper are generated by modulating fluid-flow orifices via a control scheme involving feedback variables.

Although semiactive dampers based upon the electro-hydraulic servovalve do not consume as much power as fully active systems, they do require a number of 
mechanical components, each manufactured to fine tolerances. One way to simplify the construction of a semiactive device is to obtain continuous control of damping by exploiting "smart" materials. Among these different materials, the electro-rheological fluids (ER fluids), which have variable-shear characteristics, can undergo significant instantaneous reversible changes in damping characteristics when subjected to electrostatic potentials. This makes their application to real-time semiactive vibration control very attractive. ER fluids were discovered by Willis $\mathrm{M}$. Winslow in 1939 and have attracted intense interest in recent years (Stanway et al. 1989; Wong et al. 1992; Wu et al. 1990). Because the apparent viscosity of ER fluids can be conveniently controlled by an applied electric field, permitting the fluids to change from normal to viscous and back again in less than a millisecond, the damping effect can be altered even at high speeds.

It is thought that ER fluids are particularly suited for continuously adjustable dampers in semiactive suspension systems for ground vehicles. In essence, this type of damper behaves like a conventional viscous damper with an adjustable orifice, but is controlled by activating the electrodes and thus needs no mechanical moving parts. In addition, such devices could be made without the need for precision machining, special fits, or exotic materials. It should be possible to reduce component costs, in relation to active system, by employing continuously controllable damping available with ER fluids. The use of ER fluids as a direct interface between mechanical suspension components and control electronics offers an elegant solution to the problem of implementing semiactive control. A semiactive suspension system with ER dampers employing the continuous control strategy has the potential to provide ground vehicles with significantly improved ride comfort over that of conventional passive suspensions (Wong et al. 1992).

\subsection{Modeling of Maglev Vehicle Suspensions for Control Designs}

To investigate the improvement of the dynamic response and ride comfort of maglev systems, different control designs (active and semiactive) are examined in this study.

For most control law synthesis, it is desirable to work with linear dynamic models of low order. A low-order maglev vehicle model, which may be selected as a two-degree-of-freedom quarter-vehicle model representing primary and secondary suspensions, is necessary in control design to formulate a low-order controller. Again, a vertical model is sufficient to perform control-law design for maglev systems when considering vehicle dynamics and ride comfort to passengers. 
For these reasons, a one-dimensional vehicle model with two degrees of freedom (Fig. 18) and consisting of two lumped masses $m_{p}$ and $m_{s}$, two linear springs $k_{p}$ and $k_{s}$, and two viscous dampings $c_{p}$ and $c_{s}$, representing primary and secondary suspensions, respectively, is used in the control synthesis of maglev systems. This model is simple to analyze and is used mainly to gain a basic understanding of the suspension concept. Such a simplified model can be sufficient to predict the behavior of the system. In addition, with this model, the coupling effects of primary and secondary suspensions will not be ignored; this is very important for suspension control design because coupling of both suspensions may result in interaction forces or kinematic constraints and can thus affect ride comfort.

A mechanical control method is favored in our study because it is able to change conjugate eigenvalues of the system, while controlled coils or controlled magnet current can only change real poles of the system (Faye et al. 1989; Kortum et al. 1988).

The passive parameters of the German Transrapid Maglev System TR06, (summarized in Table 2) are utilized for analysis in this study because no other Transrapid data are available in the literature (Bohn and Steinmetz 1985; Bohn and Alscher 1986).

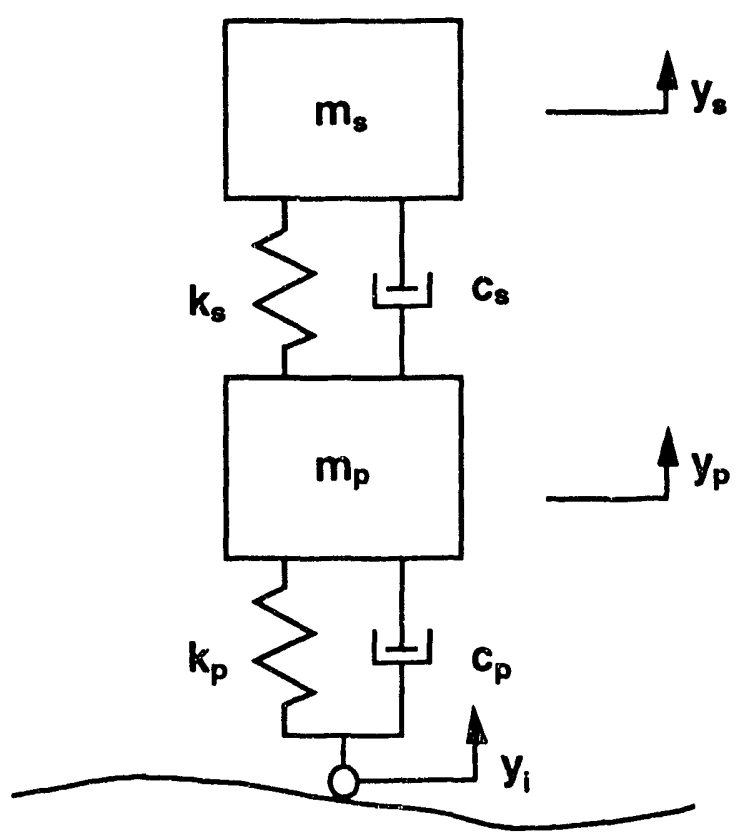

Fig. 18. One-dimensional two-degree-offreedom vehicle model with primary and secondary suspensions for maglev systems 
Table 2. Vehicle vertical dynamics model parameters of German Transrapid Maglev System TR06

Primary suspension mass $m_{p}$

Secondary suspension mass $\mathbf{m}_{\mathrm{s}}$

Primary suspension damping $c_{p}$

Secondary suspension damping $c_{s}$

Primary suspension stiffness $\mathbf{k}_{\mathbf{p}}$

Secondary suspension stiffness $k_{s}$
$3.20 \times 10^{4} \mathrm{~kg}$

$2.92 \times 10^{4} \mathrm{~kg}$

$1.13 \times 10^{6} \mathrm{~N}-\mathrm{s} / \mathrm{m}$

$8.80 \times 10^{4} \mathrm{~N}-\mathrm{s} / \mathrm{m}$

$6.18 \times 10^{7} \mathrm{~N} / \mathrm{m}$

$7.37 \times 10^{5} \mathrm{~N} / \mathrm{m}$

For this model, the equations of motion when the vehicle is at an equilibriurn position are then

$$
\begin{aligned}
& m_{p} \ddot{y}_{p}+c_{p}\left(\dot{y}_{p}-\dot{y}_{i}\right)+k_{p}\left(y_{p}-y_{i}\right)-c_{s}\left(\dot{y}_{s}-\dot{y}_{p}\right)-k_{s}\left(v_{s}-y_{p}\right)=0 \\
& m_{s} \ddot{y}_{s}+c_{s}\left(\dot{y}_{s}-\dot{y}_{p}\right)+k_{s}\left(y_{s}-y_{p}\right)=0
\end{aligned}
$$

from Eqs. 27 and 28, there is

$$
m_{p} \ddot{y}_{p}+m_{s} \ddot{y}_{s}+c_{p}\left(\dot{y}_{p}-\dot{y}_{i}\right)+k_{p}\left(y_{p}-y_{i}\right)=0
$$

where $y_{p}$ and $y_{s}$ are positions of primary and secondary suspensions, and $y_{i}$ is disturbance from guideway irregularity. System parameters, i.e., masses mp and $m_{s}$, stiffnesses $k_{p}$ and $k_{s}$, and dampings $c_{p}$ and $c_{s}$ for primary and secondary suspensions, are listed in Table 2.

Table 3 shows eigenvalues, frequencies, and damping ratios for both primary and secondary suspensions in this model.

\subsection{Dynamic Response of Maglev Suspensions}

Taking the Laplace transform of the differential equations of Eqs. 28 and 29, and assuming all initial conditions to be zero, yields

$$
\left(m_{p} s^{2}+c_{p} s+k_{p}\right) Y_{p}+m_{s} s^{2} Y_{s}-\left(c_{p} s+k_{p}\right) Y_{i}=0
$$

and 
Table 3. Eigenvalues, frequencies, and damping ratios in 1-D vehicle model with two degrees of freedom

\begin{tabular}{llcc}
\hline & $\begin{array}{c}\text { Eigenvalue } \\
\sigma \pm j \omega\end{array}$ & $\begin{array}{c}\text { Frequency } \\
\mathrm{f}(\mathrm{Hz})\end{array}$ & $\begin{array}{c}\text { Damping } \\
\mathrm{z}\end{array}$ \\
\hline TR06 & $-1.479 \pm 4.779 \mathrm{j}$ & 0.80 & 0.30 \\
& $-19.06 \pm 39.81 \mathrm{j}$ & 7.03 & 0.43 \\
Passive Adj'.stments & $-3.024 \pm 4.027 \mathrm{j}$ & 0.80 & 0.60 \\
& $-22.02 \pm 37.93 \mathrm{j}$ & 6.98 & 0.50 \\
Primary Feedback & $-1.479 \pm 4.779 \mathrm{j}$ & 0.80 & 0.30 \\
& -23.89 & -- & - \\
Primary and & $-65.71 \pm 84.55 \mathrm{j}$ & 17.05 & 0.61 \\
Secondary & $-3.014 \pm 4.020 \mathrm{j}$ & 0.80 & 0.60 \\
Feedback & -23.89 & -- & - \\
& $-65.71 \pm 84.55 \mathrm{j}$ & 17.05 & 0.61 \\
\hline
\end{tabular}

$$
\left(m_{s} s^{2}+c_{\mathbb{E}} s+k_{s}\right) Y_{s}-\left(c_{s} s+k_{s}\right) Y_{p}=0
$$

where $s$ is the Laplace transform operator, and $Y_{p}, Y_{s}$, and $Y_{i}$ are the Laplace transforms of $y_{p}, y_{s}$, and $y_{i}$.

From Eqs. 30 and 31, transfer functions for primary and secondary suspensions when considering guideway disturbance $Y_{i}$ as an input variable can be as described below:

$$
\begin{aligned}
G_{p}(s) & =\frac{Y_{p}(s)}{Y_{i}(s)} \\
& =\frac{\left(c_{p} s+k_{p}\right)\left(m_{s} s^{2}+c_{s} s+k_{s}\right)}{\left(m_{p} s^{2}+c_{p} s+k_{p}\right)\left(m_{s} s^{2}+c_{s} s+k_{s}\right)+m_{s} s^{2}\left(c_{s} s+k_{s}\right)} \\
& =\frac{m_{s} c_{p} s^{3}+\left(m_{s} k_{p}+c_{p} c_{s}\right) s^{2}+\left(c_{p} k_{s}+c_{s} k_{p}\right) s+k_{p} k_{s}}{m_{p} m_{s} s^{4}+\left[m_{p} c_{s}+m_{s}\left(c_{p}+c_{s}\right)\right] s^{3}+\left[m_{p} k_{s}+m_{s}\left(k_{p}+k_{s}\right)+c_{p} c_{s}\right] s^{2}+\left(c_{p} k_{s}+c_{s} k_{p}\right) s+k_{p} k_{s}}
\end{aligned}
$$




$$
\begin{aligned}
G_{s}(s) & =\frac{Y_{g}(s)}{Y_{i}(s)} \\
& =\frac{\left(c_{p} s+k_{p}\right)\left(c_{s} s+k_{s}\right)}{\left(m_{p} s^{2}+c_{p} s+k_{p}\right)\left(m_{s} s^{2}+c_{s} s+k_{s}\right)+m_{s} s^{2}\left(c_{s} s+k_{s}\right)} \\
& =\frac{c_{p} c_{s} s^{2}+\left(c_{p} k_{s}+c_{s} k_{p}\right) s+k_{p} k_{s}}{m_{p} m_{s} s^{4}+\left[m_{p} c_{s}+m_{s}\left(c_{p}+c_{s}\right)\right] s^{3}+\left[m_{p} k_{s}+m_{s}\left(k_{p}+k_{s}\right)+c_{p} c_{s}\right] s^{2}+\left(c_{p} k_{s}+c_{g} k_{p}\right) s+k_{p} k_{s}} .
\end{aligned}
$$

From Eqs. 30 to 33, by connecting signals properly, we can construct a block diagram for the system, as shown in Fig. 19.

In many practical cases, the desired performance characteristics of control systems are specified in terms of time-domain quantities or of transient response to a unit-step input because such input is easy to generate and is sufficiently drastic. The transient response of a system to a unit-step input depends on the initial conditions. For convenience in comparing transient responses, it is common practice to use the standard initial condition that the system is at rest initially, with output and all time derivatives thereof equal to zero.

From the given transfer function in Eqs. 32 and 33, the corresponding differential equation can be obtained as

$$
\begin{aligned}
& \dddot{y}_{p}+a_{1} \dddot{y}_{p}+a_{2} \ddot{y}_{p}+a_{3} \dot{y}_{p}+a_{4} y_{p}=b_{p 1} \dddot{y}_{i}+b_{p 2} \ddot{y}_{i}+b_{p 3} \dot{y}_{i}+b_{p 4} y_{i} \\
& \dddot{y}_{s}+a_{1} \dddot{y}_{s}+a_{2} \ddot{y}_{s}+a_{3} \dot{y}_{s}+a_{4} y_{s}=b_{s} \dddot{y}_{i}+b_{s 2} \ddot{y}_{i}+b_{s 3} \dot{y}_{i}+b_{s 4} y_{i}
\end{aligned}
$$

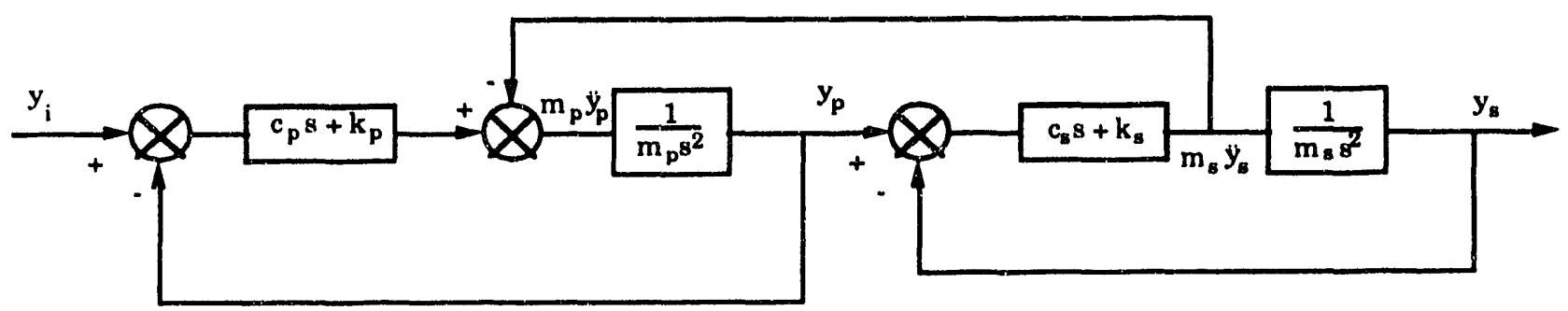

Fig. 19. Block diagram for two-degree-of-freedom vehicle model 
37

where

$$
\begin{aligned}
& a_{1}=\frac{m_{p} c_{s}+m_{s}\left(c_{p}+c_{s}\right)}{m_{p} m_{s}} \\
& a_{2}=\frac{m_{p} k_{s}+m_{s}\left(k_{p}+k_{s}\right)+c_{p} c_{s}}{m_{p} m_{s}} \\
& a_{3}=\frac{c_{p} k_{s}+c_{s} k_{p}}{m_{p} m_{s}} \\
& a_{4}=\frac{k_{p} k_{s}}{m_{p} m_{s}}
\end{aligned}
$$

$b_{p 1}=\frac{m_{s} c_{p}}{m_{p} m_{s}}=\frac{c_{p}}{m_{p}}$

$b_{p 2}=\frac{m_{s} k_{p}+c_{p} c_{s}}{m_{p} m_{s}}$

$$
b_{p 3}=\frac{c_{p} k_{s}+c_{s} k_{p}}{m_{p} m_{s}}
$$

$$
b_{p 4}=\frac{k_{p} k_{s}}{m_{p} m_{s}}
$$

(37)

and 


$$
\begin{aligned}
& b_{s 1}=0 \\
& b_{s 2}=\frac{c_{p} c_{s}}{m_{p} m_{s}} \\
& b_{s 3}=\frac{c_{p} k_{s}+c_{s} k_{p}}{m_{p} m_{s}} \\
& b_{s 4}=\frac{k_{p} k_{s}}{m_{p} m_{s}}
\end{aligned}
$$

We define state variables $\mathrm{x}_{1}, \mathrm{x}_{2}, \mathrm{x}_{3}$, and $\mathrm{x}_{4}$ as follows:

$$
\begin{aligned}
& x_{1}=y_{p} \\
& x_{2}=\dot{x}_{1}-\beta_{1} y_{i} \\
& x_{3}=\dot{x}_{2}-\beta_{2} y_{i} \\
& x_{4}=\dot{x}_{3}-\beta_{3} y_{i}
\end{aligned}
$$

where

$$
\begin{aligned}
& \beta_{1}=b_{p 1} \\
& \beta_{2}=b_{p 2}-a_{1} \beta_{1} \\
& \beta_{3}=b_{p 3}-a_{1} \beta_{2}-a_{2} \beta_{1} \\
& \beta_{4}=b_{p 4}-a_{1} \beta_{3}-a_{2} \beta_{2}-a_{3} \beta_{1}
\end{aligned}
$$

Note that

$$
\dot{x}_{4}=-a_{4} x_{1}-a_{3} x_{2}-a_{2} x_{3}-a_{1} x_{4}+\beta_{4} y_{i}
$$

The state equation and output can be obtained as 


$$
\left[\begin{array}{c}
\dot{x}_{1} \\
\dot{x}_{2} \\
\dot{x}_{3} \\
\dot{x}_{4}
\end{array}\right]=\left[\begin{array}{cccc}
0 & 1 & 0 & 0 \\
0 & 0 & 1 & 0 \\
0 & 0 & 0 & 1 \\
-a_{4} & -a_{3} & -a_{2} & -a_{1}
\end{array}\right]\left[\begin{array}{l}
x_{1} \\
x_{2} \\
x_{3} \\
x_{4}
\end{array}\right]+\left[\begin{array}{l}
\beta_{1} \\
\beta_{2} \\
\beta_{3} \\
\beta_{4}
\end{array}\right] y_{i}
$$

and

$$
y_{p}=\left[\begin{array}{llll}
1 & 0 & 0 & 0
\end{array}\right]\left[\begin{array}{l}
x_{1} \\
x_{2} \\
x_{3} \\
x_{4}
\end{array}\right]
$$

Then the unit-step response of primary suspension $y_{p}(t)$ versus time $t$, when input variable $y_{i}$ reached 1 , can be calculated from Eqs. 42 and 43 by the fourth-order Runge-Kutta method. Similarly, the unit-step response of the secondary suspension $y_{s}(t)$ can be obtained by rewriting state variables in Eqs. 39 and 40.

The frequency responses of the vehicle model, by which we mean the steadystate responses of suspension systems to a sinusoidal input, can be obtained directly from the transfer function; i.e., $s$ in the transfer function is replaced by $j \omega$, where $\omega$ is angular frequency. Hence, the frequency responses of $G_{p}(j \omega)$ and $\mathrm{G}_{\mathrm{s}}(j \omega)$ for primary and secondary suspension with respect to the input sinusoid can be obtained from Eqs. 32 and 33 by substituting $j \omega$ for $s$. The magnitude ratios and phase shifts of $G_{p}(j \omega)$ and $G_{s}(j \omega)$ can be presented by separate plots in Bode diagrams, that is, a plot of the logarithm of the magnitude of a sinusoidal transfer function, and a plot of the phase angle; both are plotted against the frequency in logarithm scale.

With the frequency transfer function, the acceleration output PSD of the secondary suspension, which is a measurement of vehicle ride comfort, can be derived. The surface roughness of guideways can be described approximately by the PSD of surface profile,

$$
\mathrm{S}(\omega)=\mathrm{Av} / \omega^{2}
$$

where $\mathrm{v}$ is vehicle velocity, and $\mathrm{A}$ is roughness amplitude that ranges from $0.6 \times$ $10^{-6}$ to $20 \times 10^{-6} \mathrm{~m}$ (Gottzein et al. 1974; Brock 1973). Acceleration output PSD of secondary suspension $\Phi(\omega)$ can then be obtained from Katz et al. (1974) as

$$
\Phi(\omega)=A v\left|j \omega \cdot G_{s}(j \omega)\right|^{2} \cdot \frac{2 \pi}{g}
$$


where $g$ is acceleration of gravity, and the factor $2 \pi$ is needed to convert from a per-rad/s to a per-Hertz basis.

With the data given in Table 2, dynamic responses of the system (see Figs. 18 and 19) are then calculated.

Figures 20 and 21 show transient responses of primary and secondary suspensions with unit-step input of guideway perturbation. Maximum

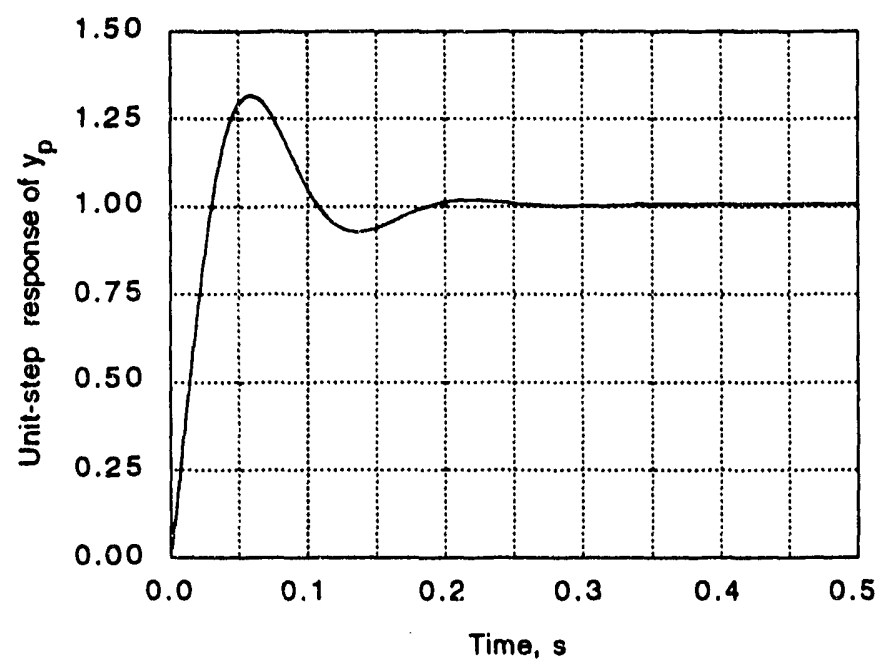

Fig. 20. Transient response $y_{p}$ of primary suspension of TR06 with unit-step input of guideway perturbation

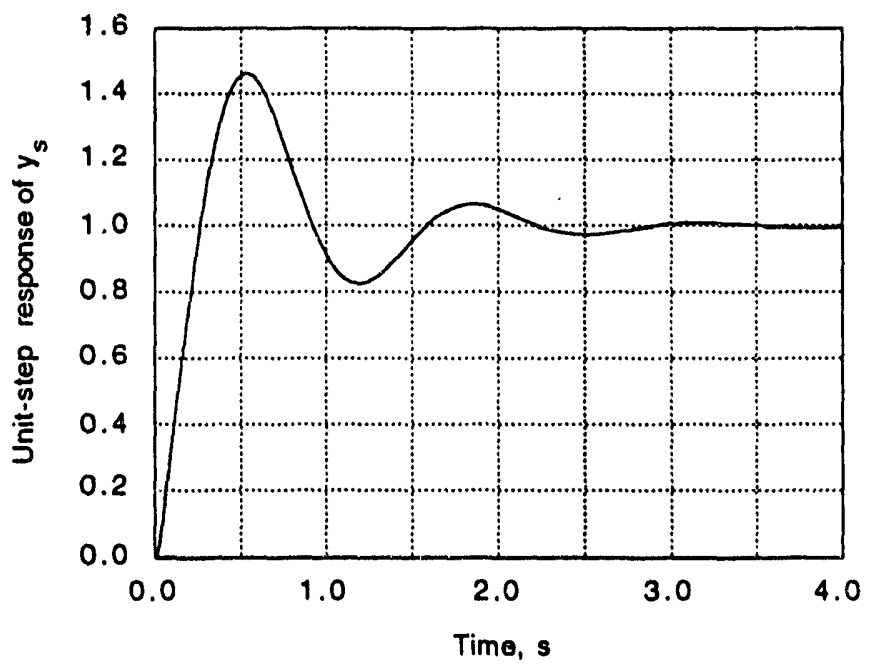

Fig. 21. Transient response $y_{s}$ of secondary suspension of TRO6 with unit-step input of guideway perturbation 
overshoots of $M_{p}$ for primary and secondary suspensions are $31.6 \%$ and $46.3 \%$, respectively; and setting times of $t_{\mathrm{s}}$ are $0.157 \mathrm{~s}$ and $2.000 \mathrm{~s}$ ( $5 \%$ criterion is chosen); see Tables 4 and 5. Obviously, these dynamic responses are not desirable for maglev systems, for which transient responses must be sufficiently damped. For a desirable transient response of a second-order system, the damping ratio must be between 0.4 and 0.8 . Based on data in Table 2, the damping ratios for primary and secondary suspensions are 0.43 and 0.30 (see Table 3), which are below the desirable value and yield excessive overshoots in transient responses (see Figs. 20 and 21, and Tables 4 and 5).

Figures 22 and 23 show frequency responses (Bode diagrams) for primary and secondary suspensions; these indicate particular features of second-order systems for both suspensions. Responses of both suspensions have excessive overshoots, which agrees well with Figs. 20 and 21.

Figure 24 shows the normalized output acceleration PSD of vehicle body $\left(\mathrm{m}_{\mathrm{s}}\right)$, where $\mathrm{A}=1 \times 10^{-6} \mathrm{~m}$ and $\mathrm{v}=100 \mathrm{~m} / \mathrm{s}$. From Fig. 24, the first peak of the PSD of vehicle acceleration satisfies the UTACV ride comfort criterion; however, the second peak (which corresponds to coupling effects of the primary suspension) exceeds this criterion. No matter what other features are used in the secondary suspension, oscillation of the primary suspension still affects ride comfort.

Table 4. Transient measurement of unit-step response of primary suspension $y_{p}$

\begin{tabular}{lccc}
\hline & $\mathrm{M}_{\mathrm{p}}(\%)$ & $\mathrm{t}_{\mathrm{p}}(\mathrm{s})$ & $\mathrm{t}_{\mathrm{s}}(\mathrm{s})$ \\
\hline TR06 & 31.6 & 0.058 & 0.157 \\
Passive Adjustment & 26.8 & 0.058 & 0.104 \\
Primary Feedback & 0.0 & -- & 0.110 \\
Primary and Secondary Feedback & 0.0 & -- & 0.108 \\
\hline
\end{tabular}

Table 5. Transient measurement of unit-step response of secondary suspension $y_{s}$

\begin{tabular}{|c|c|c|c|}
\hline & $\mathrm{M}_{\mathrm{p}}(\%)$ & $t_{p}(s)$ & $t_{s}(s)$ \\
\hline TR06 & 46.3 & 0.520 & 2.000 \\
\hline Passive Adjustment & 25.7 & 0.456 & 0.868 \\
\hline Primary Feedback & 44.8 & 0.554 & 2.020 \\
\hline Primary and Secondary Feedback & 12.3 & 0.630 & 0.964 \\
\hline
\end{tabular}




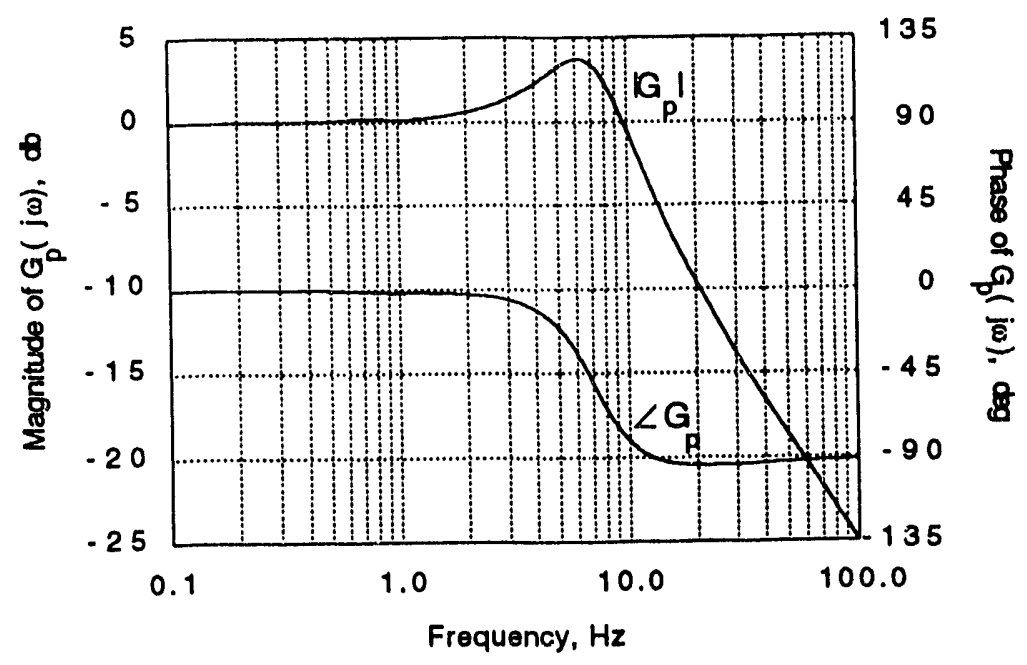

Fig. 22. Frequency response $G_{p}(j \omega)$ of primary suspension of TRO6

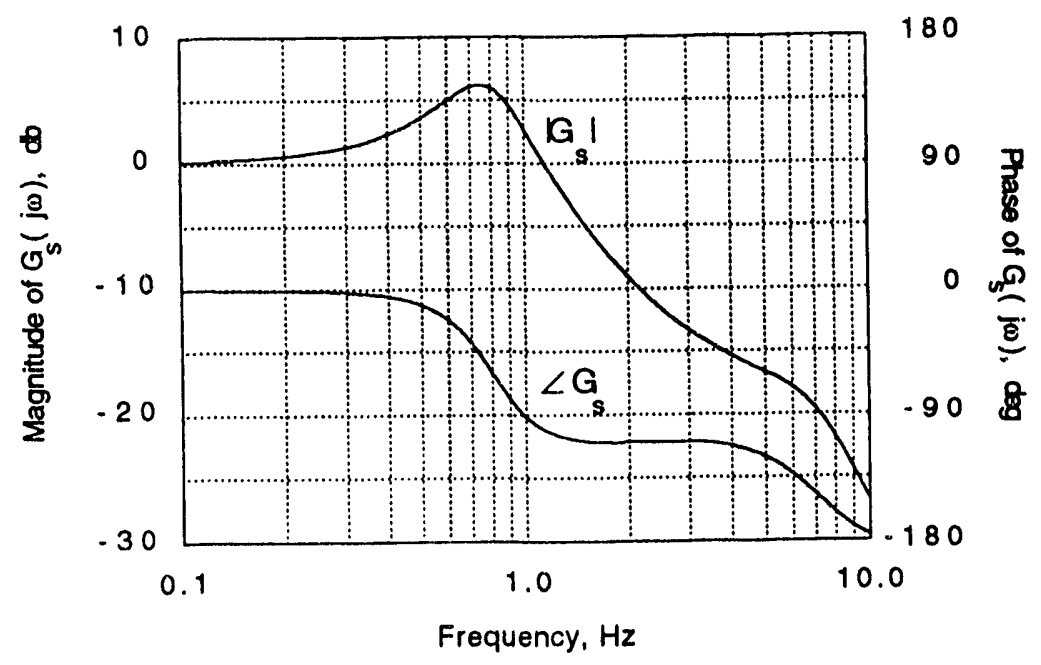

Fig. 23. Frequency response $G_{s}(j \omega)$ of secondary suspension of TRO6

\subsection{Passive Controi Design}

To improve dynamic response of the system, a passive control design was examined. The passive parameters of stiffness and dampings were utilized in modulating eigenvalues of the system to provide desirable transient response.

As shown in Table 3, placing two pairs of conjugate eigenvalues of the system at $-3.024 \pm 4.027 \mathrm{j}$ and $-22.02 \pm 37.93 \mathrm{j}$ changes the damping ratios of two suspensions from $\zeta_{p}=0.43$ and $\zeta_{s}=0.3$ to $\zeta_{p}=0.50$ and $\zeta_{s}=0.60$ while system frequencies remain the same. 


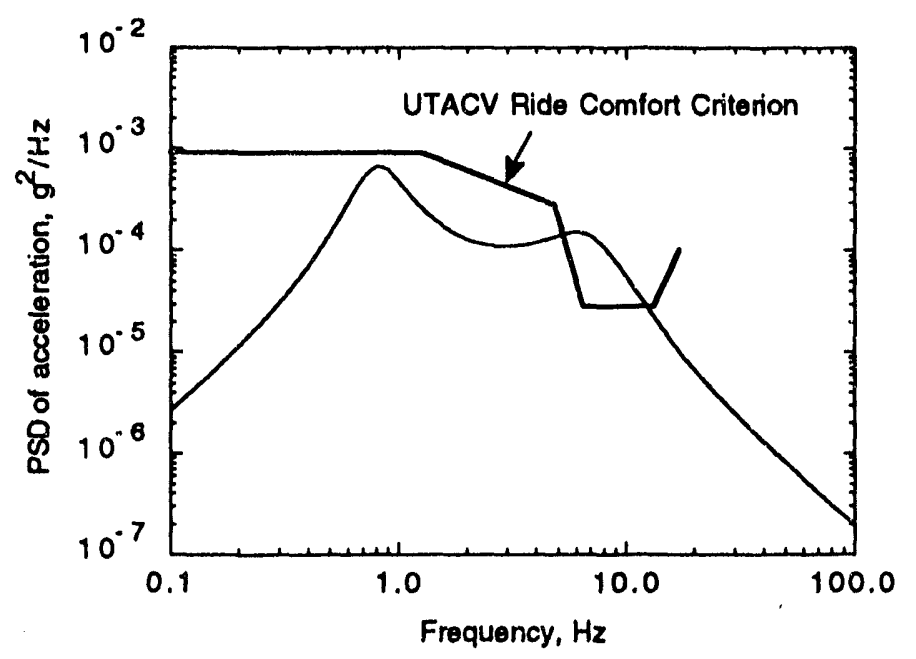

Fig. 24. PSD of vehicle acceleration of TR06 with vehicle speed $v=100 \mathrm{~m} / \mathrm{s}$ and guideway roughness amplitude $A=10^{-6} \mathrm{~m}$

Figures 25 and 26 show the transient response of both primary and secondary suspensions with unit-step input of guideway disturbance. Maximum overshoots of $\mathrm{M}_{\mathrm{p}}$ for primary and secondary suspension are $26.8 \%$ and $25.7 \%$, respectively; and setting times of $t_{s}$ are $0.104 \mathrm{~s}$ and $0.868 \mathrm{~s}$. These results are much better than that of TR06. System response appears to be faster and more damped than before.

Figures 27 and 28 are frequency responses for the primary and secondary suspensions, respectively, and show the same good results as in Figs. 25 and 26.

When we look at the PSD of vehicle acceleration in Fig. 29, the result is not satisfied for coupling effects of the primary suspension in higher-frequency-range increase and ride quality becomes worse. This is because when we change poles of transfer function of the system, we also change zeros of transfer function of the system, which is not desirable in this design. It is verified that passive suspension control will not eliminate acceleration amplitude.

\subsection{Active Control of Primary Suspension}

As mentioned before, primary suspension control is needed to maintain the vehicle in a stable levitation and guidance attitude against various guideway irregularities and to hold a constant air gap between magnets and guideway. In addition, the primary suspension control should attenuate coupling effects of primary suspension oscillation during acceleration of the secondary suspension, in order to achieve acceptable ride comfort. With a passive control method, however, these goals cannot be achieved satisfactorily. 


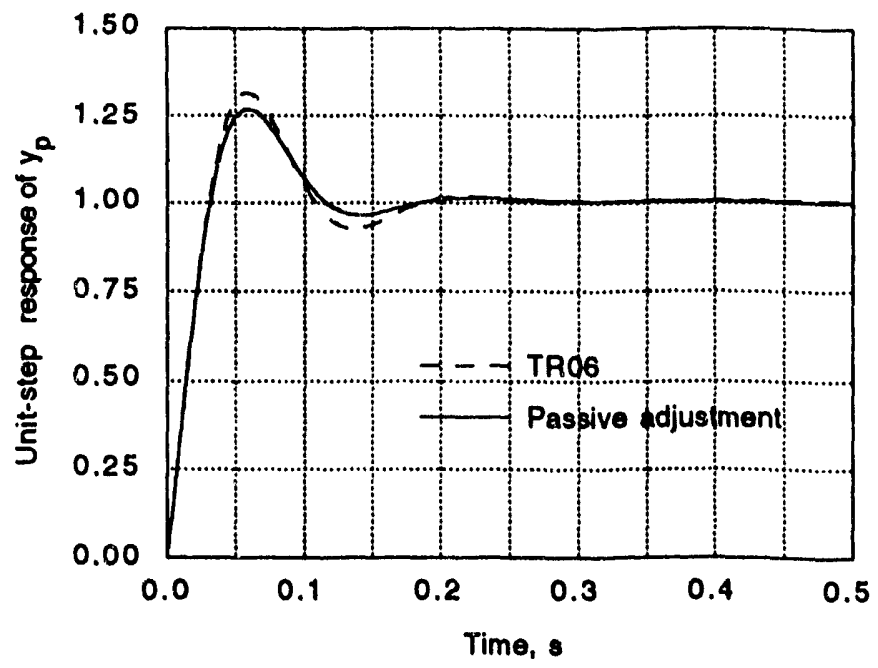

Fig. 25. Transient response $y_{p}$ of primary suspension with unit-step input of guideway perturbation using passive adjustments

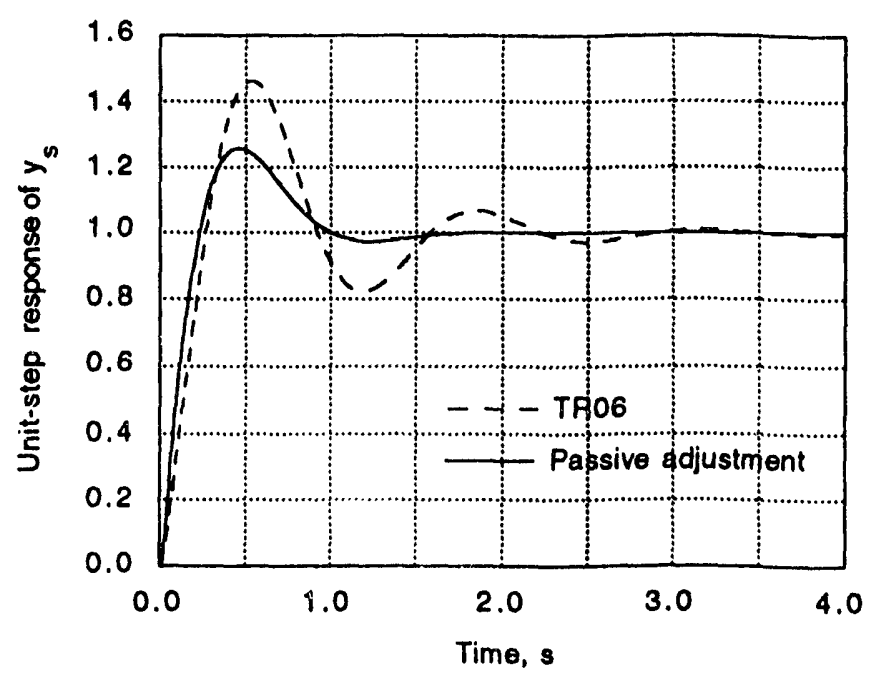

Fig. 26. Transient response $y_{s}$ of secondary suspension with unit-step input of guideway perturbation using passive adjustments

An active primary suspension system is suitable for maglev vehicles. Such a system provides continuous or discrete variation in effective spring constants and damping coefficients, according to some control law that may be designed in software rather than hardware. Figure 30 shows this control configuration as a 


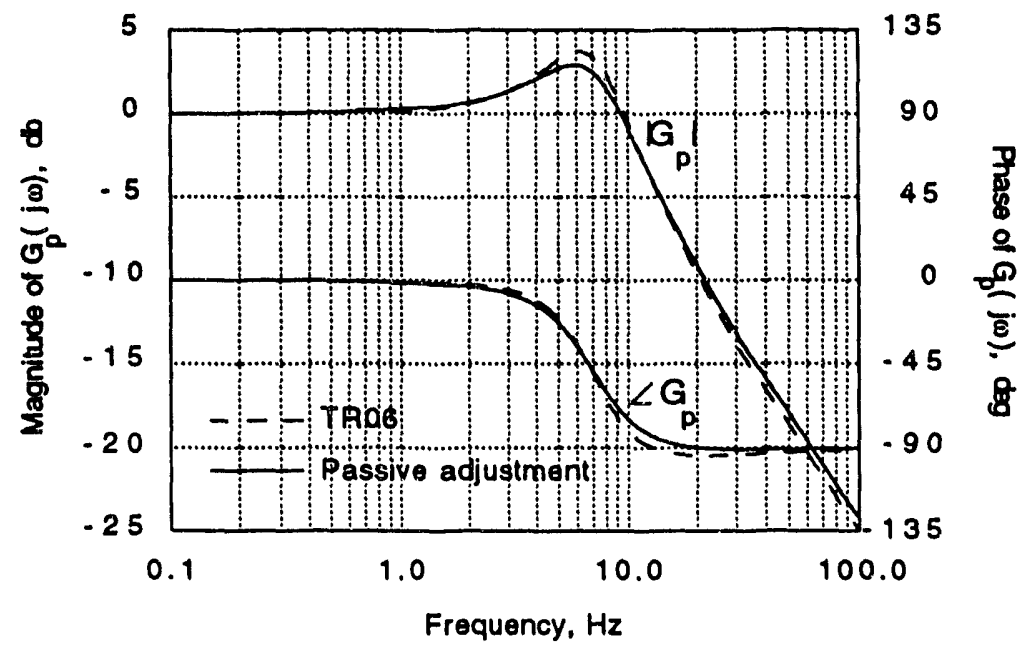

Fig. 27. Frequency response $G_{p}(j \omega)$ of primary suspension using passive adjustments

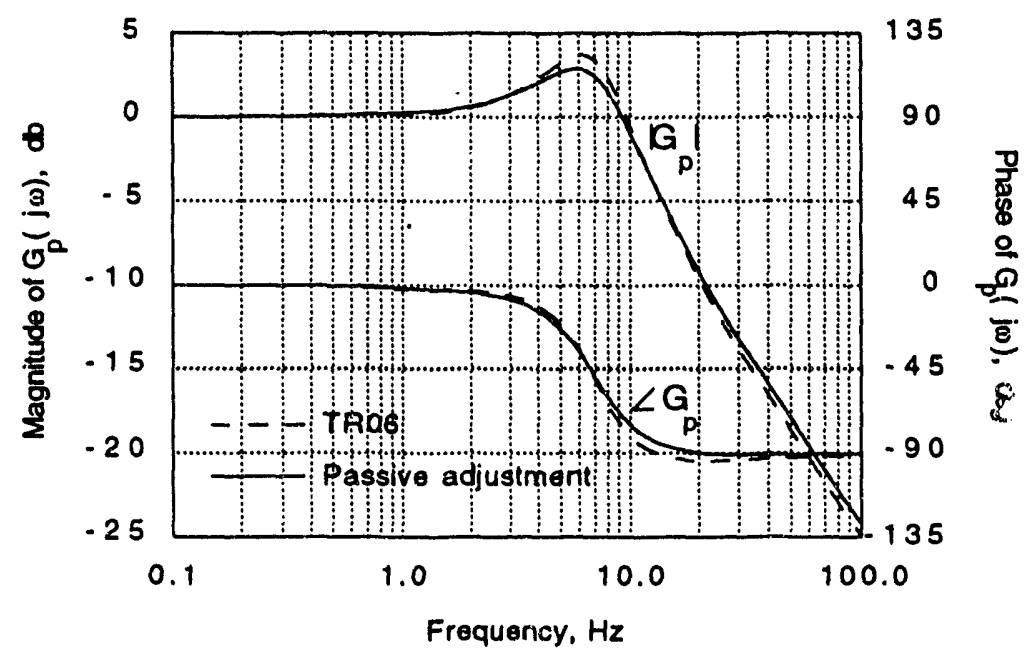

Fig. 28. Frequency response $G_{s}(j \omega)$ of secondary suspension using passive adjustments

single-degree-of-freedom model. An active force element is added to the passive spring and damper assembly and will continuously vary the force acting on the primary mass to change the response characteristics and eliminate acceleration amplitude. In this approach, the force element can be realized with a linear electrohydraulic actuator that connects magnet and bogie in the primary suspension (see Fig. 31). A position sensor detects the air gap between magnet and guideway, and an accelerometer, mounted on the bogie, detects bogie motion. 


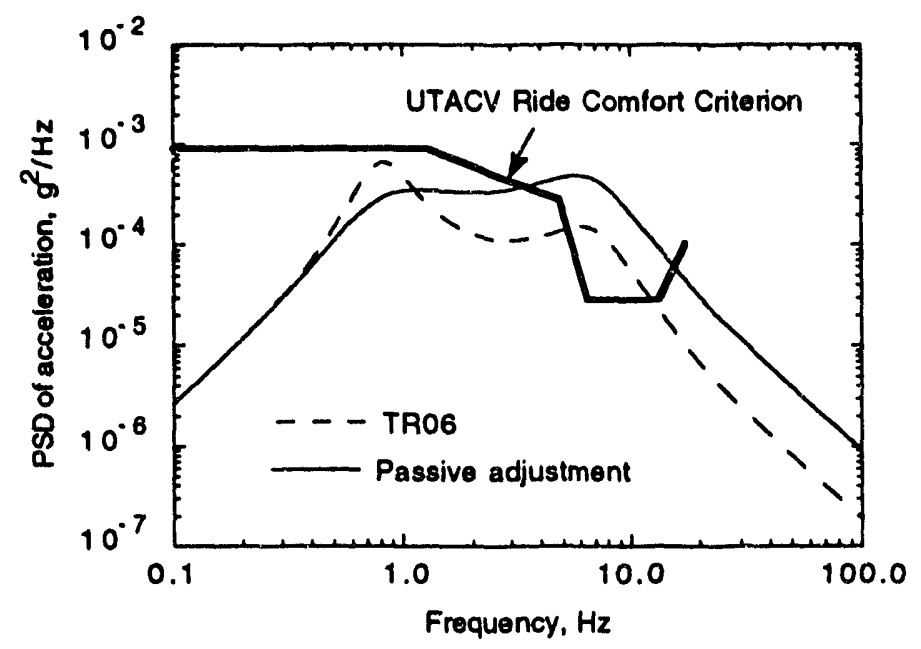

Fig. 29. PSD of vehicle acceleration using passive adjustments with vehicle speed $v=100 \mathrm{~m} / \mathrm{s}$ and guideway roughness amplitude $A=10^{-6} \mathrm{~m}$

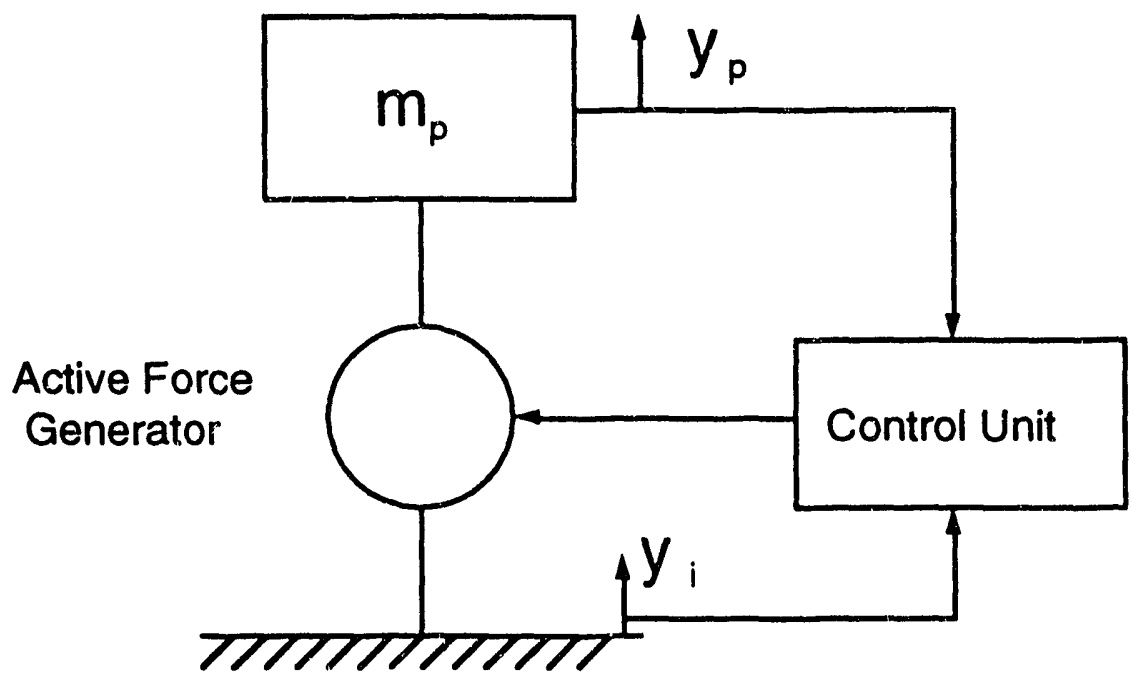

Fig. 30. Active control configuration for primary suspension

The resulting signals are processed by the controller according to designed control law in software, in turn causing the actuator to ensure that the air gap does not exceed specific tolerances within the safety margin and that the acceleration PSD of the suspension remains as low as possible in the specified frequency ranges in order to guarantee good ride comfort. In practice, when the magnet quickly follows guideway deviations caused by dynamic and static deflections or constructional features, the magnet oscillations may transfer to the 


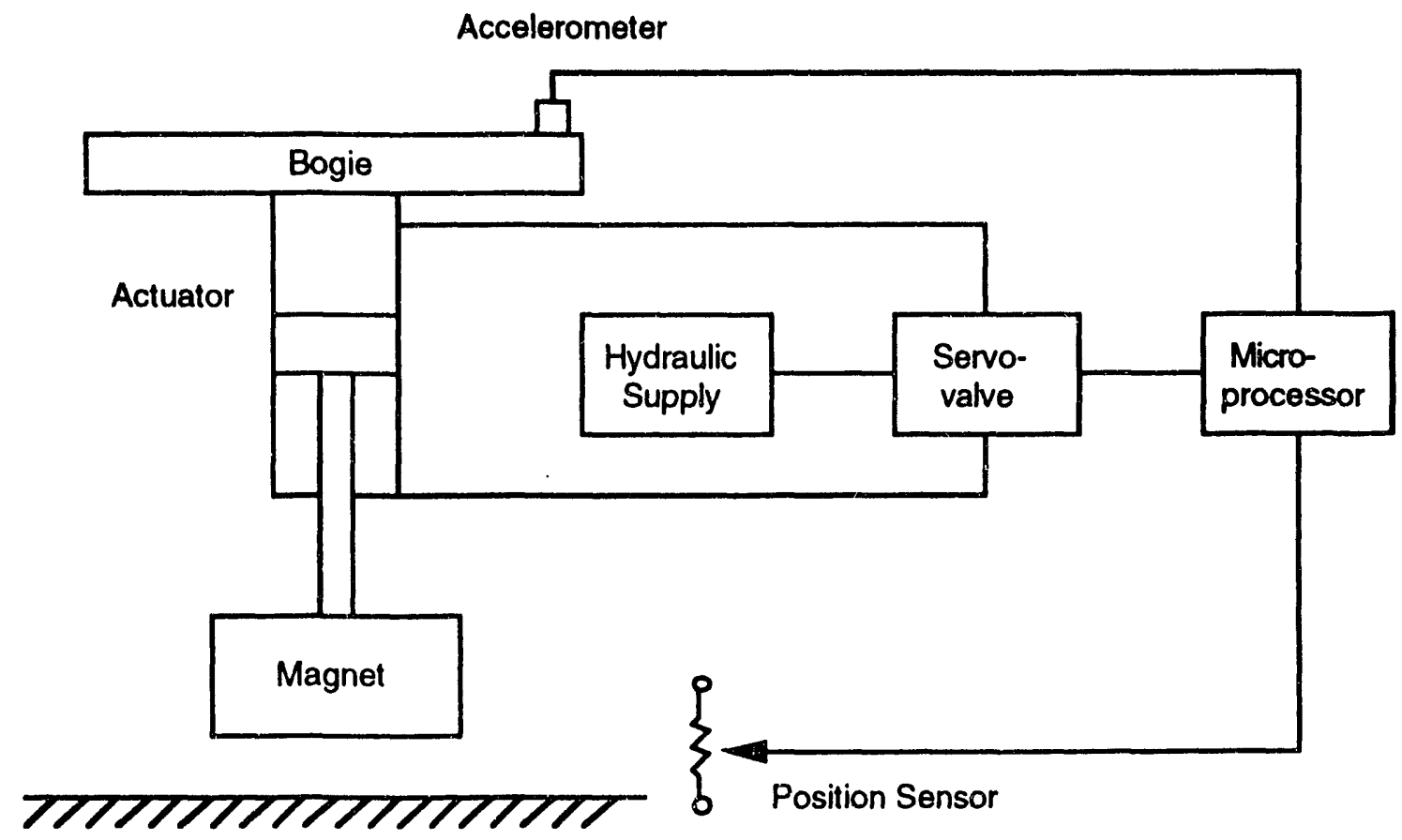

Guideway Surface

Fig. 31. Active electro-hydraulic system

bogie. Therefore, an optimal/adaptive control law should be exploited in the controller, and some trade-offs may be needed to achieve a constant air gap and a low acceleration level in the suspension system.

In this study, an active feedback control path is applied to the simplified vehicle model with the pole-assignment approach, which provides a less complicated control model. According to the analysis of acceleration PSD in Fig. 24, to attenuate the coupling effects of primary suspension oscillation in the high-frequency range, a lag-lead regulator is designed in the inner feedback path for the primary suspension (see Fig. 32).

The pole-assignment method involves selecting a set of desired pole locations and calculating the gains required to achieve such a pole configuration and hence the desired system response. By selecting new open-loop zero $a=-5(1 / \mathrm{s})$, and pole $b=-120(1 / \mathrm{s})$ in the lag-lead feedback network, the root locus plot of the primary suspension is given in Fig. 33. For feedback gain $k_{p}=2.7 \times 10^{8} \mathrm{~N}$, the closed-loop eigenvalues are given in Fig. 35 and Table 3, e.g., -23.89 and $-65.71 \pm 84.55$ j; this changes the damping ratio of the primary suspension to 0.61 , which is sufficient to attenuate the oscillation, and the frequency to $17.05 \mathrm{~Hz}$, which is desirable because the higher the natural frequency of the primary suspension the tighter 


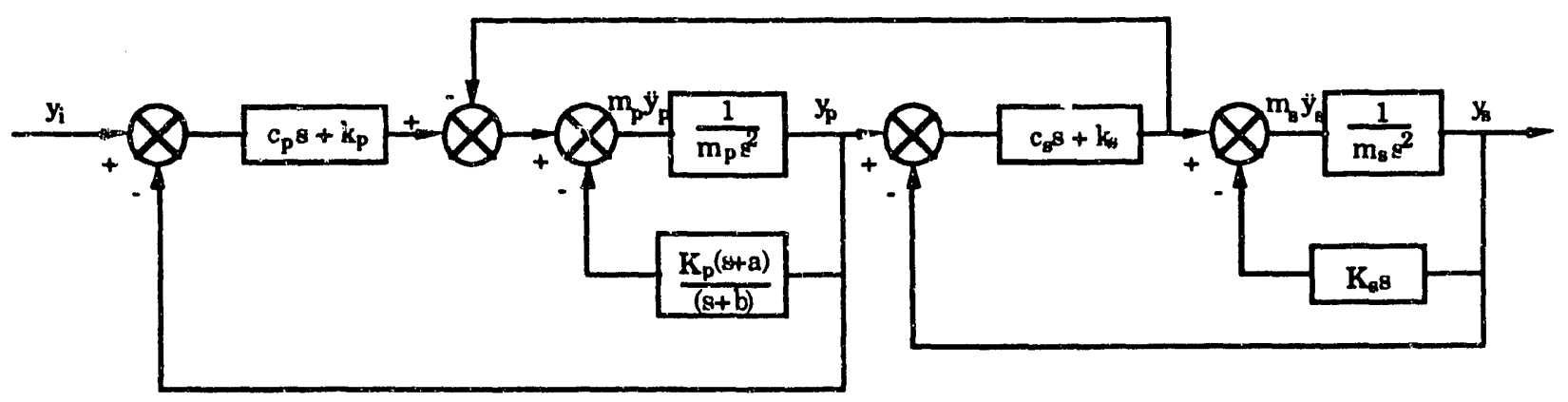

Fig. 32. Block diagram for two-degree-of-freedom vehicle model of maglev system with primary and secondary suspension feedback controls

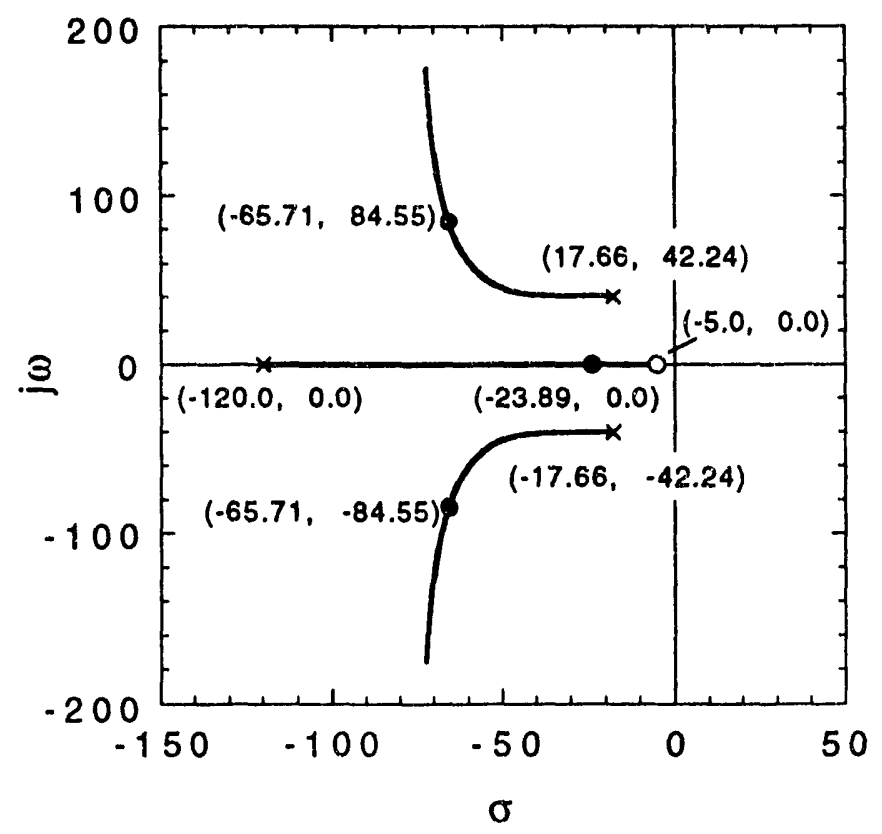

Fig. 33. Root-locus diagram for primary suspension feedback control design

the tracking will be. It should be noted that with mechanical control devices, such as electrohydraulic servovalves, the complex pair of suspension eigenvalues can be easily changed. However, the controlled coils or controlled magnet current car change only the real poles of the suspension system.

Figure 34 is a comparison of vehicle acceleration PSDs. With primary suspension feedback control, the second peak of acceleration, which reflects the coupling effects of the primary suspension, is much lower and meets the criterion with parameter selections of $\mathrm{k}_{\mathrm{p}}$, a, and $\mathrm{b}$, as described in Fig. 32. 


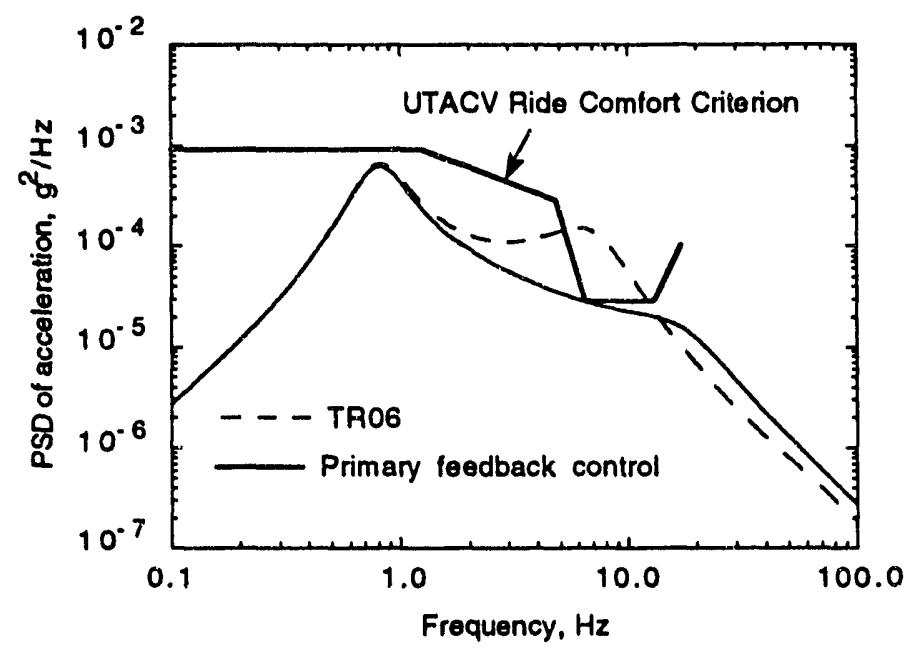

Fig. 34. PSD of vehicle acceleration using active feedback controls in primary suspension with vehicle speed $v=$ $100 \mathrm{~m} / \mathrm{s}$ and guideway roughness amplitude $A=10^{-6} \mathrm{~m}$

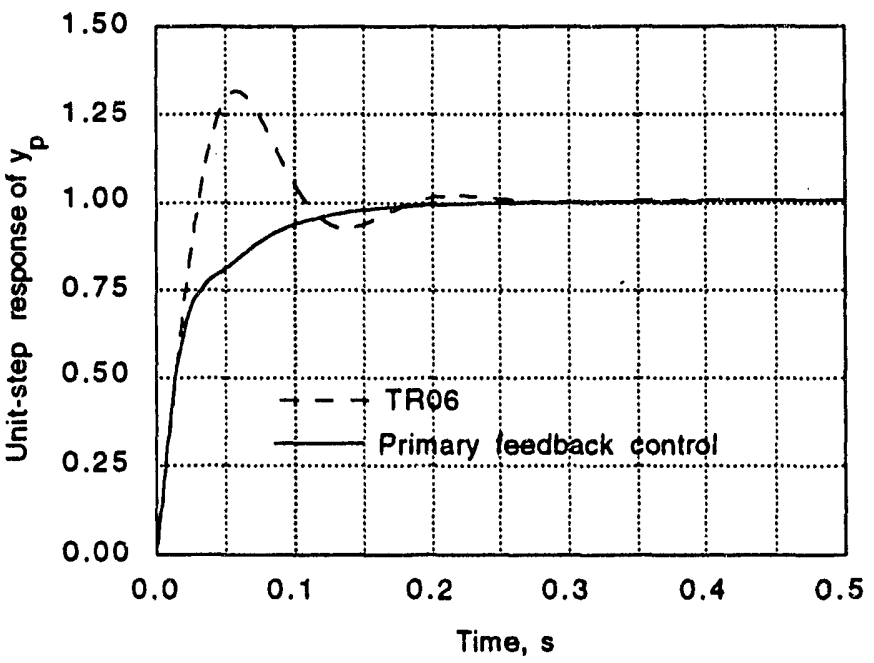

Fig. 35. Transient response $y_{p}$ of primary suspension with unit-step input of guideway perturbation using active feedback controls in primary suspension

Figures 35 and 36 compare transient responses of the primary and secondary suspensions with unit-step input of guideway disturbance. With primary suspension feedback control, dynamic response of the primary suspension is significantly improved (see Fig. 35 and Table 4) and the setting time is reduced to $t_{s}=0.115 \mathrm{~s}$, but it does not affect the response of the secondary suspension and the setting time of $t_{\mathrm{s}}$ remains the same as before (see Fig. 36 and Table 5). 


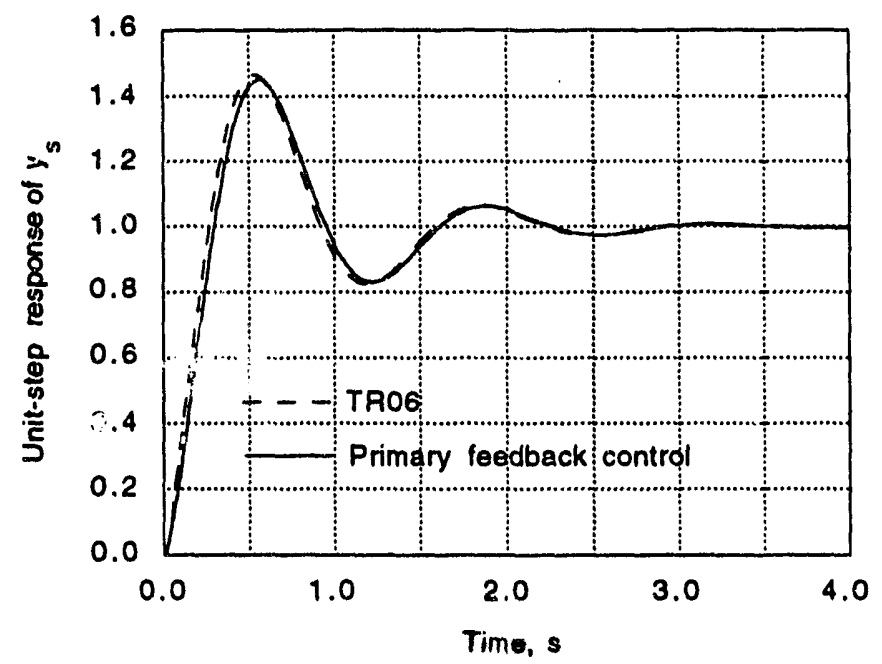

Fig. 36. Transient response $y_{s}$ of secondary suspension with unit-step input of guideway perturbation using active feedback controls in primary suspension

Figures 37 and 38 show a comparison of frequency responses of both primary and secondary suspension. With primary suspension feedback control, the results are the same as in Figs. 35 and 36.

It is noted that the active primary suspension system does not damp the excessive overshoots of secondary suspension in the transient response (see Fig. 36) and the frequency response (see Fig. 38). To achieve the desirable values of the overshoots and the setting time, a semiactive control is introduced into the secondary suspension.

\subsection{Semiactive Control of Secondary Suspension}

Semiactive suspension controls use an active damper in parallel with a passive spring (see Fig. 39). Desired forces in the damper are generated by modulation via fluid-flow orifices (hydraulic or pneumatic) based on a control scheme that uses feedback variables. With the spring-damper arrangement in Fig. 39, the damper can produce a force that is a function of relative velocity, in our case, $\dot{y}_{s}-\dot{y}_{p}$, of two masses. What is required for significantly improved control of transmissibility is a damper producing a force proportional to the absolute velocity, $\dot{y}_{s}$, of the mass. In physical terms, this can be interpreted as the provision of a dashpot between the mass and an inertial reference, as shown in Fig. 40. This arrangement, which has been described as a "skyhook" damper, 


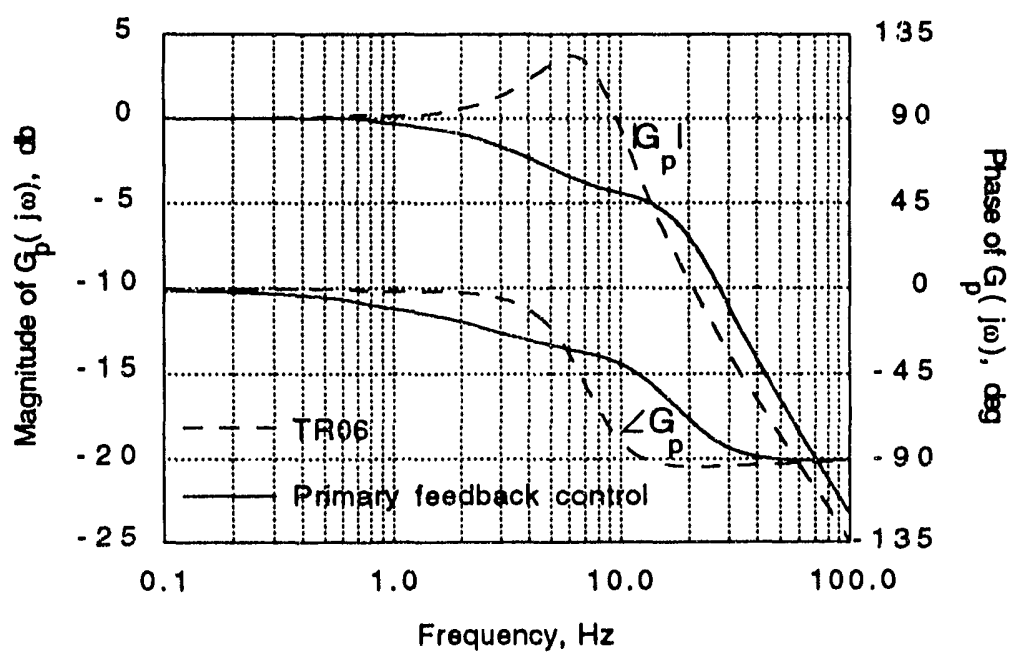

Fig. 37. Frequency response $G_{p}(j \omega)$ of primary suspension using active feedback controls in primary suspension

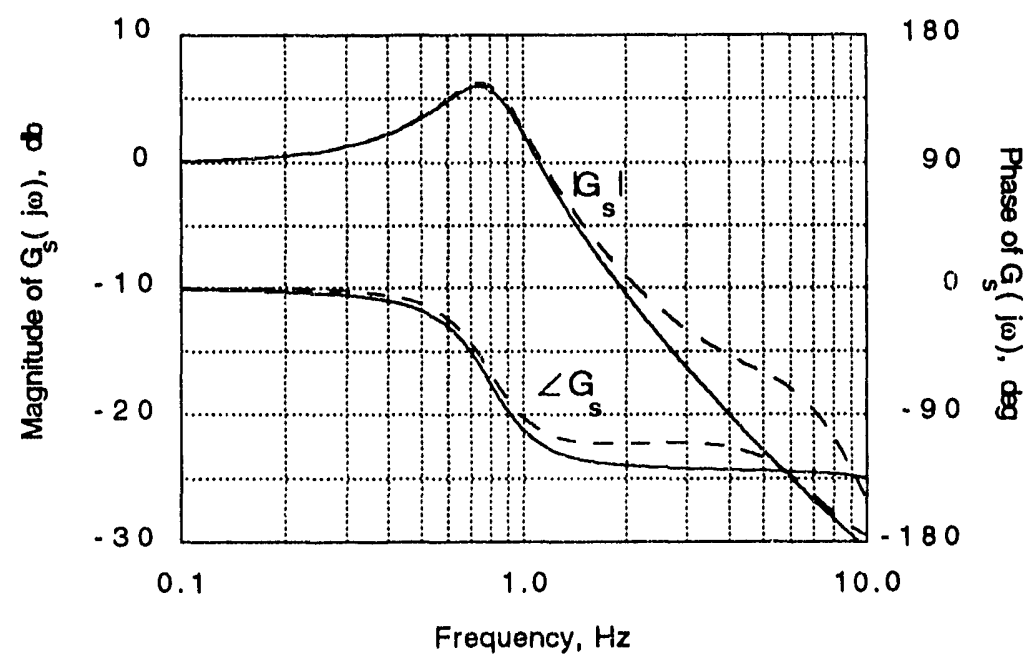

Fig. 38. Frequency response $G_{s}(j \omega)$ of secondary suspension using active feedback controls in primary suspension

offers a considerable advantage in terms of transmissibility control. It can be constructed, without the need for an inertial reference, using an active element under feedback control. It is straightforward to show that this can be done by a proportional control law involving the absolute velocity of the mass. It was proved that semiactive control with the skyhook configuration can increase the damping factor and that the resonant peak is suppressed while high-frequency transmission is reduced simultaneously (Stanway et al. 1989). 


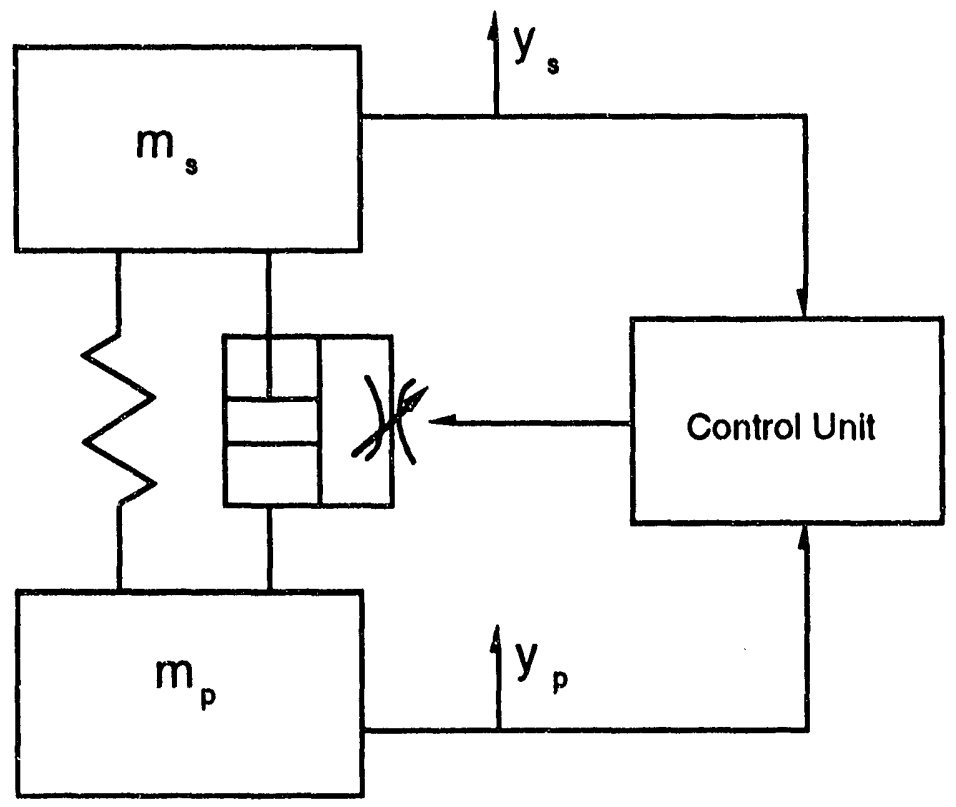

Fig. 39. Semiactive control for secondary suspensions

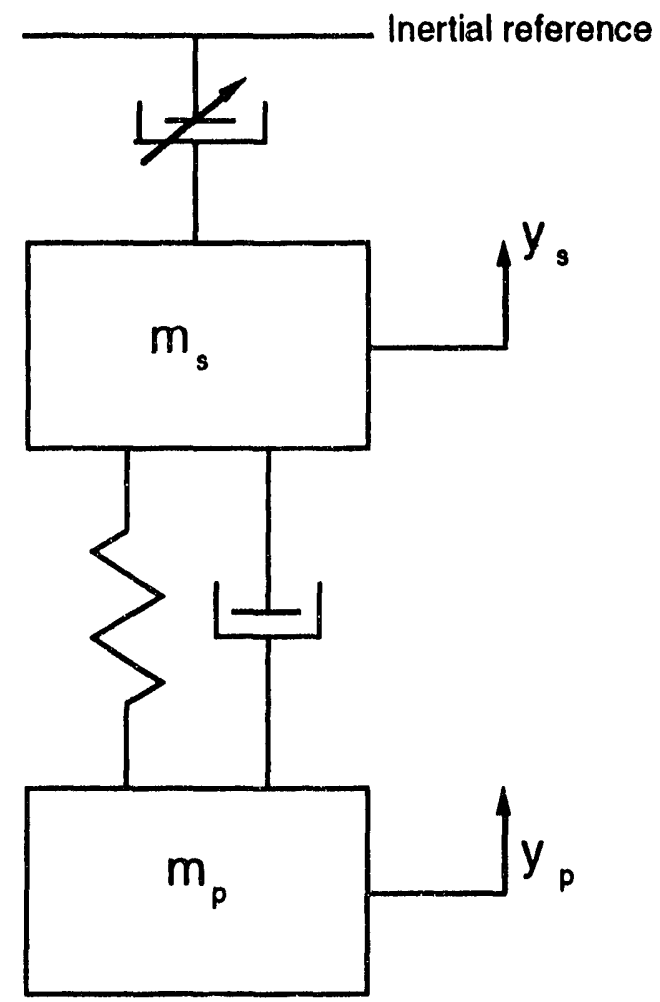

Fig. 40. Skyhook damper for secondary suspensions 


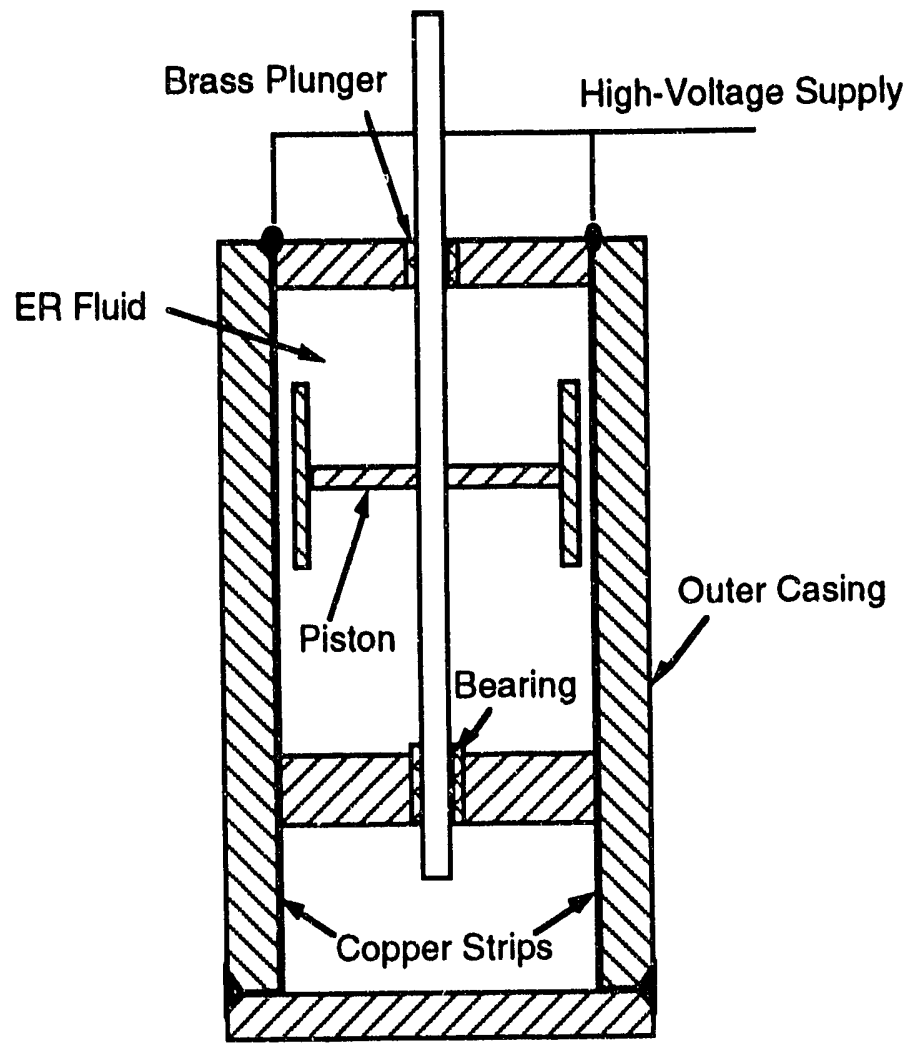

Fig. 41. ER fluids damper based on shearmode principle

Therefore, the semiactive control with the skyhook configuration is desirable for the secondary suspension to provide good ride comfort at lower costs. This control design can be realized by a semiactive ER fluid damper based on the shear-mode principle (see Fig. 41). In this configuration, one of a pair of electrodes is fixed to the piston and the other is attached to the damper casing. The relative movement of the electrodes results in shear stress on the surfaces. The damping force is the product of the shear stress and the surface area of the moving electrodes. The shear stress and hence the damping force can be controlled by the voltage applied to the electrodes.

Based on the principle of semiactive control of the secondary suspension, a feedback control path $k_{8} s$ (active damping) is added to the secondary suspension (see Fig. 32). The root-locus for the secondary suspension is given in Fig. 42. New eigenvalues are $-3.014 \pm 4.020 \mathrm{j}$, with $\mathrm{k}_{\mathrm{s}}=8.8 \times 10^{4} \mathrm{~N} \cdot \mathrm{s}$ when using pole assignment in the secondary suspension control design. The damping ratio of the secondary suspension becomes 0.60 .

The PSD of vehicle acceleration with both primary and secondary feedback control is shown in Fig. 43. Ride comfort is much improved. 
54

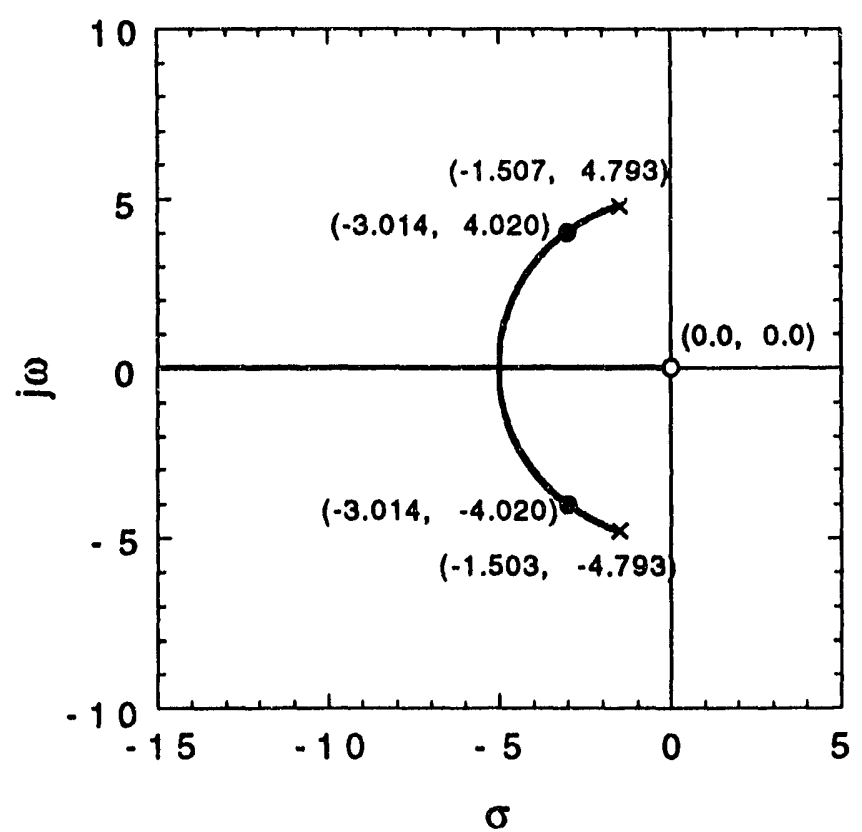

Fig. 42. Root-locus diagram for secondary suspension feedback control design

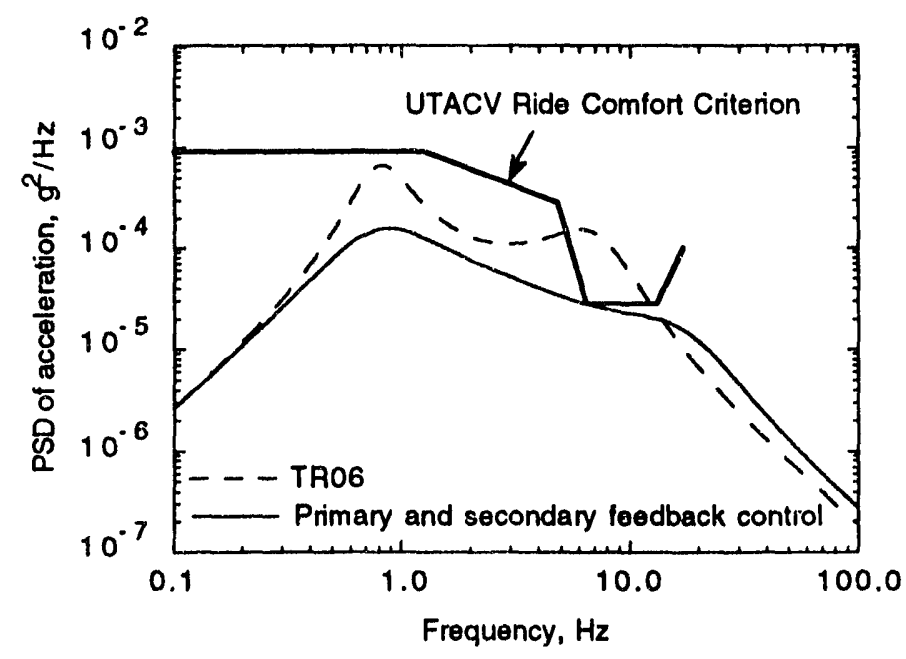

Fig. 43. PSD of vehicle acceleration using active and semiactive feedback controls in primary and secondary suspensions with vehicle speed $v=$ $100 \mathrm{~m} / \mathrm{s}$ and guideway roughness amplitude $A=10^{-6} \mathrm{~m}$ 
Figures 44 and 45 show the comparison of transient responses of primary and secondary suspensions with unit-step input of guideway disturbance. Response of the secondary suspension is improved, and the setting time of $t_{s}$ declines to $0.964 \mathrm{~s}$ from $2.000 \mathrm{~s}$ and overshooting $\mathrm{M}_{\mathrm{p}}$ becomes $12.3 \%$, a significant drop from the original $46.3 \%$ (see Fig. 45 and Table 5).

Figures 46 and 47 show comparisons of frequency responses of both primary and secondary suspension with both primary and secondary feedback control. These figures show effects in reducing vehicle response similar $t$ those in Figs. 44 and 45.

\subsection{Parametric Analysis of Control Designs}

When the mechanical control method is exploited in maglev suspension systems, system parameters of feedback control are of particular importance in depressing oscillation and providing acceptable ride comfort. As shown in the root-locus plots of primary and secondary suspensions (Figs. 33 and 34), as feedback gains increase, system dampings will decrease and natural frequencies will increase. However, as the feedback gains exceed certain values, an extra power source is required and may bring unnecessary cost to a maglev system.

Although we do not extensively discuss the effects of system parameters in control designs, which we believe are essential to any conceptual design of the maglev system, several comparisons on parametric analysis for control design of maglev suspension systerns are performed in this study.

1 "gures 48-50 show the transient frequency responses of the primary suspension and the PSD of vehicle acceleration, with various primary feedback gains $\mathrm{k}_{\mathrm{p}}$. When $\mathrm{k}_{\mathrm{p}}>1.3 \times 10^{8} \mathrm{~N}$, the oscillation of primary suspension is depressed. However, only when $k_{p}>2.7 \times 10^{8} \mathrm{~N}$ does the PSD of vehicle acceleration reach the UTACV ride comfort criterion.

Figures 51-53 show the transient and frequency responses of the secondary suspension and the PSD of vehicle acceleration, with various secondary feedback gains $\mathbf{k}_{\mathrm{s}}$. When $\mathbf{k}_{\mathrm{s}}>6.0 \times 10^{4} \mathrm{~N} \cdot \mathrm{s}$, setting times and oscillation depression seem to be acceptable. 


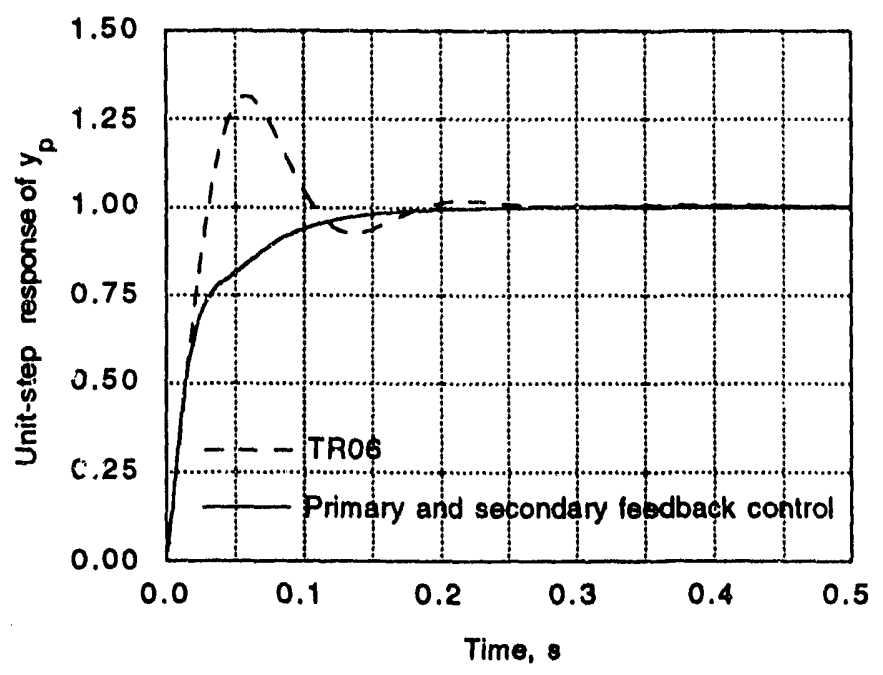

Fig. 44. Transient response $y_{p}$ of primary suspension with unit-step input of guideway perturbation using active and semiactive feedback controls in primary and secondary suspensions

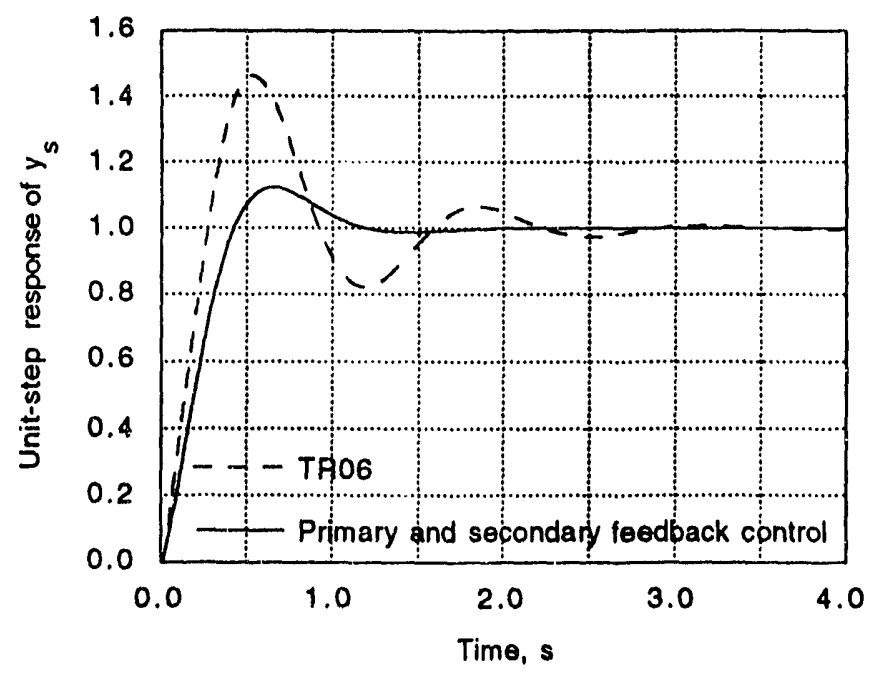

Fig. 45. Transient response $y_{s}$ of secondary suspension with unit-step input of guideway perturbation using active and semiactive feedback controls in primary and secondary suspensions 


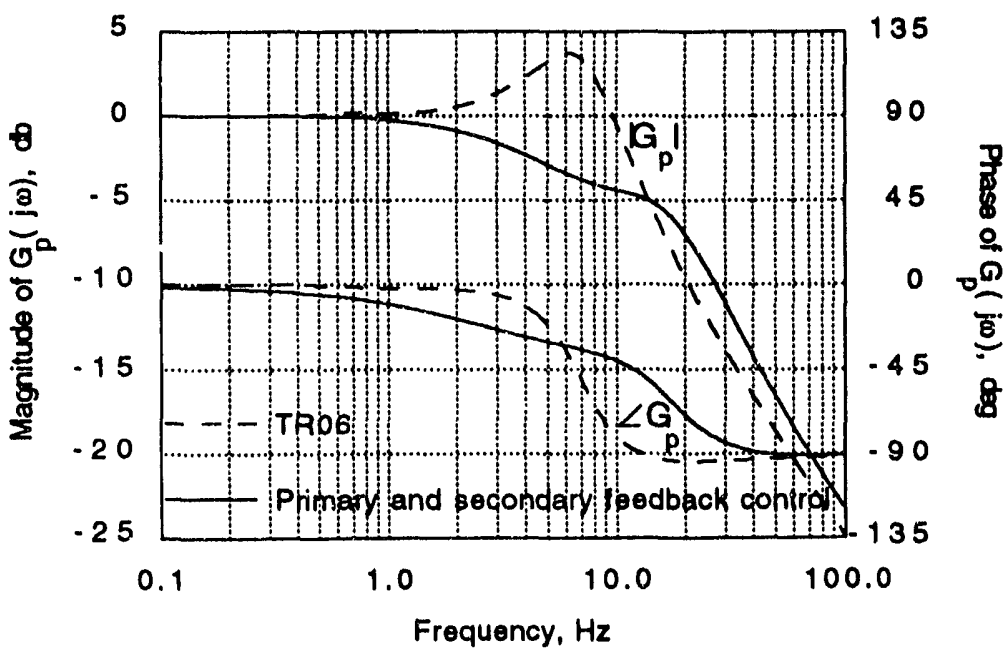

Fig. 46. Frequency response $G_{p}(j \omega)$ of primary suspension using active and semi. active feedback controls in primary and secondary suspensions

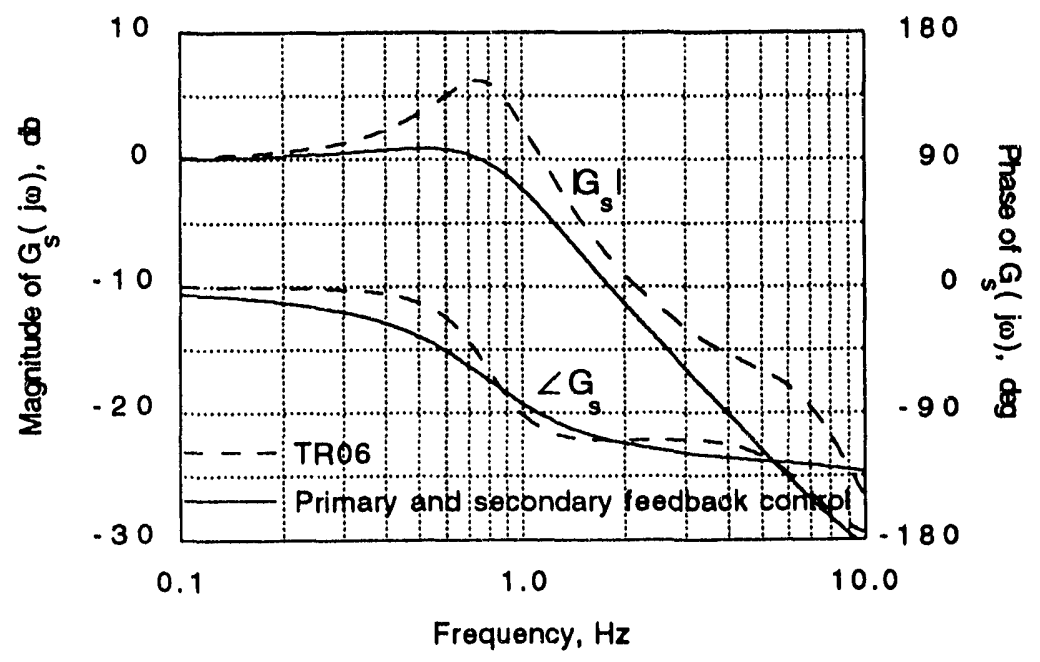

Fig. 47. Frequency response $G_{s}(j \omega)$ of secondary suspension using active and semiactive feedback controls in primary and secondary suspensions 


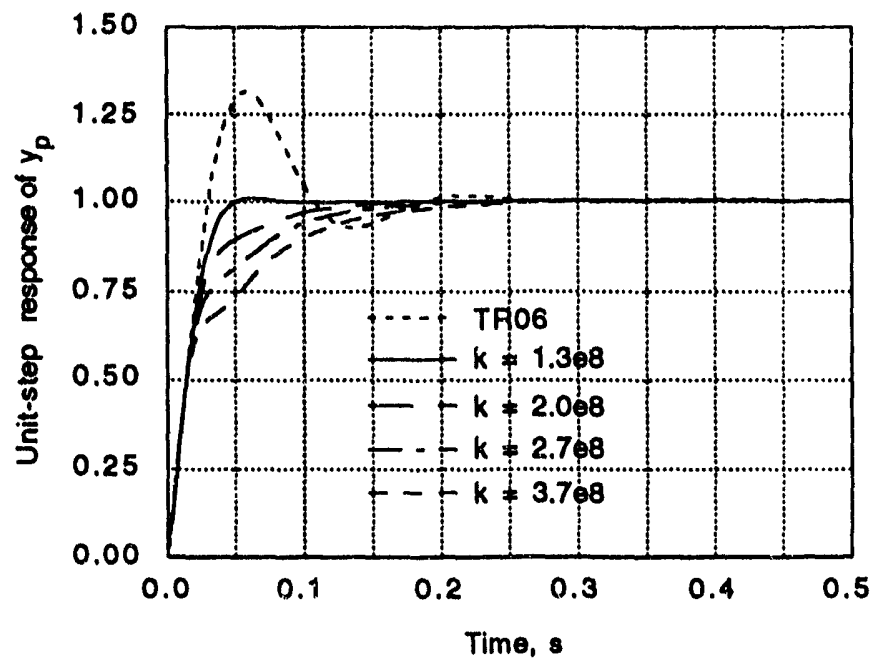

Fig. 48. Comparison of transient response $y_{p}$ of primary suspension with unitstep input of guideway perturbation using active and semiactive feedback controls in primary and secondary suspensions when $k_{s}=$ $8.8 \times 10^{4} \mathrm{~N} \cdot \mathrm{s}$ and $k_{p}=1.3 \times 10^{8}, 2.0 \times$ $10^{8}, 2.7 \times 10^{8}$, and $3.7 \times 10^{8} \mathrm{~N}$

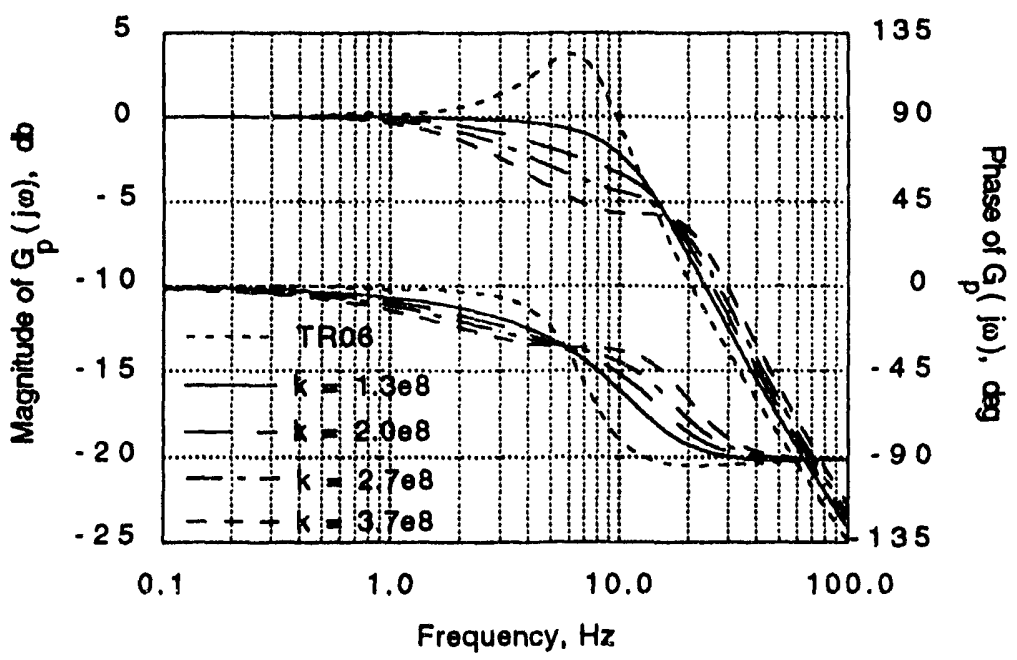

Fig. 49. Comparison of frequency response $G_{p}(j \omega)$ of primary suspension using active and semiactive feedback controls in primary and secondary suspensions when $k_{s}=$ $8.8 \times 10^{4} \mathrm{~N} \cdot \mathrm{s}$ and $k_{p}=1.3 \times 10^{8}, 2.0 \times 10^{8}$, $2.7 \times 10^{8}$, and $3.7 \times 10^{8} \mathrm{~N}$ 


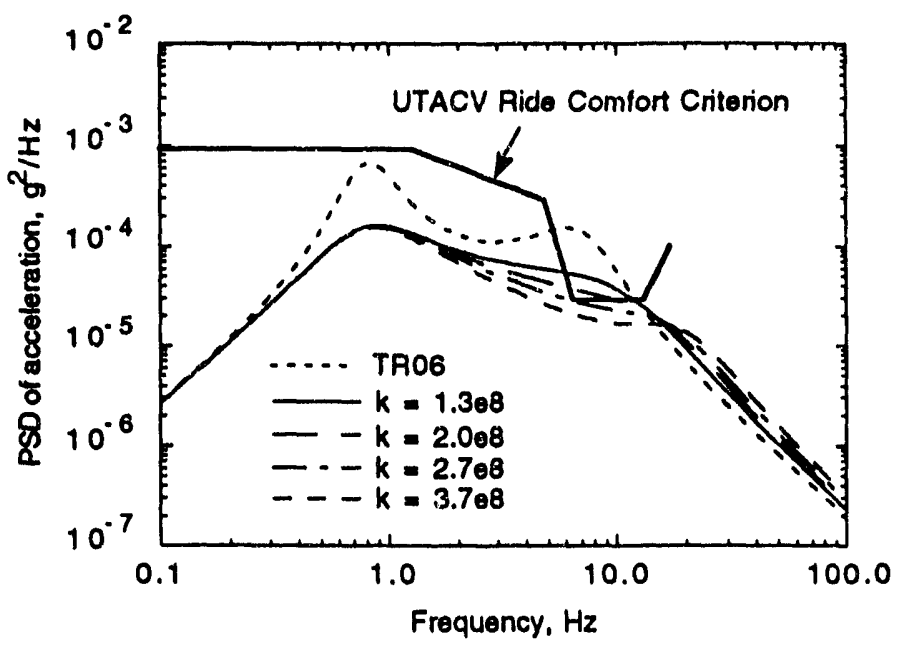

Fig. 50. Comparison of PSD of vehicle acceleration using active and semiactive feedback controls in primary and secondary suspensions with vehicle speed $v=$ $100 \mathrm{~m} / \mathrm{s}$ and guideway roughness amplitude $A=10^{.6} \mathrm{~m}$ when $k_{s}=8.8 \times$ $10^{4} \mathrm{~N} \cdot \mathrm{s}$ and $k_{p}=1.3 \times 10^{8}, 2.0 \times 10^{8}$, $2.7 \times 10^{8}$, and $3.7 \times 10^{8} \mathrm{~N}$

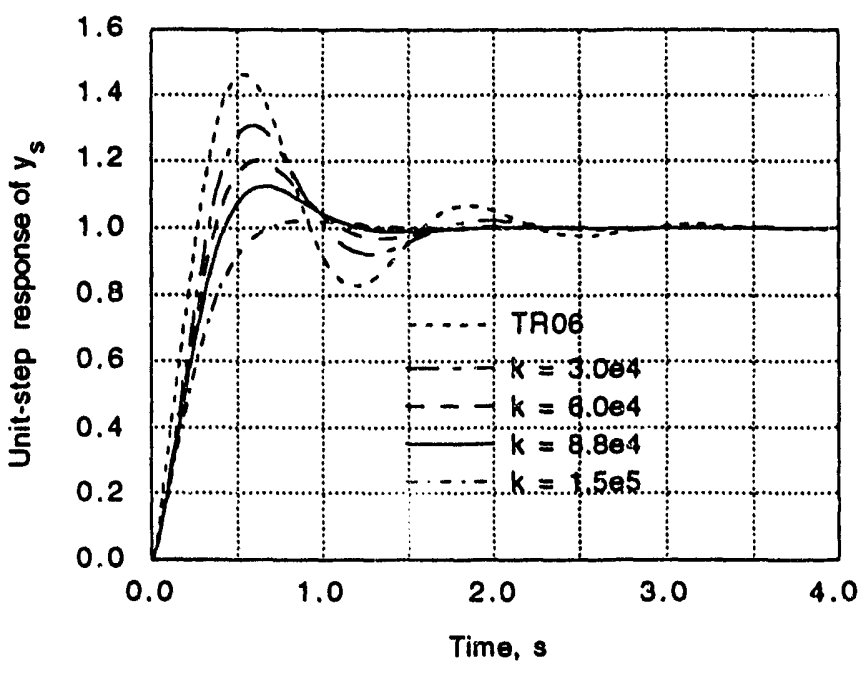

Fig. 51. Comparison of transient response $y_{s}$ of secondary suspension with unit-step input of guideway perturbation using active and semiactive feedback controls in primary and secondary suspensions when $k_{p}=$ $2.7 \times 10^{8} \mathrm{~N}$ and $k_{s}=3.0 \times 10^{4}, 6.0 \times$ $10^{4}, 8.8 \times 10^{4}$, and $1.5 \times 10^{5} \mathrm{~N} \cdot \mathrm{s}$ 
60

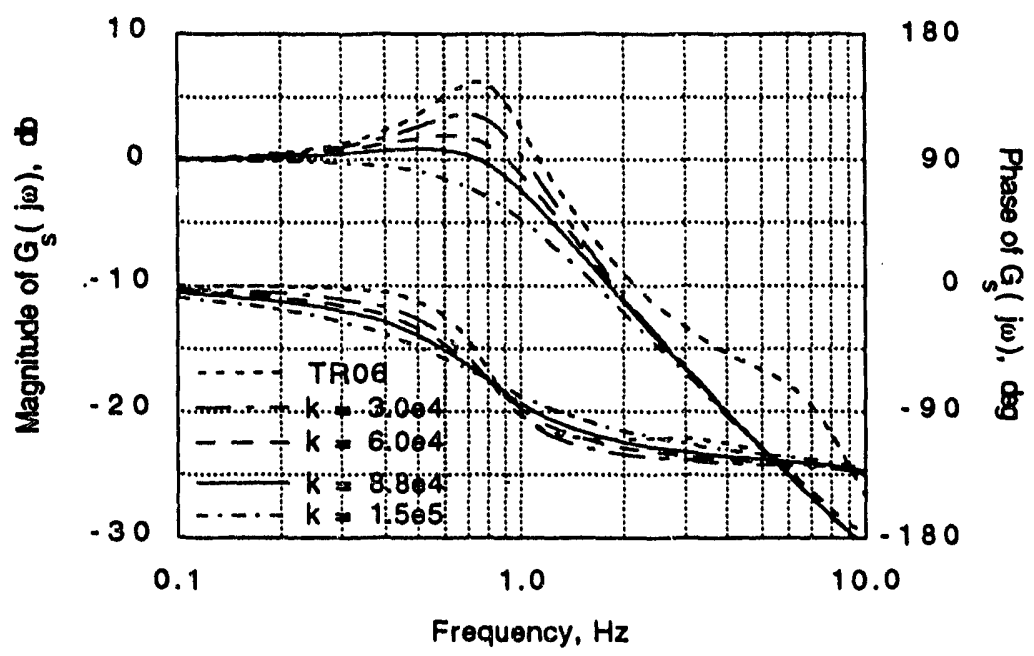

Fig. 52. Frequency response $G_{s}(j \omega)$ of secondary suspension using astive and semiactive feedback controls in primary and secondary suspensions when $k_{p}=2.7 \times 10^{8} \mathrm{~N}$ and $k_{\mathrm{s}}=3.0 \times 10^{4}, 6.0 \times 10^{4}, 8.8 \times 10^{4}$, and $1.5 \times$ $10^{5} \mathrm{~N} \cdot \mathrm{s}$

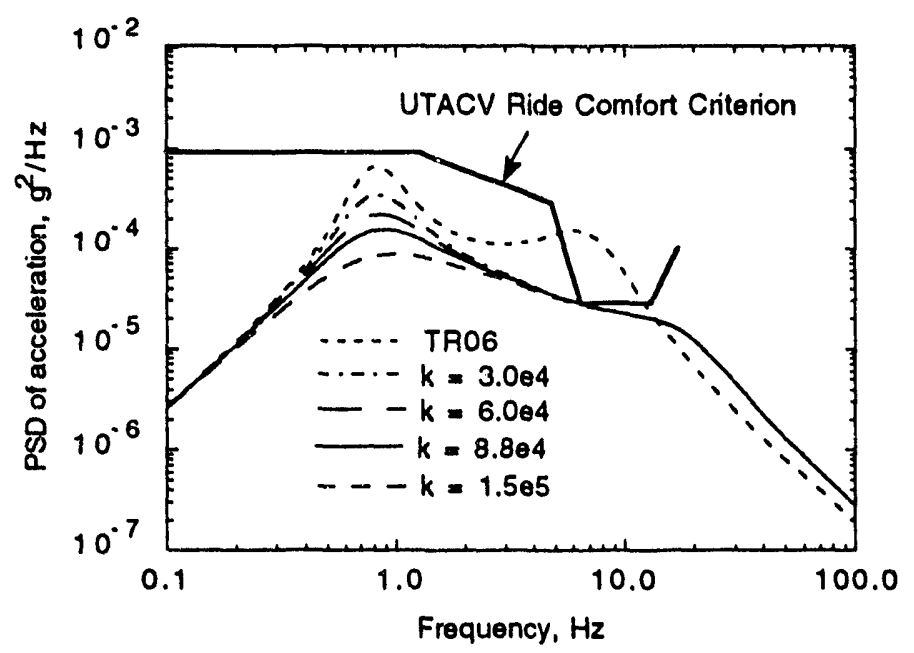

Fig. 53. Comparison of PSD of vehicle acceleration using active and semiactive feedback controls in primary and secondary suspensions with vehicle speed $v=100 \mathrm{~m} / \mathrm{s}$ and guideway roughness amplitude $A=$ $10^{-6} \mathrm{~m}$ when $k_{p}=2.7 \times 10^{8} \mathrm{~N}$ and $k_{s}=$ $3.0 \times 10^{4}, 6.0 \times 10^{4}, 8.8 \times 10^{4}$, and $1.5 \times$ $10^{5} \mathrm{~N} \cdot \mathrm{s}$ 


\section{Closing Remarks}

(1) The dynamic interaction model of a maglev system with a multicar, multiload vehicle traveling along a flexible guideway was developed in this study. It was verified that this model is desirable for analyses of vehicle/guideway interactions in maglev systems. The model can be incorporated into future computer codes for nonlinear dynamic analyses of maglev systems. Incorporation of this model into a computer code that contains a six-degree-offreedom rigid-vehicle body has recently been performed at Argonne National Laboratory. The model should have a bright future with many applications in commercial maglev systems.

(2) A distributed-load vehicle model is better than a concentrated-load model that may result in large amplitudes of both guideway deflections and vehicle accelerations in simulations. Multicar vehicles have less car-body acceleration than does a single-car vehicle because of intercar constraints. This indicates that the multicar vehicle would provide better ride comfort.

(3) Active and semiactive feedback control designs in primary and secondary suspensions can be realized through electro-hydraulic systems. The conceptual designs of hydraulic controllers will be taken into account in our future work. The ER fluids damper may offer an elegant solution to the problem of implementing semiactive control in the secondary suspension, which shows great potential for reducing costs and improving ride comfort.

(4) Maglev may become a major transportation mode in the 21st century. Because the cost for a commercial maglev system is still very high, it is wise to consider dynamic control systems before completing the guideway design so that overall system cost can be reduced.

\section{Acknowledgments}

This work was performed under the sponsorship of the U.S. Army Corps of Engineers and the Federal Railroad Administration through interagency agreements with the U.S. Department of Energy.

Additional thanks to Dr. S. Zhu for many helpful discussions. 


\section{References}

Alonoly, J., and Sankar, S. 1987. "A New Concept in Semiactive Vibration Isolation," ASME Trans., J. of Mechanisms, Transmissions, and Automation Design, 109(2), pp. 242-247.

Alonoly, J., and Sankar, S. 1988. "Semiactive Force Generators for Shock Isolation," J. of Sound and Vibration, 126(1), pp. 145-156.

Bernard, J., Vanderploeg, M., and Shanan, J. 1987. "Literature Review: Recent Developments in Vehicle Dynamics," Shock and Vibration Digest, 19(4), pp. 10-17.

Bohn, G., and Alscher, H. 1986. "The Magnetic Train Transrapid 06," Proc. Int. Conf. Maglev and Linear Drives, May 14-16, 1986, Vancouver, B.C., Canada, Publ. by IEEE, $86 \mathrm{CH} 2276-4$, pp. 233-242.

Bohn, G., and Steinmetz, G. 1985. "The Electromagnetic Suspension System of the Magnetic Train 'TRANSRAPID,'" Proc. Int. Conf. Maglev Transport '85, Sept. 17-19, 1985, Keidanren Kaikan, Tokyo, Japan, Publ. by IEEE, Japan, pp. 107-114.

Brock, B. J. 1973. "Determination of Guideway Roughness from Construction Tolerances," Proc. 44th Shock and Vibration Symp., December 1973, pp. 83-90.

Cai, Y., Chen, S. S., and Rote, D. M. 1992a. "Vehicle/Guideway Interaction in Maglev Systems," Argonne National Laboratory Report ANL-92/19.

Cai, Y., Chen, S. S., and Rote, D. M. 1992b. "Dynamic Stability of Maglev Systems," Argonne National Laboratory Report ANL-92/21.

Cai, Y., Chen, S. S., Rote, D. M., and Coffey, H. T. 1992c. "Vehicle/Guideway Interaction for High-Speed Vehicle on a Flexible Guideway," Proc. CSME Forum 1992 "Transport 1992+," June 1-4, 1992, Montreal, Canada, Vol. III, pp. 750-757.

Chalasani, R. M. 1987. "Ride Performance Potential of Active Suspension Systems - Part I: Simplified Analysis Based on a Quarter-Car Model," ASME, AMD, 80, pp. 187-204.

Chen, S. S., Rote, D. M., and Coffey, H. T. 1992. "A Review of Vehicle/Guideway Interactions in Maglev Systems," ASME Publication, PVP-Vol. 231, pp. 81-95. 
Chiu, W. S., Smith, R. G., and Wormley, D. N. 1971. "Influence of Vehicle and Distributed Guideway Parameters on High Speed Vehicle-Guideway Dynamic Interactions," ASME Trans. J. Dynamic Systems, Measurement, and Control, pp. 25-34.

Chu, D., and Moon, F. C. 1983. "Dynamic Instabilities in Magnetically Levitated Models," J. Appl. Phys. 54(3), pp. 1619-1625.

Coffey, H. T., et al. 1991. "Preliminary Design for a Maglev Development Facility," Argonne National Laboratory Report ANL/ESD-14.

Dukkipati, R. V., Cs.nan, M. O. M., and Vallurupalli, S. S. 1992. "Real Time Adaptive Control Compared with Stochastic Optimal Control of Active Suspension," Proc. CSME Forum 1992 "Transport 1992+," June 1-4, 1992, Montreal, Canada, Vol. I, pp. 192-198.

Elmadany, M. M. 1990. "Optimal Linear Active Suspensions with Multivariable Integral Control," Vehicle System Dynamics, 19, pp. 313-329.

Faye, I., Kortum, W., and Schwartz, W. 1989. "Modeling, Control Design, and Performance Evaluation of High Speed Ground Vehicle Dynamics," Mech. Struct. \& Mach., 17(2), pp. 259-281.

Fryba, L. 1972. "Vibration of Solids and Structures Under Moving Loads," Noordhoff International Publishing, Groningen, The Netherlands.

Goodal, R. M., and Kortum, W. 1983. "Active Controls in Ground Transportation A Review of the State-of-the-Art and Future Potential," Vehicle System Dynamics, 12 , pp. 225-257.

Gottzein, E., Lange, F., and Ossenberg-Franzes, F. 1974. "Control System Concept for a Passenger Carrying Maglev Vehicle," High Speed Ground Transportation J., 9(1), pp. 435-447.

Hrovat, D., Margolis, D. L., and Hubbard, M. 1988. "An Approach Toward the Optimal Semiactive Suspension," ASME Trans., J. of Mechanisms, Transmissions, and Automation Design, 110, pp. 288-296.

Iguchi, M., and Hara, H. 1985. "A Resonance-Eliminated Design of Simply Supported Beam for a Guideway of a High Speed Maglev System," Proc. Int. Conf. on Maglev Transport '85, Sept. 17-19, 1985, Keidanren Kaikan, Tokyo, Japan, Publ. by IEEE, Japan, pp. 217-224. 
Johnson, L. R., et al. 1989. "Maglev Vehicles and Superconductor Technology: Integration of High-Speed Ground Transportation into the Air Travel System," Argonne National Laboratory Report ANL/CNSV-67.

Karnopp, D., Crosby, M. J., and Harwood R. A. 1974. "Vibration Control Using Semiactive Force Generators," ASME Trans., J. of Engineering for Industry, 96, pp. 619-626.

Karnopp, D. C., and Margolis, D. 1984. "Adaptive Suspension Concepts for Road Vehicles," Vehicle System Dynamics, 13, pp. 145-160.

Katz, R. M., Nene, V. D., Ravera, R. J., and Skalski, C. A. 1974. "Perfornance of Magnetic Suspensions for High Speed Vehicles Operating over Flexible Guideways," ASME Trans., J. of Dynamic Systems, Measurement, and Control, 96, pp. 204-212.

Kortum, W., Schwartz, W., and Faye, I. 1988. "Dynamic Modeling of High Speed Ground Transportation Vehicles for Control Design and Performance Evaluation," Dynamics of Controlled Mechanical Systems, IUTAM/IFAC Symposium, Zurich, Switzerland, 1988, pp. 336-350.

Kortum, W., and Utzt, A. 1984. "Control Law Design and Dynamic Evaluations for a Maglev Vehicle with a Combined Lift and Guidance Suspension System," ASME Trans., J. of Dynamic Systems, Measurement, and Control, 106, pp. 286-292.

McCormac, A. W., Wilson, J. N., and Klassen, N. D. 1992. "Active Seat Suspension Systems for Off-Road Vehicles," Proc. CSME Forum 1992 "Transport 1992+," June 1-4, 1992, Montreal, Canada, Vol. I, pp. 180-185.

Moon, F. C. 1974. "Laboratory Studies of Magnetic Levitation in the Thin Track Limit," IEEE Trans. on Magnetics, MAG-10, No. 3, pp. 439-442.

Moon, F. C. 1975. "Vibration Problems in Magnetic Levitation and Propulsion," Transport Without Wheels, ed. by E. R. Laithwaite, Elek Science, London, pp. 122-161.

Olsson, M. 1985. "Finite Element, Modal Co-Ordinate Analysis of Structures Subjected to Moving Loads," J. of Sound and Vibration, 99(1), pp. 1-12.

Richardson, H. H., and Wormley, D. N. 1974. "Transportation Vehicle/BeamElevated Guideway Dynamic Interactions: A State-of-the-Art Review," ASME Trans., J. Dynamic Systems, Measurement, and Control, 96, pp. 169-179. 
Sinha, P. K. 1987. "Electromagnetic Suspension, Dynamics and Control," Peter Peregrinus Ltd., London, U.K.

Smith, C. C., Gilchrist, A. J., and Wormley, D. N. 1975a. "Multiple and Continuous Span Elevated Guideway-Vehicle Dynamic Performance," ASME Trans., J. Dynamic Systems, Measurement, and Control, 97, pp. 30-40.

Smith, C. C., and Wormley, D. N. 1975b. "Response of Continuous Periodically Supported Guideway Beams to Traveling Vehicle Loads," ASME Trans., J. Dynamic Systems, Measurement, and Control, 97, pp. 21-29.

Snyder, J. E., and Wormley, D. N. 1977. "Dynamic Interactions Between Vehicles and Elevated, Flexible Randomly Irregular Guideways," ASME' Trans., J. Dynamic Systems, Measurement, and Control, 99, pp. 23-33.

Stanway, R., Sproston, J. L., and Wu, X. 1989. "Variable Suspension Damping Using Electro-Rheological Fluids," IMechE C382/034, pp. 547-558.

Vu-Quoc, L., and Olsson, M. 1989. "Formulation of a Basic Building Block Model for Interaction of High Speed Vehicles on Flexible Structures," ASME Trans., J. of Applied Mechanics, 56, pp. 451-458.

Uher, R. A. 1989. "MAGLEV: An Emerging Transportation Technology to Meet an Imminent Transportation Need," Proc. Int. Conf. Maglev '89, July 1989, pp. 115-122.

Wang, Z., Chen, S. S., and Rote, D. M. 1991. "Present Status of Computational Tools for Maglev Development," Argonne National Laboratory Report ANL/ESD/TM-24.

Wong, J. X., Wu, X. M., Sturk, M., and Bortolotto, C. 1992. "On the Applications of Electro-Rheological Fluids to the Development of Semiactive Suspension Systems for Ground Vehicles," Proc. CSME Forum 1992 "Transport 1992+," June 1-4, 1992, Montreal, Canada, Vol. I, pp. 186-191.

Wu, X. M., Stanway, R., and Sproston, J. L. 1990. "Electro-Rheological Fluids and Their Applications in Power Transmission and Active Suspension," Proc. 22nd Int. Symposium on Automotive Technology and Automation, Florence, Italy, May 14-18, 1990, pp. 823-830.

Zicha, J. H. 1986. "Civil Aspects of Maglev Design," Int. Conf. Maglev and Linear Drives, Publication IEEE 86CH2276, pp. 69-87. 


\section{Distribution for ANL-92/43}

Internal

Y. Cai (10)

C. E. Till

S. S. Chen (10)

R. A. Valentin

H. T. Coffey

M. W. Wambsganss (3)

J. L. He

Z. Wang

L. R. Johnson

R. W. Weeks

C. A. Malefyt (2)

S. Zhu

T. M. Mulcahy

ANL Patent Dept.

D. M. Rote (10)

TIS Files

\section{External}

DOE-OSTI for distribution per UC-330 (85)

ANL Libraries

ANL-E

ANL-W

Manager, Chicago Operations Office, DOE

Director, Technology Management Div., DOE-CH

D. L. Bray, DOE-CH

A. L. Taboas, DOE-CH

Materials and Components Technology Division Review Committee:

H. K. Birnbaum, University of Illinois at Urbana-Champaign, Urbana

R. C. Buchanan, University of Cincinnati, Cincinnati, $\mathrm{OH}$

M. S. Dresselhaus, Massachusetts Institute of Technology, Cambridge, MA

B. G. Jones, University of Illinois at Urbana-Champaign, Urbana

C.-Y. Li, Cornell University, Ithaca, NY

S.-N. Liu, Electric Power Research Institute, Palo Alto, CA

R. E. Smith, Engineering Applied Sciences, Inc., Trafford, PA

J. S. Coleman, DOE, Washington, DC

D. Frederick, DOE, Washington, DC

O. P. Manley, DOE, Washington, DC

F. C. Moon, Cornell University, Ithaca, NY 

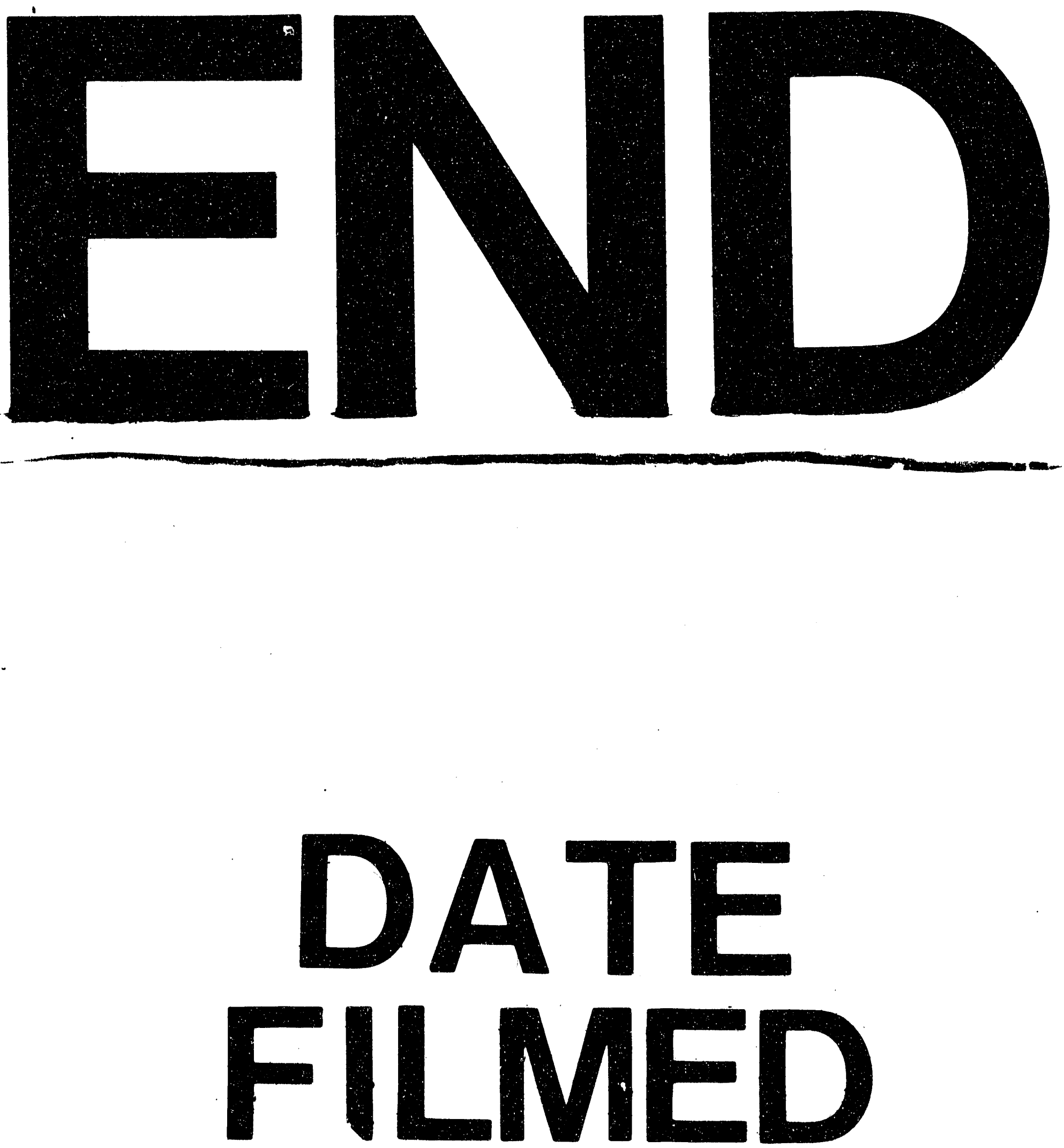

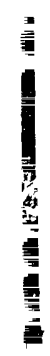

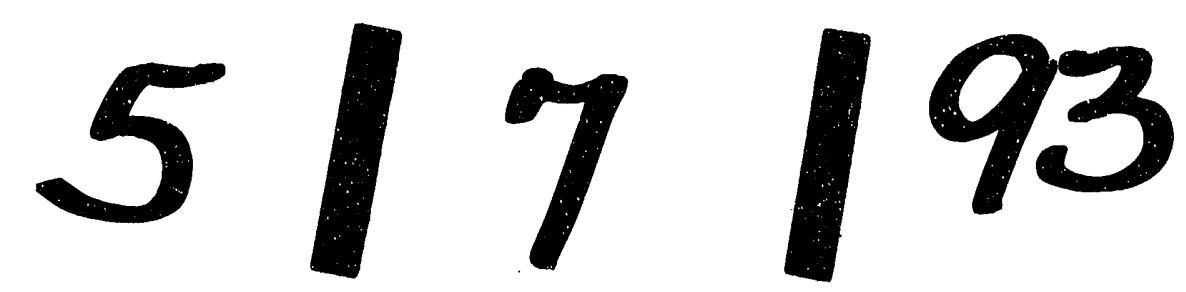


